\begin{abstract}
Aus der Arbeitsgruppe
Klinische Neurowissenschaften

(Leiterin: Prof. Dr.med. Dr.med.vet. H. Ehrenreich)

des Max-Planck-Institutes für experimentelle Medizin

in Göttingen
\end{abstract}

Experimentelles Neurotrauma

im Mausmodell:

Neuroprotektive Therapie in

Verhaltensbiologie, Histologie und Bildgebung

\author{
INAUGURAL-DISSERTATION \\ zur Erlangung des Doktorgrades \\ der Medizinischen Fakultät \\ der Georg-August-Universität zu Göttingen
}

vorgelegt von

Daniel A. Kämmer

aus

Freudenberg

Göttingen 2004 
Dekan:

I. Beric hterstatterin:

II. Beric hterstatter/in:

III. Beric hterstatter/in:

Tag der mündlichen Prüfung:
Prof. Dr.med. M. Droese

Prof. Dr.med. Dr.med.vet. H. Ehrenreich

Prof. Doz. Dr. med. Prinz

Prof.Dr. R.Gold

04. Juli 2005 


\section{Inhaltsverzeichnis}

1 EINLEITUNG $\quad 1$

1.1 Klinische Relevanz des Schädel-Hirn-Traumas . . . . . . . . . . . . . . 1

1.2 Pathophysiologie des Schädel-Hirn-Traumas . . . . . . . . . . . . 3

1.3 Ansätze zur Therapie des Schädel-Hirn-Traumas . . . . . . . . . . . 5

1.3.1 Symptomatische Therapie . . . . . . . . . . . . . . 5

1.3.2 Neuroprotektive Therapie . . . . . . . . . . . . . . 6

1.4 Modellierung des Schädel-Hirn-Traumas . . . . . . . . . . . . . 7

1.5 Erythropoietin und sein Rezeptor . . . . . . . . . . . . . . . . 9

1.6 Zielsetzung der Arbeit . . . . . . . . . . . . . . . . 15

2 MATERIAL UND METHODEN 16

2.1 Verwendete Chemikalien und Lösungen . . . . . . . . . . . . . . . 16

2.1 .1 Eosinlösung . . . . . . . . . . . . . . . . 16

2.1.2 Erythropoietin und Trägerlösung . . . . . . . . . . . . . 17

2.1.3 Evans-Blue-Lösung . . . . . . . . . . . . . . . . . . . . . 17

2.1.4 Hämalaunlösung . . . . . . . . . . . . . . . . 17

2.1.5 Paraformaldehyd ....................... 17

2.1.6 Phosphatgepufferte Kochsalzlösung . . . . . . . . . . . . . . . . 18

2.1 .7 2,2,2-Tribromoethanol . . . . . . . . . . . . . . . 18

2.2 Kälteläsionsmodell . . . . . . . . . . . . . . . . . . 18 


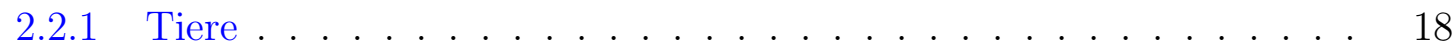

2.2 .2 Narkose . . . . . . . . . . . . . . . . . . . . . . 18

2.2 .3 Läsion . . . . . . . . . . . . . . . . . . . 19

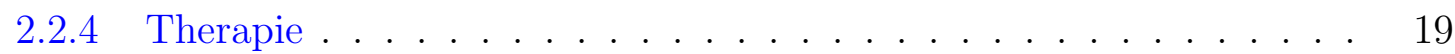

2.3 Verhaltenstestung . . . . . . . . . . . . . . . . . . . . . 19

2.3.1 VideoMot System . . . . . . . . . . . . . . . . . . 20

2.3.2 Elevated Plus Maze . . . . . . . . . . . . . . . . . . 20

2.3.3 Akzelerierendes Rotarod . . . . . . . . . . . . . . . . . 21

2.3.4 Open-field ......................... 21

2.3.5 Hole-Board . . . . . . . . . . . . . . . . . 22

2.3.6 Morris-Water-Maze . . . . . . . . . . . . . . . . . 23

2.3.7 Furchtkonditionierung . . . . . . . . . . . . . . 25

2.4 Magnetresonanztomographie . . . . . . . . . . . . . . 26

2.4.1 Darstellung der Läsion . . . . . . . . . . . . . . . . . . 27

2.4.2 Volumetrie....................... 27

2.5 Gewebsaufbereitung . . . . . . . . . . . . . . 28

2.5.1 Verarbeitung der Blutproben . . . . . . . . . . . 28

2.5.2 Präparation des Hirngewebes . . . . . . . . . . . . . . . . . . . . . 29

2.5.3 Routinefärbungen . . . . . . . . . . . . . . . . . 30

2.6 Auswertung der Standardhistologie . . . . . . . . . . . . . . 31

2.7 Untersuchung der Blut-Hirn-Schrankenfunktion . . . . . . . . . . . . 31

2.8 Experimentalgruppen . . . . . . . . . . . . . . . . . . . 32

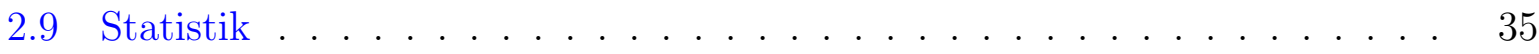

3 ERGEBNISSE $\quad 36$

3.1 Hämatologische Auswirkungen der

Erythropoietinapplikation ................. 36

3.2 Verhaltensbiologie . . . . . . . . . . . . . . . 38 
3.3 Magnetresonanztomographie .................. 61

3.3.1 Darstellung der Läsion . . . . . . . . . . . . . . . . 61

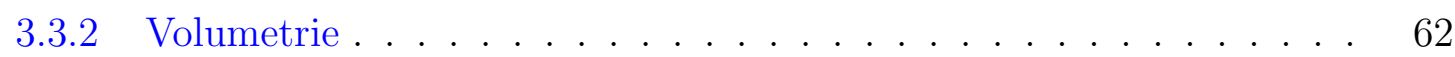

3.4 Routinefärbungen und Zellzahl . . . . . . . . . . . . . . . . 63

3.5 Blut-Hirn-Schrankenfunktion . . . . . . . . . . . . . . . . . . 64

4 DISKUSSION $\quad 67$

4.1 Zusammenfassung der Ergebnisse . . . . . . . . . . . . . . 67

4.2 Identifikation von Verhaltensänderungen nach Neurotrauma . . . . . . . . 68

4.3 Morphologie und Funktion . . . . . . . . . . . . . . . 70

4.4 Pharmakologische Neuroprotektion . . . . . . . . . . . . . . . 72

4.5 Grundlagen gestörter Neuronenfunktion . . . . . . . . . . . . . . 73

$\begin{array}{lll}5 & \text { ZUSAMMENFASSUNG } & 76\end{array}$

$\begin{array}{lll}6 & \text { ANHANG } & 78\end{array}$

LITERATURVERZEICHNIS . . . . . . . . . . . . . . . . . . 79

ABBILDUNGSVERZEICHNIS . . . . . . . . . . . . . . . . . 95

TABELLENVERZEICHNIS . . . . . . . . . . . . . . . . . . 96

ABKÜRZUNGSVERZEICHNIS . . . . . . . . . . . . . . . . . . 97 


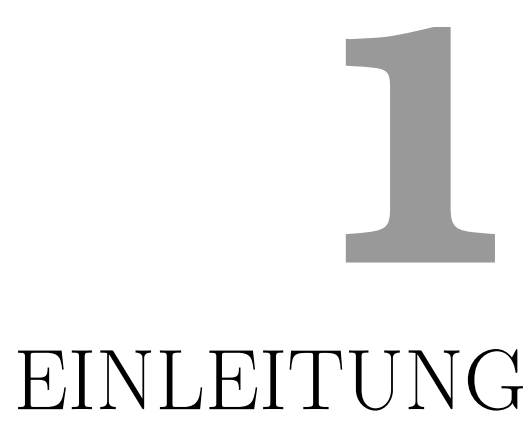

In der vorliegenden Arbeit wird ein grundlagenorientierter Ansatz zur Therapie des Schädel-Hirn-Traumas im Tiermodell behandelt. Fortschritte im Bereich der Prävention und der symptomatischen Therapie sind von großer klinischer Relevanz, es fehlt aber immer noch ein der Pathophysiologie und Dynamik dieser Erkrankung gerecht werdender protektiver Ansatz (Narayan et al. 2002).

Einleitend werden neben klinischen und pathophysiologischen Überlegungen Tiermodelle des Schädel-Hirn-Traumas vorgestellt. Daran anschließend wird ein Überblick über die bestehende Literatur zum neuroprotektiven Wachstumsfaktor Erythropoietin und seiner Wirkung gegeben, um seinen Einsatz im Tiermodell für experimentelles Neurotrauma zu rechtfertigen.

\subsection{Klinische Relevanz des Schädel-Hirn-Traumas}

Das Schädel-Hirn-Trauma (SHT) ist mit einem Durchschnittsalter der Erkrankten von 39 Jahren eine Erkrankung des jungen Menschen, mit entsprechend verheerenden Folgen 
für die Betroffenen wie für die Gesellschaft (Firsching und Woischneck 2001). Mit über einer Viertelmillion Fällen in Deutschland und 17500 Toten in den USA (Firsching und Woischneck 2001; Narayan et al. 2002) wäre eine effektive Therapie mehr als wünschenswert, zumal näherungsweise ein Drittel aller Patienten auch bei Behandlung in Spezialkliniken verstirbt.

Das SHT wird klinisch nach der Glasgow-Coma-Scale in drei verschiedene Schweregrade eingeteilt: schwer 3-8 Punkte, mittel 9-12, leicht 13-15 (Ghajar 2000). Die Mehrzahl der Traumata wird in Europa durch Verkehrsunfälle verursacht, in den USA überwiegen Schußverletzungen (Narayan et al. 2002). Diese Ursachen legen es nahe, bevorzugt im Bereich der Prävention tätig zu werden, was auch erhebliche Fortschritte erzielt hat (Firsching und Woischneck 2001). Im Bereich der Akutversorgung wurde mit Hilfe von Richtlinien beispielsweise des European Brain Injury Consortiums (Maas et al. 1997) und der Brain Trauma Foundation (The Brain Trauma Foundation 2000) durch Standardisierung der Prähospital- und Hospitalversorgung eine erhebliche Reduzierung der Mortalität und ein verbessertes Outcome der Patienten mit schwerem SHT erreicht (Ghajar 2000; Elf et al. 2002).

Von Interesse ist in diesem Zusammenhang allerdings auch eine erhöhte Inzidenz und Lebenszeitprävalenz von neurologischen und psychiatrischen Erkrankungen bei SHT-Patienten (Reekum et al. 2000; Shoumitro et al. 1999; Graham et al. 2000) teilweise noch nach Jahrzehnten und unabhängig von der Schwere des Traumas (Reekum et al. 2000; Koponen et al. 2002). Bis zu 29\% der Patienten beklagen Einschränkungen, die länger als 6 Monate persistieren (Hofman et al. 2001). Beschrieben sind Konzentrationsstörungen, Kopfschmerz, Schwindel (Hofman et al. 2001; Graham et al. 2000), depressive Episoden, bipolare Affektstörungen, Angststörungen, Persönlichkeitsstörungen (Reekum et al. 2000; Shoumitro et al. 1999; Koponen et al. 2002) sowie ein erhöhtes Risiko für Demenzen (Lye und Shores 2000) und die Parkinsonsche Erkrankung (Graham et al. 2000). Vermutet wird nach dem „Two-Hit Modell“ eine Assoziation des SHT mit Schizophrenie (McAllister 1998) und kontrovers diskutiert das Auftreten von Hydrozephalus und Hirnatrophie schon nach leichtem SHT (Licata et al. 2001), das sich allerdings in Longitudinaluntersuchungen zu bestätigen scheint (MacKenzie et al. 2002). Bei schwersten kognitiven Beeinträchtigungen durch das Trauma ist ein Teil dieser Krankheiten eventuell gar nicht mehr diagnostizierbar (Reekum et al. 2000), aber Probleme wie lebenslange Pflegebedürftigkeit durch schwerste motorische Beeinträchtigungen bleiben bestehen (Elf et al. 2002).

Vornehmliches Ziel der aktuellen Bemühungen zur Verbesserung der Therapie ist der oben 
genannte verbesserte Outcome und nicht eine erhöhte Anzahl von Patienten, die mit schwersten Behinderungen oder im vegetativen Stadium überleben, was zu der Überlegung führen muß, wie die adäquate Funktion des zentralen Nervensystems akut und auf lange Sicht erhalten werden kann.

\subsection{Pathophysiologie des Schädel-Hirn-Traumas}

\section{Phasen der Schädigung}

Das SHT ist in seiner Entstehung typischerweise eine in einem kurzen Zeitraum auftretende punktuelle Läsion, die sich durch eine charakteristische Dynamik auszeichnet (Reilly 2001). Nach Entstehung der Primärläsion entwickelt sich diese zeitnah und wird kompliziert durch die sogenannte Sekundärläsion oder weitere Läsionen (Phase 2). Im Anschluß an diese Entwicklung setzt ein Wiederherstellungsprozeß (Phase 3) ein, der den Gewebsschaden minimiert, im ungünstigsten Falle aber die Funktionalität des Nervensystems weiter einschränkt. Die klinische Therapie kann nur symptomatisch erfolgen, während das Hauptaugenmerk gegenwärtiger experimenteller Therapieansätze auf die Beeinflussung der Phase 2 gerichtet ist.

\section{Hirnödem}

In der Folge der Primärläsion entsteht das Hirnödem (Ghajar 2000) mit den typischen Begleitkomplikationen Hirndruckerhöhung und Ischämie. Die physiologisch bestehende BlutHirn-Schranke verhindert den Übertritt von Makromolekülen aus dem Blut in das Hirngewebe durch nicht fenestriertes Endothel, dessen Zellen über Zonulae occludentes (,tight junctions“) verbunden sind (Nag 2002), und durch die den Gefäßen von außen anliegenden Astrozytenendfüße. Nach Klatzo (1987) ist das Hirnödem eine abnormale Ansammlung von Flüssigkeit im Hirnparenchym, resultierend in einer volumenmäßigen Vergrößerung des Gewebes. Gängige Lehrmeinung ist die formale Trennung in intrazelluläres „zytotoxisches“ und in das durch den Zusammenbruch der Blut-Hirn-Schranke verursachte „vasogene" Ödem. Das zytotoxische Ödem entsteht durch Einschränkung im Metabolismus der Zelle, was zum Einstrom von Elektrolyten ins Zytosol und nachfolgend zur Zellschwellung führt. Das vasogene Ödem führt zu einer Extravasation von Proteinen und Retention von Wasser im Parenchym (Klatzo et al. 1958; Klatzo 1967). 


\section{Inflammation}

Durch eine Läsion am Gehirn werden verschiedene Kaskaden in Gang gesetzt, die lokale sowie systemische Entzündungsreaktionen verursachen. Lokal von entscheidender Bedeutung ist die Freisetzung von Zytokinen, Interleukinen und verwandten Mediatoren. Obwohl einzelne Stoffe und punktuell auch die biochemischen Reaktionswege bekannt sind, ist das Zusammenspiel der Mediatoren weiterhin dringender Gegenstand der aktuellen Forschung (Graham et al. 2000; Longhi et al. 2001). Prototypische proinflammatorische Stimuli nach Läsionen sind die Zytokine $\mathrm{TNF}-\alpha$, IL-1 $\beta$ und IL-6, die neben ihrer lokalen Wirkung auch systemische Effekte haben (Rothwell und Luheshi 2000; Merrill und Beneveniste 1996; Knerlich et al. 1999), sowie die Reduktion der Oxidationskapazität des Gewebes unter anderem durch die Bildung von Stickoxid (NO) und Radikalen (Merrill und Beneveniste 1996). Ein weiterer zellschädigender Mechanismus ist die sogenannte Exzitotoxizität, die durch erhöhte Ausschüttung von Glutamat und seine überschießende Wirkung vornehmlich am N-methyl-D-aspartat-Rezeptor entsteht. Die Folge ist ein erhöhter Influx von Calcium, Natrium und Wasser, nachfolgend Mitochondriendysfunktion, Radikalproduktion und Zelluntergang (Sattler und Tymianski 2001).

Merrill und Beneveniste (1996) postulieren ein „inflammatorisches Oxymoron“, welches durch die Rückwirkung von aktivierten inflammatorischen Zellen auf Parenchymzellen zustande kommt. Die aktivierten Parenchymzellen unterhalten in der Folge durch Mediatorausschüttung die lokale Entzündung und führen zu weiterer Invasion von inflammatorischen Zellen (Merrill und Beneveniste 1996; Knerlich et al. 1999). Abhängig vom Zelltyp haben die Mediatoren bestimmte spezifische und unspezifische Effekte (Ihle 1995). Eine ausführliche Darstellung der morphologischen, para- und endokrinen Reaktionen der verschiedenen Zelltypen im Gehirn findet sich bei Merrill und Beneveniste (1996).

\section{Zelltod}

Das Zusammenwirken der zellschädigenden Prozesse nach einer Läsion des zentralen Nervensystems resultiert in Zelluntergang, der klassischerweise in die zwei Formen Apoptose und Nekrose unterteilt wird.

Das Konzept der Apoptose wurde von Kerr et al. (1972) entwickelt und seine morphologischen Überlegungen zu Zelluntergängen, die unter physio- und pathologischen Bedingungen in Geweben auftreten und mit charakteristischen Vorgängen wie der Kondensation 
von Nukleus und Zytoplasma, der Fragmentation des Nukleus, der Bildung von Apoptosekörperchen und anschließender phagozytärer Abräumreaktion einhergehen, werden heute mit detaillierter Kenntnis der biochemischen Vorgänge (Morita-Fujimura et al. 1999; Longhi et al. 2001; Merrill und Beneveniste 1996) untermauert. Die Apoptose ist der „programmierte Zelltod“, der unter Ausbleiben von deutlicher Entzündung stattfindet und durch zwei Reaktionswege initiiert werden kann. Der extrinsische Weg wird durch Bindung von Botenstoffen an Zelltodrezeptoren gesteuert, während der intrinsische Weg mit der Freisetzung von mitochondrialem Cytochrom c und dessen Bindung an Apaf-1 beginnt (Morita-Fujimura et al. 1999). Im weiteren werden Kaskaden in Gang gesetzt, in denen Schlüsselrollen von den Caspasen, einer Klasse von Cystein-Proteasen, übernommen werden (Raghupathi et al. 2000; Yakovlev und Faden 2001). Durch Einflußnahme auf diese Kaskaden könnte das geschädigte Gewebe geschützt werden.

Weniger sinnvoll scheint solch ein Schutz im Falle des nekrotischen Zelluntergangs zu sein, da die Zellen zu stark geschädigt sind (Morganti-Kossmann et al. 2002); folglich wird diesem Teil der Läsion weniger Therapiepotential zugesprochen. Nekrotische Zellen gehen ungeordnet und mit deutlicher Entzündungsreaktion des umgebenden Gewebes zugrunde. Es wurde aber auch ein Kontinuum zwischen apoptotischem und nekrotischem Zelltod vorgeschlagen (Leist und Jäätelä 2001), was anti-'apoptotische' Schutzmechanismen auch für stark geschädigte Zellen nutzbar machen würde.

\subsection{Ansätze zur Therapie des Schädel-Hirn-Traumas}

\subsubsection{Symptomatische Therapie}

Die Akuttherapie ist neben der Prävention der wichtigste verfügbare Einflußparameter auf die Mortalität des SHT (Firsching und Woischneck 2001). Während 30\% der Patienten noch am Unfallort versterben, sind für die Überlebenden folgende Maßnahmen von entscheidender Bedeutung: der sogenannte „Advanced Life Support“, Transport in eine Spezialklinik, die Anwendung fortschrittlicher Verfahren in der Intensivmedizin, wie z.B. Monitoring von Hirndruck und Liquordrainage, und die Schnelligkeit des Handelns nach Erkennen einer Akutsituation, wie zum Beispiel Kraniotomie bei „Talk-and-Die“-Patienten mit klarer Bewußtseinslage, aber schwerer intrakranieller Blutung (Ghajar 2000; Elf et al. 2002; Firsching und Woischneck 2001). So konnte beispielsweise die Mortalität bei Patienten mit subduralem Hämatom in Abhängigkeit von der Zeitspanne bis zur Kraniotomie 
von $90 \%$ auf $30 \%$ reduziert werden (Elf et al. 2002). Neben chirurgischen Eingriffen zur Hirndruckentlastung bei starken Blutungen und Ödemen kommen auch Drucksenkungen durch Hyperventilation, osmotische Diurese durch Mannitol und Barbiturate zur Anwendung (Maas et al. 1997; The Brain Trauma Foundation 2000). Eine Immunsuppression durch Corticosteroide gilt nach den Erkenntnissen des CRASH-Trials heute als obsolet (Narayan et al. 2002), ebenso die Epilepsieprophylaxe und Hypothermie (Ghajar 2000).

Eine evidenzbasierte Untersuchung der routinemäßig durchgeführten Therapien kommt zu dem Ergebnis, daß eine prophylaktische Anwendung nicht von Nutzen ist und nur individuell angepaßte und symptomorientierte Therapie ein Benefit für den Patienten bedeutet (Roberts et al. 1998). Durch die Therapie verursachte Komplikationen wie beispielsweise Hypotension können direkt oder indirekt (z.B. durch Minderung der zerebralen Perfusion) den Schaden für bestimmte Patienten vergrößern. Wird jedoch die Standardisierung der Therapie wie empfohlen durchgesetzt, könnten in großen klinischen Studien Patientensubgruppen identifiziert werden, die von bestimmten Therapiemaßnahmen profitieren (Roberts et al. 1998).

\subsubsection{Neuroprotektive Therapie}

Die neuen Erkenntnisse über biochemische Mechanismen der Entwicklung der Primärläsion und die Entstehung der Sekundärläsion haben einen neuen Ansatz zur Therapie geliefert. Neuroprotektion hat zum Ziel, Gewebe und Funktionalität im zentralen Nervensystem zu erhalten (Narayan et al. 2002; McIntosh et al. 1998; Bullock et al. 1999; Park et al. 1999; Statler et al. 2001).

Die Ansatzpunkte könnten sein, körpereigene Schutz- beziehungsweise Angriffsmechanismen zu beeinflussen, was zum Beispiel durch Eingreifen in den Entzündungsprozeß durch Zytokine und die zelluläre Abräumreaktion, aber auch durch den Erhalt metabolischer Funktionen im Sinne von Verhinderung der Ödembildung geschehen kann. Die traumatische Pänumbra ist ein Gebiet, das als Zielregion der Neuroprotektion anzusehen ist. Ursprünglich geprägt wurde der Begriff als „ischämische Pänumbra“, das Randgebiet, in dem sich der Sekundärschaden nach Schlaganfall manifestiert.

Viele Substanzen haben sich in der präklinischen Testung als vielversprechend dargestellt, doch nur einige von ihnen sind in den klinischen Phasen der Testung über die Phase II hinausgekommen. Zudem sind bis heute alle Substanzen in Phase-III-Studien hinter den Erwartungen zurückgeblieben (Narayan et al. 2002; Bullock et al. 1999). Zu den getesteten 
Substanzen gehören Glutamatantagonisten, Steroide, Radikalfänger, Calciumantagonisten, Bradykininantagonisten, Cannabinoide und Antikonvulsiva. Ansätze zur Beeinflussung der Physiologie wie Perfusionsdruckkontrolle und Hypothermie zeigten ebenfalls kein besseres Outcome für die Patienten (Narayan et al. 2002).

Trotz dieser zum gegenwärtigen Zeitpunkt entmutigenden Ergebnisse ist der Ansatz vielversprechend, und ein großer Teil der Probleme wurde durch Fehler im Studiendesign, durch Protokollverletzungen und verfrühte Abbrüche aufgrund von finanziellen Problemen verursacht (Narayan et al. 2002; Bullock et al. 1999).

\subsection{Modellierung des Schädel-Hirn-Traumas}

Vor dem oben beschriebenen Hintergrund wird deutlich, wie vorsichtig eine Modellierung des Schädel-Hirn-Traumas im Tierversuch geschehen muß. Ein Konsens vieler Forschungsgruppen über Forderungen an ein Modell zur Testung von neuroprotektiven Substanzen wurde von Bullock et al. (1999) beschrieben. Das Tiermodell sollte den gleichen zellulären Mechanismus der Schädigung zeigen wie das SHT beim Menschen. Die potentiell neuroprotektive Substanz sollte diesen Mechanismus effektiv blockieren, ihre Sicherheit und Verträglichkeit sollte bewiesen und eine Penetration ins Hirngewebe bei adäquater Dosis während des therapeutischen Fensters sichergestellt sein. Zuletzt ist eine sensitive OutcomeMessung notwendig, die auch kleinere Alterationen detektieren kann.

Heutzutage werden in der präklinischen Testung bevorzugt Kleintiermodelle des SHT genutzt. Deren Vorteile (geringe Kosten, einfache Testung, genetische Techniken) überwiegen in einer frühen Phase der Testung deutlich gegenüber den Nachteilen wie lissenzephaler Hirnanatomie und der Tatsache, daß keine Komamodellierung möglich ist (Povlishock et al. 1994; Park et al. 1999; Bullock et al. 1999). Statler et al. (2001) schlagen vor, die unzureichend modellierten Aspekte klinischer Szenarien wie Sekundärinfarkt, Koma, Neurointensivmonitoring und chirurgische Interventionen nach erfolgreichen Kleintierversuchen im Großtiermodell umzusetzen und damit gleichzeitig die Forderung nach Wirksamkeit der Substanz in verschiedenen Modellen mit unterschiedlichen experimentellen Bedingungen zu erfüllen.

Modelle für das SHT sind vielzählig und wurden mehrfach vergleichend untersucht (Laurer und McIntosh 1999; Park et al. 1999; Statler et al. 2001; Povlishock et al. 1994; Gennarelli 1994). Der Tenor dieser Darstellungen ist, daß jedes Modell einzelne Aspekte des SHT be- 
vorzugt aufgreift und eine Kombination der Verfahren zu den besten Aussagen führen wird. Die Kleintiermodelle wurden an verschiedenen Spezies entwickelt, sind aber inzwischen nahezu alle an die Maus adaptiert worden (Steward et al. 1999). Diese Spezies zeigt durch das inzwischen bekannte Genom, eine Vielzahl von gut charakterisierten Inzuchtstämmen und die gentechnischen Methoden (transgene Strategien, induzierte und natürliche $\mathrm{Mu}$ tationen, Knock-Out-Technik) ein weitreichendes Forschungspotential. Im speziellen ist auch der C57BL/6J-Stamm in verschiedenen Modellen des SHT untersucht worden und scheint vielfach geringe Schäden auszubilden und gutes Regenerationspotential zu besitzen (Steward et al. 1999). Dieser Stamm ist von besonderem Interesse, da er als genetischer Hintergrund für die oben genannten gentechnischen Methoden verwendet wird.

\section{Kälteläsionsmodell}

Das von uns verwendete Kälteläsionsmodell wurde von Klatzo et al. (1958) an der Katze entwickelt und von Murakami et al. (1997) an die Maus adaptiert und für sie charakterisiert (Murakami et al. 1997; 1999). Das Modell ist hoch reproduzierbar und verursacht einen lokalen Zusammenbruch der Blut-Hirn-Schranke mit vasogenem Ödem (Klatzo et al. 1958; Klatzo 1967), gefolgt von einer Beeinträchtigung des Zellstoffwechsels und Ischämie (Schneider et al. 2002). Bekannt ist das Auftreten von histologisch sichtbaren Sekundärschäden bereits nach einer Stunde, mit einem Höhepunkt in der Läsionsregion nach 24 Stunden und einer Verlagerung in die Peripherie nach 72 Stunden (Murakami et al. 1997). Die Blut-Hirn-Schranke ist nach 24 Stunden wieder undurchlässig für hochmolekulare Stoffe, während das Läsionsvolumen erst nach 72 Stunden maximal ist (Murakami et al. 1997). Die zur Apoptose führende Ausschüttung von mitochondrialem Cytochrom c hat ihren Höhepunkt nach 4 Stunden, geht der DNA-Fragmentierung voraus (Morita-Fujimura et al. 1999) und ist wahrscheinlich verursacht durch eine erhöhte Produktion von reaktiven Sauerstoffverbindungen. Ebenfalls beschrieben ist die Koexistenz von nekrotischem und apoptotischem Zelluntergang im Läsionsgebiet und dessen Peripherie, die mit einer Invasion von Makrophagen und einer Aktivierung von Mikroglia einhergeht (Murakami et al. 1999).

Neben der Blut-Hirn-Schranken-Reintegration wurde an diesem Modell die Regeneration von Hirngefäßen studiert (Nag 2002). Die Basalmembran der geschädigten Gefäße ist entscheidend für eine geordnete Regeneration mit Bildung von Endothel, Knüpfung von astrozytären Verbindungen und Schluß der Zonulae occludentes (Cancilla et al. 1979). Dieser Vorgang ist erst nach 5 bis 8 Tagen vollständig abgeschlossen. 
Die Spätfolgen der Kälteläsion wurden von Riechers (2004) beschrieben. In einer Untersuchung bis zu 9 Monate nach Läsion zeigen sich diskrete verhaltensbiologische Alterationen, die zu späten Zeitpunkten mit Lerndefiziten, also beeinträchtigten HippokampusFunktionen einhergehen. Die früh nach Trauma in der Magnetresonanztomographie sichtbare Beeinträchtigung der Blut-Hirn-Schranke und metabolischen Versorgung des Gewebes (Schneider et al. 2002) geht mit Veränderungen in der Morphologie zu späten Zeitpunkten einher (Riechers 2004; Sirén et al. 2004).

Da das Ödem eine der Hauptkomplikationen des SHT beim Menschen ist, schien das Modell geeignet, um die pathophysiologischen Vorgänge im Tiermodell darzustellen. Die veränderten Reaktionen in transgenen und Knock-Out-Tieren (Chan et al. 1991; Kakinuma et al. 1998; Murakami et al. 1999; Penkowa et al. 1999; Giralt et al. 2002; Flentjar et al. 2002) sind ebenso wie pharmakologische Auswirkungen (Olson et al. 1987; Krejčí et al. 1993; Pratt et al. 1999; Hortobágyi et al. 2000; Görlach et al. 2001) charakterisiert worden und werden genauer im Zusammenhang mit den Ergebnissen dieser Arbeit diskutiert.

\subsection{Erythropoietin und sein Rezeptor}

\section{Expressionsmuster}

Erythropoietin (EPO) ist ein Glykoprotein mit einem Gewicht von $30.4 \mathrm{kDa}$, das zuerst als hämatopoietischer Wachstumsfaktor entdeckt und erforscht wurde (Jelkmann 1996). Daß Erythropoietin und sein Rezeptor im menschlichen Zentralnervensystem exprimiert werden, ist eine relativ neue Erkenntnis (Masuda et al. 1993; Konishi et al. 1993; Marti et al. 1996). Dame et al. (2000) fanden eine fetale neuronale Expression in subkortikalen Bereichen ebenso wie im Kortex, zusätzlich astrozytäre und neuronale Expression von Erythropoietinrezeptor (EPOR). Die Expression wird in einer späteren Phase der Entwicklung herunterreguliert (Juul et al. 1998), ist aber unter hypoxischen oder ischämischen Bedingungen weiter verfügbar (Sirén et al. 2001b). Unter pathologischen Bedingungen wird EPO verstärkt im Endothel, in Neuronen, Astrozyten und inflammatorischen Zellen exprimiert; EPOR wird hingegen in Neuronen und Astrozyten, aber nur schwächer im Endothel und in inflammatorischen Zellen gebildet. Ein ähnliches Expressionsmuster in der fetalen sowie adulten Phase und unter pathologischen Bedingungen findet sich in der Maus (Digicaylioglu et al. 1995; Bernaudin et al. 1999). 
Diese Erkenntnisse gaben Anlaß zur Charakterisierung der Expression von EPO und EPOR in der Zellkultur. Auch hier zeigt sich in embryonalen Zellen oder Zellen von neugeborenen Tieren eine Expression von EPO und EPOR (Bernaudin et al. 2000), während in adulten hippokampalen Neuronen keine Expression der beiden Proteine detektierbar ist (Lewczuk et al. 2000).

\section{Zelluläre Wirkungskaskaden}

Wie Yu et al. (2002) zeigen konnten, ist der EPOR unabkömmlich zur normalen Hirnentwicklung der Maus. Die Reaktionskaskaden in der Erythropoiese konnten detailliert beschrieben werden (Jelkmann 1996), und es scheint, daß ein Großteil von ihnen auch in der zentralnervösen Wirkung von EPO eine Rolle spielt (Sirén et al. 2001a; Digicaylioglu und Lipton 2001; Ruscher et al. 2002).

Die Zytokinrezeptoren, zu denen auch der EPOR gehört, sind gut charakterisiert. Die Hauptaufgabe des Liganden ist eine Aggregation der Rezeptoren untereinander und mit den Janus-Kinasen (JAKs) (Ihle 1995). EPOR gehört zur Zytokin-Rezeptor-Familie Typ I und wird nach Bindung von EPO durch Dimerisierung und Assoziation mit JAK2 aktiviert (Ferrag et al. 1998). Im weiteren werden der EPOR und die Janus-Kinase autophosphoryliert (Merrill und Beneveniste 1996). Die aktivierten Janus-Kinasen sind in der Lage, die sogenannten STATs (Signal Transducers and Activators of Transcription) zu phosphorylieren (Ihle 1995); im Falle von JAK2 wird STAT5 aktiviert. Auch der Faktor I $\kappa$ B $\alpha$ wird phosphoryliert und entläßt NF $\kappa \mathrm{B}$ ins Zytosol. Beide Faktoren (STAT5 und NF $\kappa \mathrm{B}$ ) translozieren in den Nukleus und sind nach Bindung an die DNA in der Lage, die Transkription zu beeinflussen (Tilbrook und Klinken 1999). JAK2 kann weiterhin die Ras/MAP-KinaseKaskade beeinflussen (Bittorf et al. 1997; Sirén et al. 2001a). Eine Interaktion des EPOR mit PI(3)-Kinase/Akt ist vorbeschrieben (Bittorf et al. 1997), und EPO kann unter Hypoxie verhindern, daß die phosphorylierten Formen von STAT5 und PI(3)-Kinase/Akt herunterreguliert werden (Sirén et al. 2001a). Eine Inaktivierung der Wirkung von EPO am EPOR findet wahrscheinlich durch die Phosphatase SH-PTP1 statt, die mit dem EPOR assoziiert (Bittorf et al. 1997). Beschrieben ist auch eine Interaktion mit der bcl-2-Familie, in der EPO die antiapoptotischen Mitglieder zu stimulieren scheint (Silva et al. 1996); eine Bestätigung dieser Wirkung in Zellen des zentralen Nervensystems steht aber noch aus. 


\section{In-vivo-Applikation von Erythropoietin}

Die ermutigenden Ergebnisse in der Zellkultur forderten eine Übertragung und Überprüfung der neuroprotektiven Wirkung von EPO im Tierversuch. Eine Zusammenstellung der bis dato vorliegenden Veröffentlichungen zur Applikation von Erythropoietin in tierexperimentellen Studien findet sich in Tabelle 1.1 auf Seite 13.

Zusammenfassend läßt sich sagen, daß auch im In-vivo-Experiment vornehmlich vielversprechende Erfahrungen gesammelt wurden. EPO wurde unter anderem appliziert in Tiermodellen für Schlaganfall (Aydin et al. 2003; Bernaudin et al. 1999; Brines et al. 2000; Calapai et al. 2000; Catania et al. 2002; Kumral et al. 2004; Matsushita et al. 2003; Sadamoto et al. 1998; Sakanaka et al. 1998; Sirén et al. 2001a; Villa et al. 2003; Wen et al. 2002), neurodegenerative Erkrankungen (Genc et al. 2001; 2002), Neuroinflammation (Agnello et al. 2002; Brines et al. 2000), Rückenmarksläsion (Celik et al. 2002; Gorio et al. 2002; Kaptanoglu et al. 2004), Nervenläsion (Campana und Myers 2003; Iwasaki et al. 2002; Sekiguchi et al. 2003), Retinaischämie (Junk et al. 2002; Weishaupt et al. 2004), Subarachnoidalblutung (Alafaci et al. 2000; Buemi et al. 2000; Brines et al. 2000; Springborg et al. 2002), Krampfanfälle (Brines et al. 2000), Schock (Romsi et al. 2002; Squadrito et al. 1999), diabetische Neuropathie (Bianchi et al. 2004), Myokardinfarkt (Calvillo et al. 2003; Moon et al. 2003) und Neurotrauma (Brines et al. 2000; Mogensen et al. 2004).

\section{Neuroprotektive Wirkung}

Durch die eingehende Analyse der Wirkungskaskade wird verständlich, daß EPO in Zellkulturmodellen neuroprotektiv wirkt. Glutamattoxizität wird verhindert (Morishita et al. 1997; Digicaylioglu und Lipton 2001), hypoxie-vermittelte Zellschäden unterdrückt (Sirén et al. 2001a) und die Radikalproduktion vermindert (Sakanaka et al. 1998; Squadrito et al. 1999). Ein Entzug von Glukose oder Serum wird bei EPO-Zugabe von den Zellen besser toleriert (Sirén et al. 2001a; Ruscher et al. 2002).

Die oben genannten Mechanismen scheinen auch im Tiermodell wirksam zu sein. EPO entfaltet seine zentralnervöse Wirkung bei systemischer Gabe (siehe dazu die Applikationsart in Tabelle 1.1) und überschreitet die Blut-Hirn-Schranke. Es ist in vivo in der Lage, antiapoptotisch, antiinflammatorisch, antioxidativ und angiogenetisch zu wirken sowie Neuronen vor dem Zelltod zu schützen und ihre Funktion zu erhalten.

Die Forderungen an eine potentiell neuroprotektive Substanz nach Bullock et al. (1999) 
sind also erfüllt: Die Mechanismen der Sekundärschädigung nach Neurotrauma sind hinreichend bekannt und von EPO beeinflußbar. EPO ist eine Substanz, die im Tierversuch wie im klinischen Alltag arm an Nebenwirkungen ist und die Blut-Hirn-Schranke auch beim Menschen überschreitet (Brines et al. 2000; Ehrenreich et al. 2004; Juul et al. 2004); außerdem ist das Zeitfenster einer möglichen Therapie in Ansätzen bekannt (Bernaudin et al. 1999; Brines et al. 2000; Genc et al. 2001). Das beim Menschen bestehende Problem einer sensiblen Outcome-Messung ist im Tierversuch durch verhaltensbiologische Experimente und histologische Aufbereitung des entnommenen Gewebes gelöst. Ehrenreich et al. (2002) haben in einer Human-Studie mit Schlaganfallpatienten bereits die klinische Wirksamkeit in Bezug auf neurologische Nachfolgeuntersuchungen und Magnetresonanztomographie gezeigt. 


\begin{tabular}{|c|c|c|c|c|c|c|}
\hline$\overline{\text { Autor }}$ & Spezies & 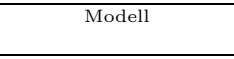 & $\begin{array}{l}\text { Applikationsart } \\
\text { und -zeitpunkt }\end{array}$ & $\begin{array}{l}\text { Dosierung } \\
\end{array}$ & $\begin{array}{c}\text { Ende der } \\
\text { Beobachtung }\end{array}$ & beobachtete EPO-Wirkung \\
\hline \multirow[t]{2}{*}{$\begin{array}{l}\text { Agnello et al. (2002) } \\
\end{array}$} & \multirow[t]{2}{*}{ Lewis-Ratten } & $\begin{array}{l}\text { experimentelle Auto- } \\
\text { immun-Enzephalitis }\end{array}$ & i.p. ab Tag 3 nach Induktion & $0.5-5 \mathrm{U} / \mathrm{g} \mathrm{KG}$ über $16 \mathrm{~d}$ & $60 \mathrm{~d}$ & $\begin{array}{l}\text { verzögerter Beginn, Linderung der } \\
\text { Symptome, erniedrigte IL-6 Level, } \\
\text { verzögerter TNF- } \alpha \text { Anstieg }\end{array}$ \\
\hline & & Arthritis & i.p. ab Tag 3 nach Induktion & $5 \mathrm{U} / \mathrm{g} \mathrm{KG}$ & $14 \mathrm{~d}$ & kein Effekt \\
\hline Alafaci et al. (2000) & NZW-Rabbit & $\begin{array}{l}\text { akute Ischämie } \\
\text { nach SAB }\end{array}$ & i.p. 5 min nach Läsion & $1 \mathrm{U} / \mathrm{g} \mathrm{KG}$ einmalig & $24 \mathrm{~h}$ & $\begin{array}{l}\text { Reduktion der kortikalen Nekrose } \\
\text { erhöhte EPO-Werte im CSF }\end{array}$ \\
\hline Aydin et al. (2003) & $\begin{array}{c}\text { neugeborene } \\
\text { Wistar-Ratten } \\
\end{array}$ & Hypoxie-Ischämie & $\begin{array}{l}\text { i.c.v. direkt nach } \\
\text { Hypoxie-Ischämie }\end{array}$ & $20 \mathrm{U}$ einmalig & $7 \mathrm{~d}$ & kleineres Infarktvolumen \\
\hline Bernaudin et al. (1999) & OF1-Mäuse & $\begin{array}{l}\text { permanente fokale } \\
\text { cerebrale Ischämie }\end{array}$ & $\begin{array}{c}\text { i.c.v. simultan } \\
\text { oder } 24 \mathrm{~h} \text { vor Ischämie }\end{array}$ & $0.4 \mu \mathrm{g} / \mathrm{kg} \mathrm{KG}$ & $24 \mathrm{~h}$ & $\begin{array}{l}\text { nur Vorbehandlung reduziert } \\
\text { Infarktvolumen um } \approx 47 \%, \text { Hypoxie } \\
\text { moduliert EPO- und EPOR-Produktion }\end{array}$ \\
\hline \multirow[t]{2}{*}{ Bianchi et al. (2004) } & SD-Ratten & \multirow[t]{2}{*}{$\begin{array}{c}\text { diabetische } \\
\text { Neuropathie }\end{array}$} & $\begin{array}{l}\text { i.p. } 2 \text { Tage oder } 5 \text { Wochen } \\
\text { nach Diabetesinduktion }\end{array}$ & $\begin{array}{l}40 \mu / \mathrm{kg} \mathrm{KG} 3 \times \text { pro } \\
\text { Woche für } 5 \text { Wochen }\end{array}$ & \multirow[t]{2}{*}{$77 \mathrm{~d}$} & \multirow{2}{*}{$\begin{array}{l}\text { erhaltene Nervenleitgeschwindigkeit, } \\
\text { Aktivität der Na-K-ATPase und kutane } \\
\text { Sensibilitäät und Nozizeption }\end{array}$} \\
\hline & Wistar-Ratten & & i.p. ab Diabetesinduktion & $\begin{array}{c}8 \mu \mathrm{g} / \mathrm{kg} \mathrm{KG} \\
\text { einmal pro Woche }\end{array}$ & & \\
\hline \multirow[t]{4}{*}{ Brines et al. (2000) } & SD-Ratten & $\begin{array}{c}\text { temporäre fokale } \\
\text { cerebrale Ischämie }\end{array}$ & $\begin{array}{l}\text { i.p. bis zu } 9 \mathrm{~h} \text { nach } \\
\text { und } 24 \mathrm{~h} \text { vor Ischämie }\end{array}$ & $0.25-5 \mathrm{U} / \mathrm{g} \mathrm{KG}$ & $24 \mathrm{~h}$ & $\begin{array}{l}\text { Infarktvolumen ist reduziert bei } \\
\text { Gabe bis zu } 3 \mathrm{~h} \text { nach Ischämie }\end{array}$ \\
\hline & BALB/c-Mäuse & stumpfes Neurotrauma & $\begin{array}{l}\text { i.p. bis zu } 6 \mathrm{~h} \text { nach } \\
\text { und } 24 \mathrm{~h} \text { vor Trauma }\end{array}$ & $\begin{array}{c}5 \mathrm{U} / \mathrm{g} \mathrm{KG} \\
5 \text { Dosen täglich }\end{array}$ & $10 \mathrm{~d}$ & reduzierte Inflammation \\
\hline & Lewis-Ratten & $\begin{array}{l}\text { experimentelle Auto- } \\
\text { immun-Enzephalitis }\end{array}$ & i.p. ab Tag 3 nach Induktion & $5 \mathrm{U} / \mathrm{g} \mathrm{KG}$ über $16 \mathrm{~d}$ & $21 \mathrm{~d}$ & $\begin{array}{l}\text { Linderung der Symptome } \\
\text { verzögerter Krankheitsbeginn }\end{array}$ \\
\hline & BALB/c-Mäuse & $\begin{array}{l}\text { Kainate-induzierte } \\
\text { Krämpfe }\end{array}$ & $\begin{array}{l}\text { i.p. simultan, } \\
24 \mathrm{~h} \text { oder } 30 \mathrm{~min} \text { vor } \\
\text { Injektion }\end{array}$ & $5 \mathrm{U} / \mathrm{g} \mathrm{KG}$ & $1 \mathrm{~h}$ & $\begin{array}{l}\text { verminderte Mortalität } \\
\text { erhöhte Überlebenszeit } \\
\text { verminderte Krampfanfälle nur bei } \\
\text { Gabe } 24 \mathrm{~h} \text { vor Injektion }\end{array}$ \\
\hline Buemi et al. (2000) & NZW-Rabbit & $\mathrm{SAB}$ & i.p. simultan & $1 \mathrm{U} / \mathrm{g} \mathrm{KG}$ einmalig & $72 \mathrm{~h}$ & $\begin{array}{l}\text { reduzierte Mortalität } \\
\text { normalisierte Motoraktivität }\end{array}$ \\
\hline \multirow[t]{2}{*}{ Calapai et al. (2000) } & \multirow[t]{2}{*}{$\begin{array}{l}\text { mongolische } \\
\text { Gerbils }\end{array}$} & \multirow[t]{2}{*}{$\begin{array}{l}\text { temporäre globale } \\
\text { cerebrale Ischämie }\end{array}$} & $\begin{array}{l}\text { i.p. nach Reperfusion } \\
100 \mathrm{U} \text { einmalig } 1 \mathrm{~h} \text { vorher }\end{array}$ & 12.5-100 U einmalig & \multirow[t]{2}{*}{$24 \mathrm{~h}$} & \multirow{2}{*}{$\begin{array}{l}\text { Überlebensrate erhöht nur bei Gabe } \\
\text { nach Reperfusion, dosisabhängig: } \\
\text { Reduktion des Hirnödems, der Nekrose } \\
\text { und reduzierte NO }{ }_{X} \text {-Werte } \\
\text { im Hippokampus }\end{array}$} \\
\hline & & & i.c.v. nach Reperfusion & $0.5-25 \mathrm{U}$ einmalig & & \\
\hline Calvillo et al. (2003) & SD-Ratten & koronare Ischämie & $\begin{array}{l}\text { i.p. } 24 \mathrm{~h} \text { und } 0.5 \mathrm{~h} \text { vor } \\
\text { oder direkt nach Reperfusion } \\
\text { und ab dann täglich }\end{array}$ & $5 \mathrm{U} / \mathrm{g} \mathrm{KG}$ & $7 \mathrm{~d}$ & $\begin{array}{l}\text { Kardiomyozytenverlust reduziert und } \\
\text { normale Hämodynamik nach } 1 \text { Woche }\end{array}$ \\
\hline $\begin{array}{c}\text { Campana und Myers } \\
(2003)\end{array}$ & SD-Ratten & $\begin{array}{l}\text { Spinalnerven- } \\
\text { wurzelläsion }\end{array}$ & $\begin{array}{l}\text { s.c. ab } 1 \text { Tag vor Läsion } \\
\text { täglich für } 18 \mathrm{~d}\end{array}$ & $1-5 \mathrm{U} / \mathrm{g} \mathrm{KG}$ & $84 \mathrm{~d}$ & $\begin{array}{l}\text { weniger Apoptosen, reduzierter } \\
\text { Schmerz, beschleunigte Erholung }\end{array}$ \\
\hline Catania et al. (2002) & $\begin{array}{c}\text { mongolische } \\
\text { Gerbils }\end{array}$ & $\begin{array}{l}\text { temporäre globale } \\
\text { cerebrale Ischämie }\end{array}$ & i.c.v. nach Reperfusion & $\begin{array}{l}0.5-25 \mathrm{U} \\
\text { einmalig }\end{array}$ & $7 \mathrm{~d}$ & $\begin{array}{l}\text { weniger Apoptosen der CA1-Neuronen } \\
\text { kein Defizit in der Passive Avoidance }\end{array}$ \\
\hline Celik et al. (2002) & NZW-Rabbits & $\begin{array}{c}\text { reversible globale } \\
\text { Rückenmarksischämie }\end{array}$ & i.v. nach Reperfusion & $\begin{array}{c}0.35-1 \mathrm{U} / \mathrm{g} \mathrm{KG} \\
\text { einmalig }\end{array}$ & $48 \mathrm{~h}$ & $\begin{array}{l}\text { Reduktion von Schwere und Verlauf } \\
\text { der neurologischen Ausfälle, verminderte } \\
\text { Apoptose von Motorneuronen }\end{array}$ \\
\hline $\begin{array}{l}\text { Garcia-Garcia und Krueger } \\
(2003)\end{array}$ & SD-Ratten & Spontanschlaf & $\begin{array}{l}\text { i.c.v. tags oder } \\
\text { zu Nachtbeginn }\end{array}$ & $25-75 \mathrm{ng}$ & $23 \mathrm{~h}$ & $\begin{array}{l}\text { kein Effekt am Tag, zur Nacht Modulation } \\
\text { des Schlafrhythmus }\end{array}$ \\
\hline Genc et al. (2001) & C57/BL6-Mäuse & $\begin{array}{l}\text { MPTP-induzierter } \\
\text { Parkinsonismus }\end{array}$ & $\begin{array}{l}\text { stereotaktische Injektion } \\
24 \text { Stunden vor oder direkt } \\
\text { nach MPTP-Gabe }\end{array}$ & $16 \mathrm{U}$ einmalig & $7 \mathrm{~d}$ & $\begin{array}{l}\text { Wiederherstellung der motorischen } \\
\text { Aktivität, Protektion der dopaminergen } \\
\text { Neurone }\end{array}$ \\
\hline \multirow[t]{2}{*}{ Gorio et al. (2002) } & \multirow{2}{*}{$\begin{array}{l}\text { Wistar-Ratten } \\
\text { SD-Ratten }\end{array}$} & $\begin{array}{l}\text { leichtes stumpfes } \\
\text { Rückenmarkstrauma }\end{array}$ & i.p. nach Dekompression & $\begin{array}{l}1 \mathrm{U} / \mathrm{g} \mathrm{KG}, 1 \text { oder } \\
3 \text { Dosen }\end{array}$ & $28 \mathrm{~d}$ & verbesserte Funktionserholung \\
\hline & & $\begin{array}{l}\text { schweres stumpfes } \\
\text { Rückenmarkstrauma }\end{array}$ & i.p. 1 h nach Dekompression & $\begin{array}{l}5 \mathrm{U} / \mathrm{g} \mathrm{KG}, 1 \text { oder } \\
7 \text { Dosen }\end{array}$ & $28 \mathrm{~d}$ & $\begin{array}{l}\text { verbesserte Funktionserholung } \\
\text { reduzierte Inflammation und Cavitation }\end{array}$ \\
\hline
\end{tabular}




\begin{tabular}{|c|c|c|c|c|c|c|}
\hline Autor & Spezies & Modell & $\begin{array}{l}\text { Applikationsart } \\
\text { und -zeitpunkt }\end{array}$ & Dosierung & $\begin{array}{c}\text { Ende der } \\
\text { Beobachtung }\end{array}$ & beobachtete EPO-Wirkung \\
\hline "Haroon et al. (2003) & \begin{tabular}{c|c|} 
Fischer-Ratten \\
\end{tabular} & Wundheilung & $\begin{array}{ll}\text { lokal in Fibrin } \\
\text { Z-Kammern }\end{array}$ & $10-500 \mathrm{U} / \mathrm{ml}$ & $9 \mathrm{~d}$ & $\begin{array}{l}\text { dosisabhängig verbesserte Wundheilung } \\
\text { und Vaskularisation }\end{array}$ \\
\hline Iwasaki et al. (2002) & $\begin{array}{c}\text { neugeborene } \\
\text { SD-Ratten }\end{array}$ & $\begin{array}{l}\text { Ischiadikus- } \\
\text { läsion }\end{array}$ & i.p. simultan & $\begin{array}{l}0.5-5 \mathrm{mg} / \mathrm{kg} \mathrm{KG} \text { täglich } \\
\text { für } 2 \text { Wochen }\end{array}$ & $14 \mathrm{~d}$ & $\begin{array}{l}\text { Prävention des Motorneuronverlustes und } \\
\text { Mortalität reduziert bei hoher Dosis }\end{array}$ \\
\hline Kaptanoglu et al. (2004) & Wistar-Ratten & Rückenmarkstrauma & i.p. simultan & $0.1-5 \mathrm{U} / \mathrm{g}$ KG einmalig & $2 \mathrm{~h}$ & $\begin{array}{l}\text { dosisabhängig reduzierte Lipid-Peroxidation } \\
\text { elektronenmikroskopisch geringerer Schaden }\end{array}$ \\
\hline $\begin{array}{l}\text { Kumral et al. (2003b) } \\
\text { Kumral et al. (2004) }\end{array}$ & Wistar-Ratten & $\begin{array}{c}\text { neonatale } \\
\text { Hypoxie-Ischämie }\end{array}$ & i.p. & $1 \mathrm{U} / \mathrm{g} \mathrm{KG}$ einmalig & $72 \mathrm{~h}$ & $\begin{array}{l}\text { verminderte NO-Produktion und Apoptosen, } \\
\text { kleineres Infarktvolumen }\end{array}$ \\
\hline Matsushita et al. (2003) & $\begin{array}{c}\text { neonatale } \\
\text { CD-1-Mäuse }\end{array}$ & Hypoxie-Ischämie & i.p. & $1-5 \mathrm{U} / \mathrm{g} \mathrm{KG}$ & $7 \mathrm{~d}$ & $\begin{array}{l}\text { verminderte Schäden in verschiedenen Hirnregionen } \\
\text { verminderte caspase- } 3 \text { und } N F \kappa B \text { Aktivierung }\end{array}$ \\
\hline Mittelmann et al. (2001) & BALB/c-Mäuse & Myelom & $\begin{array}{c}\text { s.c. ab Tag 10-13 } \\
\text { nach Tumorinduktion }\end{array}$ & $\begin{array}{c}30 \mathrm{U} / \text { Injektion für } 10 \mathrm{~d} \\
\text { danach } 3 \mathrm{x} \text { pro Woche für } 14 \mathrm{~d}\end{array}$ & $70 \mathrm{~d}$ & Tumorregression in $50 \%$ der Fälle \\
\hline Mogensen et al. (2004) & Ratten & $\begin{array}{l}\text { bilaterale fimbria- } \\
\text { fornix Transsektion }\end{array}$ & i.p. simultan & $5 \mathrm{U} / \mathrm{g}$ KG einmalig & $32 \mathrm{~d}$ & $\begin{array}{l}\text { weniger und vorübergehendes } \\
\text { Lerndefizit }\end{array}$ \\
\hline Moon et al. (2003) & SD-Ratten & Myokardinfarkt & i.p. simultan & $3 \mathrm{U} / \mathrm{g} \mathrm{KG}$ einmalig & $56 \mathrm{~d}$ & $\begin{array}{l}\text { verminderte Infarktgröße, wenigerApoptosen, } \\
\text { verbesserte linksventrikuläre Funktion }\end{array}$ \\
\hline Noyan et al. (2003) & SD-Ratten & Kurzdarmsyndrom & s.c. & $0.5 \mathrm{U} / \mathrm{g} \mathrm{KG}$ & $28 \mathrm{~d}$ & $\begin{array}{l}\text { höhere Kryptentiefe, stabileres anti- } \\
\text { oxidatives System }\end{array}$ \\
\hline Saray et al. (2003) & Ratten & $\begin{array}{c}\text { muskulokutaner } \\
\text { Hautlappen }\end{array}$ & s.c. & $\begin{array}{l}0.05-0.15 \mathrm{U} / \mathrm{g} \mathrm{KG} 3 \times \text { pro Woche } \\
\text { für } 1 \text { oder } 3 \text { Wochen }\end{array}$ & $7 \mathrm{~d}$ & kurzzeitige Behandlung zeigt Nekrosen \\
\hline Sekiguchi et al. (2003) & SD-Ratten & $\begin{array}{c}\begin{array}{l}\text { Spinalnerven- } \\
\text { wurzelläsion }\end{array} \\
\text { (n) }\end{array}$ & s.c. & $0.268 \mathrm{U} / \mathrm{g} \mathrm{KG}$ & $14 \mathrm{~d}$ & $\begin{array}{l}\text { weniger Apoptosen, TNF- } \alpha \text {-Produktion, } \\
\text { schnellere Erholung }\end{array}$ \\
\hline Sirén et al. (2001a) & SD-Ratten & $\begin{array}{l}\text { temporäre fokale } \\
\text { cerebrale Ischämie }\end{array}$ & i.p. simultan & $5 \mathrm{U} / \mathrm{g} \mathrm{KG}$ einmalig & $24 \mathrm{~h}$ & $\begin{array}{l}\approx 75 \% \text { reduziertes Infarktareal } \\
\text { Reduktion von Inflammation und Apoptosen }\end{array}$ \\
\hline Solaroglu et al. (2003) & $\begin{array}{l}\text { fetale Wistar- } \\
\text { Ratten }\end{array}$ & $\begin{array}{l}\text { Ischämie-Reperfusion } \\
\text { in utero }\end{array}$ & $\begin{array}{l}\text { maternal i.p. } 30 \mathrm{~min} \\
\text { vor Ischämie }\end{array}$ & $5 \mathrm{U} / \mathrm{g} \mathrm{KG}$ & $30 \mathrm{~min}$ & $\begin{array}{l}\text { intrauterin verminderte Lipid- } \\
\text { peroxidation }\end{array}$ \\
\hline Springborg et al. (2002) & SD-Ratten & $\mathrm{SAB}$ & s.c. simultan & $0.4 \mathrm{U} / \mathrm{g} \mathrm{KG}$ & $48 \mathrm{~h}$ & $\begin{array}{l}\text { Normalisierung des cerebralen } \\
\text { Blutflusses }\end{array}$ \\
\hline Squadrito et al. (1999) & SD-Ratten & $\begin{array}{l}\text { Mesenterial- } \\
\text { arterienverschluß }\end{array}$ & $\begin{array}{c}\text { i.v. } 5 \text { Minuten } \\
\text { nach Reperfusion }\end{array}$ & $0.25-1 \mathrm{U} / \mathrm{g} \mathrm{KG}$ & $4 \mathrm{~h}$ & $\begin{array}{l}\text { verminderte Mortalität, } \\
\text { iNOS-Aktivität vermindert }\end{array}$ \\
\hline Sun et al. (2004) & SD-Ratten & Hypoxie-Ischämie & $\begin{array}{c}\text { i.p. vor und } \\
2 \mathrm{~d} \text { nach Hypoxie }\end{array}$ & $300 \mathrm{U}$ einmalig & $42 \mathrm{~d}$ & $\begin{array}{l}\text { reduzierte Mortalitïät, weniger Apoptosen, geringere } \\
\text { DNA-Fragmentation, höheres Hirngewicht }\end{array}$ \\
\hline Villa et al. (2003) & $\begin{array}{l}\mathrm{Crl}: \mathrm{CD}(\mathrm{SD}) \mathrm{BR}- \\
\text { Ratten }\end{array}$ & $\begin{array}{l}\text { permanente fokale } \\
\text { cerebrale Ischämie }\end{array}$ & i.p. simultan & $5 \mathrm{U} / \mathrm{g} \mathrm{KG}$ & $24 \mathrm{~h}$ & $\begin{array}{l}\text { reduzierte Entzündung durch Wirkung auf Neuronen, } \\
\text { nicht inflammatorische Zellen }\end{array}$ \\
\hline
\end{tabular}




\subsection{Zielsetzung der Arbeit}

In der vorliegenden Arbeit sollte unter strenger Differenzierung der einzelnen Komponenten die Auswirkung einer Erythropoietinapplikation im Kälteläsionsmodell an der Maus etabliert werden. Das Modell ist im Hinblick auf Zelluntergänge, den Zusammenbruch der Blut-Hirn-Schranke (Murakami et al. 1997; 1999) und verhaltensbiologische Spätfolgen nach Neurotrauma (Riechers 2004) charakterisiert worden. Es besitzt die Fähigkeit, Ödem und Ischämie nach Läsion zu modellieren, zeigt apoptotische und inflammatorische Vorgänge in der Histologie (Murakami et al. 1997) und Beeinträchtigung der metabolischen Versorgung in bildgebenden Verfahren (Schneider et al. 2002).

Um die potentiell neuroprotektive Wirkung von Erythropoietin (EPO) im Kälteläsionsmodell zu untersuchen,

- sollte in einem ersten Schritt die hämatopoietische Wirkung von EPO bei zweiwöchiger Applikation beschrieben werden, um eventuelle Interferenz mit den verhaltensbiologischen Testungen auszuschließen.

- sollten in einem zweiten Schritt die Komponenten der Läsionsapplikation und Therapie (Operation, Injektionen und Handling) in verschiedenen Experimentalgruppen modelliert werden. Damit sollte die Differenzierung zwischen Streßkomponente beziehungsweise Artefakten und wirklicher Läsionsauswirkung möglich werden.

Das Ziel einer späten Verhaltenstestung 3 Monate nach Läsion sollte die alleinige Beschreibung nachhaltiger Änderungen im Verhalten und nicht akuter Effekte (wiederum Auswirkungen von Streßkomponente oder Therapie) sein.

Wert wurde dabei auf die Charakterisierung der Läsions- und Therapieauswirkungen auf verschiedenen Ebenen gelegt:

- Die funktionelle Ebene sollte verhaltensbiologisch getestet und mit der

- morphologischen Ebene in Magnetresonanztomographie und Histologie in Beziehung gesetzt werden.

Im Anschluß daran sollte versucht werden, einen Erklärungsansatz für die Wirkung von EPO zu liefern, indem Auswirkungen auf die Reintegration der Blut-Hirn-Schranke untersucht wurden. 


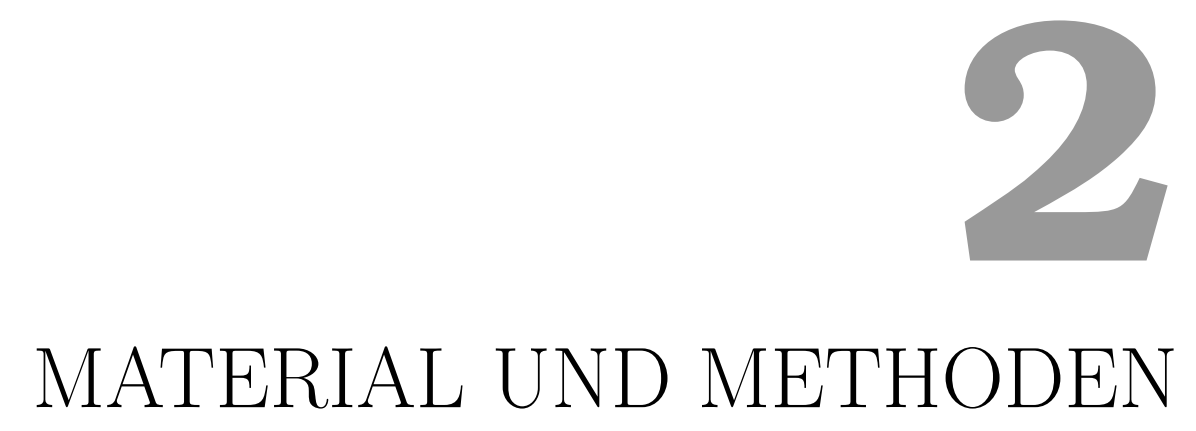

\subsection{Verwendete Chemikalien und Lösungen}

\subsubsection{Eosinlösung}

Die Eosinlösung (Eosin G, Merck, Darmstadt, Deutschland) wurde nach folgendem Protokoll hergestellt:

- $2 \mathrm{~g} \operatorname{Eosin}$

- $40 \mathrm{ml} \mathrm{H}_{2} \mathrm{O}$ bidest.

- 160 ml Ethanol 95\%

Diese Lösung wurde für den Gebrauch 1:3 mit 80\%igem Ethanol gemischt und mit $0.5 \mathrm{ml}$ Eisessig pro $200 \mathrm{ml}$ versetzt. 


\subsubsection{Erythropoietin und Trägerlösung}

Injiziert wurde Epoetin alfa der Firma Janssen-Cilag GmbH (Erypo $\left.{ }^{\odot}\right)$ in einer Konzentration von $500 \mathrm{U} / \mathrm{ml}$. Die Trägerlösung hatte folgende Inhaltsstoffe:

- $2.5 \mathrm{mg}$ humanes Albumin

- $5.8 \mathrm{mg}$ Natriumzitrat

- $5.8 \mathrm{mg}$ Natriumchlorid

- $0.06 \mathrm{mg}$ Zitronensäure

- ad $1 \mathrm{ml} \mathrm{H}_{2} \mathrm{O}$

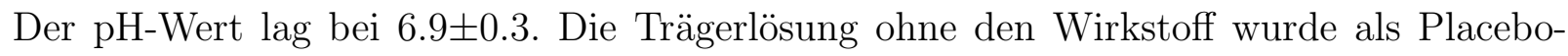
präparat verwendet.

\subsubsection{Evans-Blue-Lösung}

Es wurde $1 \mathrm{~g}$ pulverförmiges Evans-Blue (Direct Blue 53 SIGMA E-2129, Sigma, Taufenkirchen, Deutschland) in $50 \mathrm{ml}$ PBS bei $\mathrm{pH}=7.4$ gelöst, so daß sich eine $2 \%$ ige Lösung injizieren ließ.

\subsubsection{Hämalaunlösung}

MAYERS Hämalaunlösung für die Mikroskopie (Merck Darmstadt, Deutschland) wurde unverdünnt verwendet und lediglich vor der Benutzung filtriert.

\subsubsection{Paraformaldehyd}

Verwendet wurden $20 \mathrm{~g}$ Paraformaldehyd (SIGMA P-6148, SIGMA-Aldrich Chemie GmbH, Steinheim, Deutschland), gelöst in phosphatgepufferter NaCl-Lösung (SIGMA P-3813, SIGMA-Aldrich Chemie GmbH, Steinheim, Deutschland). PBS wurde auf $50^{\circ} \mathrm{C}$ erhitzt und dann das Paraformaldehyd (PFA) hinzugefügt. Bei Aufklaren der Lösung nach ungefähr 20 Minuten wurden 2 Tropfen $\mathrm{NaOH}$ hinzugefügt und dann der pH-Wert mit HCl-Lösung auf 7.2 eingestellt (Digital pH-Meter $\mathrm{pH}$ 525, Wissenschaftlich Technische Werkstätten, Weilheim, Deutschland). Die Lösung wurde gefiltert (Stericup $0.22 \mu \mathrm{m}$ GP Express Membrane, Millipore Corporation, Bedford Massachusetts, USA) und bis zur Verwendung am nächsten Tag bei $4^{\circ} \mathrm{C}$ gelagert. 


\subsubsection{Phosphatgepufferte Kochsalzlösung}

Es wurde ein Produkt der Firma SIGMA (P-3813, Phosphate buffered Saline, SIGMAAldrich Chemie GmbH, Steinheim, Deutschland) verwendet und in $1000 \mathrm{ml} \mathrm{H}_{2} \mathrm{O}$ bidest. gelöst. Der pH-Wert betrug 7.4.

\subsubsection{2,2,2-Tribromoethanol}

Es wurde $1 \mathrm{~g}$ Avertin $^{\circledR}$ (SIGMA-Aldrich Chemie GmbH, Steinheim, Deutschland) in 0.81 $\mathrm{ml}$ tert-Amylalkohol (Merck, Darmstadt, Deutschland) und $71.49 \mathrm{ml} \mathrm{H}_{2} \mathrm{O}$ bidest. bei $40{ }^{\circ} \mathrm{C}$ gelöst und anschließend steril filtriert (Stericup 0.22 $\mu \mathrm{m}$ GP Express Membrane, Millipore Corporation, Bedford Massachusetts, USA). Beim Lösen und der Lagerung wurden lichtundurchlässige Behälter verwendet. Die Aufbewahrung erfolgte maximal 24 Stunden bei $4{ }^{\circ} \mathrm{C}$, und angewendet wurden $400 \mathrm{mg} / \mathrm{kg} \mathrm{KG}$.

\subsection{Kälteläsionsmodell}

Alle Tierexperimente wurden in Übereinstimmung mit dem Antrag I509.42502/02-01.02 durchgeführt und vom Landesversorgungsamt Braunschweig genehmigt.

\subsubsection{Tiere}

Für die durchgeführten Experimente wurden männliche C57BL/6J Jungfrauen im Alter von 4 Wochen verwendet. Die Tiere wurden von der Firma Jackson (The Jackson Laboratory, Bar Harbor, USA) im Alter von 3 Wochen geliefert und nach einer Woche operiert. Je vier Tiere waren in einem Käfig mit freiem Zugang zu Wasser und Futter untergebracht. Pflege und Beobachtung der Tiere erfolgte durch Tierpfleger und -arzt im Institut.

\subsubsection{Narkose}

Die Narkose wurde mit Tribromoethanol $1.25 \%$ in einer Dosierung von $400 \mathrm{mg} / \mathrm{kg} \mathrm{KG}$ intraperitoneal durchgeführt. Nach Erlöschen des Aufricht- und des Haltungsreflexes wurde mit der Operation begonnen. 


\subsubsection{Läsion}

Das narkotisierte Tier wurde in einem Stereotakten der Firma TSE-Systems Bad Homburg (Stereotakt 4300 5-GR-GP/K) fixiert. Die Kopfhaut wurde rasiert, inzidiert und das Bregma dargestellt. Der Läsionskolben aus Kupfer besitzt ein stumpfes Ende mit $1 \mathrm{~mm}$ Durchmesser, das mit Koordinaten $1.5 \mathrm{~mm}$ rechtslateral und $1.5 \mathrm{~mm}$ posterior des Bregmas eingestellt wurde, ohne Kontakt zum Schädel zu haben. Dann wurde mit flüssigem Stickstoff der gesamte Kolben auf unter $-120^{\circ} \mathrm{C}$ gekühlt, an den genannten Koordinaten mit leichtem Druck auf die Kalotte aufgebracht und für 60 Sekunden dort belassen. Nach Ende dieser Zeit wurde die Kalotte mit Lidocainsalbe (Xylocain-Gel ${ }^{\circledR} 2 \%$, Astra-Zeneca Gmbh, Wedel, Deutschland) versorgt und die Haut mit einem Polypropylenfaden (Ethicon ${ }^{\circledR}$ Prolene 5-0, Johnson\&Johnson Intl., USA) wieder verschlossen. War das Tier für eine Therapie vorgesehen, so erfolgte die erste Präparatapplikation direkt im Anschluß.

Die Tiere wurden bis zum Wiedererwachen auf Wärmeplatten (Warming Plate HT200 minitüb GmbH, Deutschland) gelegt und beobachtet.

\subsubsection{Therapie}

Die Applikation erfolgte beginnend mit dem Tag der Läsion jeden zweiten Tag vormittags in einer Dosierung von $5 \mathrm{U} / \mathrm{g} \mathrm{KG}$ intraperitoneal; das Körpergewicht wurde bestimmt und dokumentiert. Jede Maus, die therapiert wurde, erhielt insgesamt 7 Injektionen (Protokolle zur Verteilung der Tiere auf die Experimentalgruppen siehe Absatz 2.8 auf Seite 32).

\subsection{Verhaltenstestung}

Die im Folgenden beschriebenen Verhaltensexperimente wurden im Tierhaus des MPI für biophysikalische Chemie durchgeführt. Das Haus ist mit einem automatischen Tag-NachtZyklus von 7-19 Uhr ausgestattet. Die Tiere waren zu viert in einem Käfig untergebracht, hatten freien Zugang zu Wasser und Futter, wöchentlich wurde die Streu erneuert. Die Aufbauten sind in einem reizarmen Labor untergebracht. Bei Nutzung der unten beschriebenen Videoanlage waren Experimentator und Computer in einem separaten Raum.

Zu Beginn eines Versuchstages wurden alle an diesem Tag benötigten Tiere in einen Vorraum gebracht und die Experimente erst nach 30 Minuten begonnen. Versuchsbeginn war 
immer vormittags, der Experimentator war gegenüber der Gruppenzugehörigkeit der Tiere geblindet. Im weiteren nicht erwähnt wird das intermittierende Reinigen der Versuchsanlagen mit 70\% Alkohol, falls Urin- und Kotrückstände sichtbar waren. Die folgende Reihenfolge der Beschreibung entspricht der tatsächlich durchgeführten Experimentierreihenfolge.

\subsubsection{VideoMot System}

Getrennt erwähnt wird hier die mehrfach verwendete Videoaufzeichnungsanlage der Firma TSE-Systems Bad Homburg. Im Experimentalraum zeichnet eine Kamera (Panasonic WV-BP310/G) ein Bild der Aufbauten und des Tieres auf. Ein Computer (Pentium 300 MHz, Windows 98) im Nebenraum erstellt mittels der Software VideoMot Version 5.32 eine Analyse der Bilder. Die Software erlaubt es, eine Experimentalregion zu definieren, innerhalb derer das Tier automatisch geortet wird. Die Möglichkeit, die Experimentalregion in mehrere Abschnitte zu unterteilen, erlaubt zudem Aufschluß über Verhaltensweisen und Aufenthaltsort des Tieres. Simultan erfolgt eine Beobachtung über einen Monitor (Panasonic WV-CM 1470) und teilweise eine konventionelle Aufzeichnung durch einen Videorecorder (Panasonic AG6730). Die Zeitmessung kann durch eine Fernbedienung im Experimentalraum gestartet werden.

Die gewonnenen Daten können gesichert und zur Weiterverarbeitung exportiert werden. Zur Archivierung wurde Microsoft Excel 97 verwendet; die statistische Auswertung mit SPSS wird auf Seite 35 beschrieben.

\subsubsection{Elevated Plus Maze}

In diesem eintägigen Experiment wurde die oben beschriebene Videoanlage verwendet. Der kreuzförmige Versuchsaufbau steht $40 \mathrm{~cm}$ über dem Boden und besitzt paarweise gegenüberliegende freie und geschlossene Arme, die je $31 \mathrm{~cm}$ lang sind (siehe Abb. 2.1 Seite 21). Die geschlossenen Arme sind von $16 \mathrm{~cm}$ hohen, undurchsichtigen Wänden umgeben, und das Tier wird zu Beginn des Versuchs mit der Schnauze in Richtung eines offenen Arms in die Mitte des Kreuzes gesetzt. In einer 5 minütigen Beobachtungsphase wird der Aufenthaltsort des Tieres registriert. Zur Beurteilung werden Zeit- und Gesamtdistanzanteile in den offenen und geschlossenen Armen herangezogen. Manuell werden Defäkation, Aufricht- und Putzverhalten registriert. 


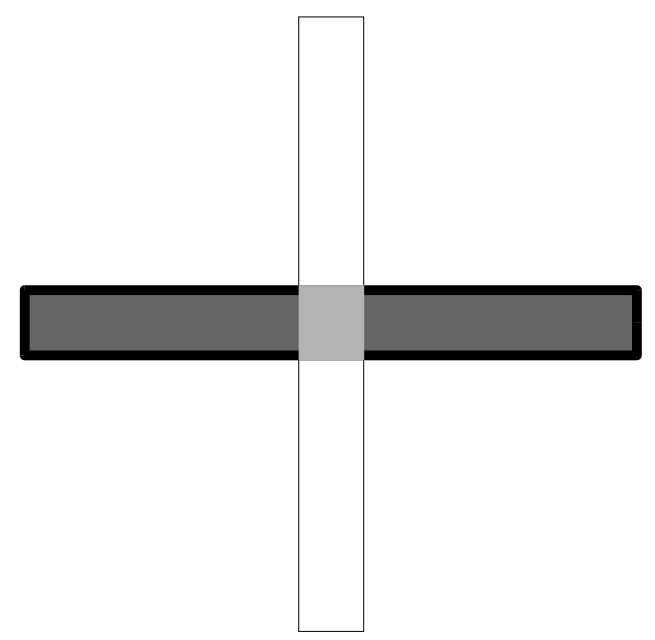

Abbildung 2.1: Skizze des Elevated Plus Maze. Dunkelgrau und fett umrandet die geschlossenen Arme, hellgrau die Zentralregion und in weiß die freien Arme ohne Wandbegrenzung

\subsubsection{Akzelerierendes Rotarod}

Zur Testung motorischer Fähigkeiten wurde das Accelerated Rotarod for mice 7650 (Jones \& Roberts, Type 337659) der Firma TSE-Systems Bad Homburg verwendet (siehe Abb. 2.2 Seite 22). Am Tag 1 des Experimentes wird das Tier auf die stillstehende Walze und nach einer 2 minütigen Gewöhnungsphase zurück in den Käfig gesetzt. Am Tag 2 und 3 wird das Tier auf die Walze gesetzt, die mit einer basalen Geschwindigkeit von 2.7 Umdrehungen pro Minute rotiert. Nach Zuschalten der Beschleunigung wird die Zeitmessung gestartet und die Latenz bis zum Fall von der Walze registriert. Die Beschleunigung erfolgt linear bis zu einer Geschwindigkeit von 33.3 Umdrehungen pro Minute. Die Latenzen an Tag 2 und 3 werden als Maß für die motorischen Basal- und Lernfähigkeiten verwertet.

\subsubsection{Open-field}

Das Verhalten im Open-field wird mit der oben beschriebenen Videoanlage aufgezeichnet. Der Versuchsaufbau besteht aus einer runden, hell beleuchteten Arena mit $120 \mathrm{~cm}$ Durchmesser, die von einer Wandung mit $25 \mathrm{~cm}$ Höhe umgeben ist. Die gesamte Arena besteht aus hellgrauem Kunststoff. Für die Registrierung werden drei Regionen der Arena unterschieden (je ein Radiusdrittel: zentral, intermediär und peripher). Das Tier wird zu Beginn des Experimentes in die Mitte der zentralen Region gesetzt und das Verhalten 


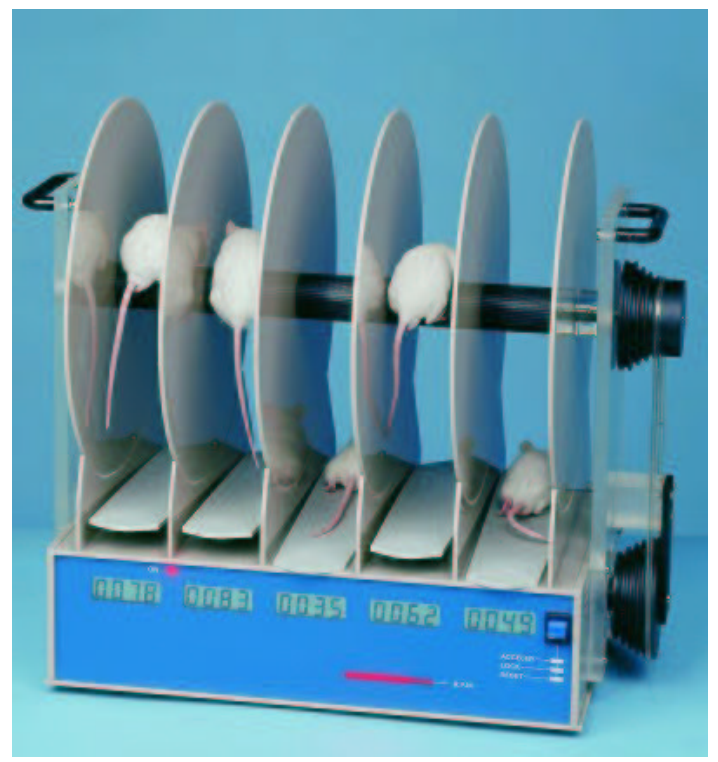

\section{Abbildung 2.2: Akzelerierendes Rotarod für Mäuse}

über 5 Minuten beobachtet und registriert. Evaluiert wurden zurückgelegte Gesamtdistanz sowie Zeit- und Distanzanteile, die in den verschiedenen Regionen zurückgelegt wurden. Zusätzlich wurden vom Untersucher manuell Putz- und Aufrichtverhalten, Erstarren und Defäkation registriert.

\subsubsection{Hole-Board}

Zur Testung des spontanen Explorationsverhaltens in streßfreier Umgebung wird das HoleBoard-Experiment in abgedunkelter und schallarmer Umgebung durchgeführt. Verwendet wird zur Registrierung das AKS-System der Firma TSE-Systems Bad Homburg. Eine Kunststoffplatte trennt zwei Ebenen von Infrarotschrankensystemen. Die obere registriert den Aufenthaltsort und die Bewegungen des Tieres, während die unteren Schranken nur durchbrochen werden, wenn das Tier den Kopf tief in eines der 12 Löcher in der Platte senkt. Die Löcher mit einem Durchmesser von $2 \mathrm{~cm}$ sind gleichmäßig in einer $4 \times 3$ Anordnung über die $34 \times 20 \mathrm{~cm}$ große Platte verteilt. In einem 3 minütigen Zeitraum kann das Tier die Umgebung frei erkunden, und die Anzahl der explorierten Löcher wird registriert. 


\subsubsection{Morris-Water-Maze}

Zur Testung des räumlichen Lernvermögens wurde der Water-Maze-Test nach Morris in einer modifizierten Variante durchgeführt (Crawley 2000). Die Datenerfassung erfolgt in diesem Experiment mittels der oben beschriebenen Videoanlage. Das benötigte Wasserbecken hat einen Durchmesser von $120 \mathrm{~cm}$ und ist bis $4 \mathrm{~cm}$ unter den Rand mit Wasser gefüllt, das durch weiße Farbe undurchsichtig gefärbt worden ist. Die Wassertemperatur beträgt $24^{\circ} \mathrm{C}$. Zur räumlichen Orientierung werden an den Wänden farbige Symbole aus Pappe für das Tier sichtbar aufgehängt und vier Einsatzstellen nur für den Experimentator sichtbar markiert. Jedes Tier wird an jedem Versuchstag je einmal in einer randomisierten Reihenfolge an den markierten Stellen eingesetzt. Der Einsatz erfolgt mit der Schnauze in Richtung Beckenrand, und ein Durchgang dauert maximal 90 Sekunden. Zwischen den einzelnen Durchgängen werden die Tiere in gewärmte Käfige (Warming Plate HT200 minitüb GmbH, Deutschland) gesetzt; das Intervall zwischen den Durchgängen beträgt 5 Minuten. Die Aufgabe der Tiere ist es, eine $9 \times 9 \mathrm{~cm}$ große Plattform zu finden, die $15 \mathrm{~mm}$ unter der Wasseroberfläche aufgestellt wurde (siehe Abb. 2.3).

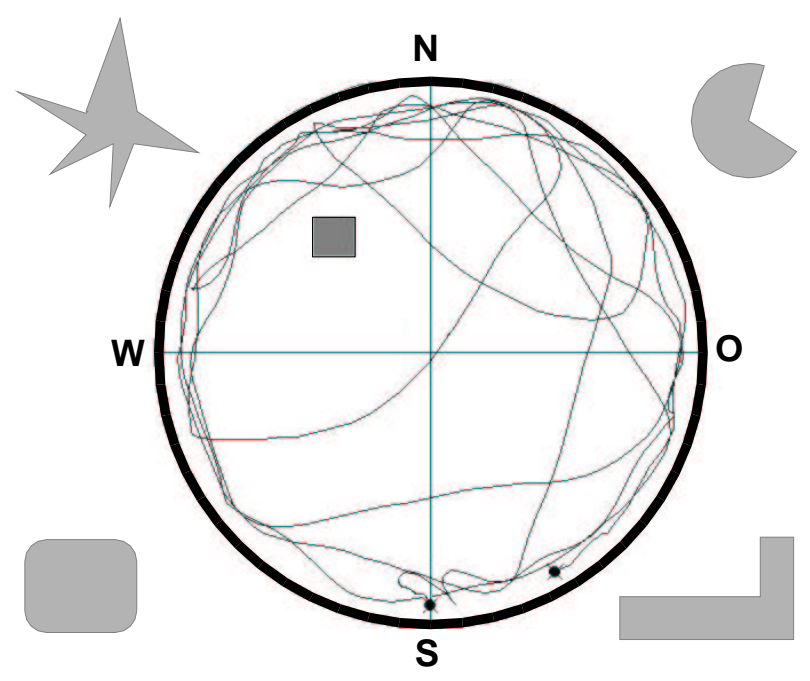

Abbildung 2.3: Schematischer Aufbau des Morris-Water-Maze.Das kleine graue Rechteck im oberen rechten Quadranten markiert den Standort der Plattform; um das Becken herum angeordnet sind die Symbole zur räumlichen Orientierung, die Einsatzstellen sind als „Himmelsrichtungen“ markiert. Das Bild enthält die aufgezeichnete Spur eines Tiers, das an der unteren Einsatzstelle beginnt und in diesem Fall die Plattform nicht findet. 
Sichtbare Plattform An den ersten beiden Tagen ist die Plattform durch eine Fahne markiert. Aufgabe der Tiere ist es, die Plattform zu erreichen und dort zu verharren.

Am Tag 1 wird die Plattform in das Zentrum eines der Quadranten gestellt. Das Tier wird eingesetzt und soll die Plattform innerhalb von 90 Sekunden finden. Ist es erfolgreich, so wird es 20 Sekunden dort sitzen gelassen und dann aus dem Becken entfernt. Bei Mißerfolg wird es per Hand auf die Plattform und wiederum nach 20 Sekunden zurück in den gewärmten Käfig gesetzt.

Am Tag 2 wird die Plattform in einen der anderen Quadranten gestellt und es wird wie oben beschrieben verfahren. Es konnte anhand der Verbesserung gegenüber Tag 1 beurteilt werden, ob die Tiere motorisch und kognitiv in der Lage waren, die Aufgabe zu erlernen. Zur Auswertung wurde die Latenz bis zum Erreichen der Plattform in Sekunden sowie der bis dorthin zurückgelegte Weg in Zentimetern herangezogen.

Unsichtbare Plattform Am Tag 3 wird wiederum die Position der Plattform variiert, von diesem Tag an aber konstant beibehalten. Ab diesem Tag wurde die Fahne entfernt und die Plattform damit unsichtbar für die Tiere. Bezüglich des Erfolges, Mißerfolges und der Einsatzstellen wird wie oben beschrieben verfahren. Auch in diesem Versuchsteil werden Latenz und zurückgelegte Distanz beurteilt.

Probe Trial Lediglich im letzten Durchgang des letzten Versuchstages wird der Aufbau variiert und die Plattform aus dem Becken entfernt; ein Erfolg im vorherigen Sinne ist also unmöglich. Das Suchverhalten wird 90 Sekunden lang aufgezeichnet und das Tier danach aus dem Becken genommen. Erfolg ist im Falle des Probe-Trials eine Präferenz für den sogenannten „Zielquadranten“, der vorher die Plattform enthielt.

Zur Bewertung wurden folgende Parameter herangezogen:

- Zeitanteile im Zielquadranten

- Gesamtdistanzanteile im Zielquadranten

- Überquerung des Bereichs, der vorher die Plattform enthielt.

Über den gesamten Versuchsverlauf wird vom Experimentator eine Bewertung des sogenannten Float-Verhaltens („Sich-Treiben-Lassen“) durchgeführt, um Tiere zu erkennen, die überhaupt kein gerichtetes Suchverhalten zeigten. 


\subsubsection{Furchtkonditionierung}

Zur Durchführung wurde das Furchtkonditionierungssystem der Firma TSE-Systems Bad Homburg (Process Control 303410) mit der Software AKS 3.04 verwendet. Das System registriert auf zwei Infrarotschrankenebenen den Aufenthaltsort und das Aufrichtverhalten des Tieres. Tonsignale werden über einen Lautsprecher an der Decke des Käfigs und Elektroschocks über ein Fußgitter appliziert. Manuell wird das sogenannte Freezing-Verhalten des Tieres („Erstarren“) in den unten beschriebenen Zeiträumen registriert. Hierzu wird jede zehnte Sekunde auf ein Lichtsignal (nur für den Experimentator sichtbar) hin beurteilt, ob gerade Bewegung stattfindet oder nicht. Als Freezing-Verhalten wird das Nichtvorhandensein von jeglicher Bewegung außer der Atemexkursion gewertet, und aus der Anzahl der registrierten Ereignisse wird ein prozentualer Anteil errechnet. Die Software registriert außerdem automatisch den Zeitanteil pro Versuchsabschnitt, in dem Bewegung stattfindet, und stellt damit eine Aktivitätsmessung zur Verfügung, die mit dem Freezing-Verhalten korreliert werden konnte.

Am Tag 1 wird das Tier in die Arena gesetzt und über 2 Minuten eine Basisaktivität erfaßt. Es folgt ein Tonsignal mit einer Lautstärke von 70 dB(A) bei 6000 Hertz über 30 Sekunden, an dessen Ende ein 2 sekündiger Elektroschock mit $0.5 \mathrm{~mA}$ über das Fußgitter appliziert wird. Nach einer 20 sekündigen Pause werden Tonsignal und Fußschock wiederholt und das Tier danach in den Käfig zurückgesetzt.

Für den Tag 2 werden die Tiere in zwei Gruppen geteilt. Die eine erhält zuerst den im Folgenden beschriebenen kontextbezogenen Test und dann den stimulusbezogenen Test; die andere Gruppe erhält die Tests in umgekehrter Reihenfolge. Diese Maßnahme diente dazu, Einflüsse der Testreihenfolge zu minimieren.

Kontextbezogenes Lernverhalten Das Tier wird in die zuvor beschriebene Arena gesetzt und über einen 2 minütigen Zeitraum auf Freezing-Verhalten hin beobachtet. Weder Tonsignal noch Fußschock werden appliziert. Bei Assoziation von Kontext und früher erfahrenem aversivem Stimulus (Fußschock) sollte sich ein erhöhtes Freezing-Verhalten (bezogen auf die Basisaktivität) zeigen.

Stimulusbezogenes Lernverhalten Vor Beginn dieses Abschnitts wird der Versuchsaufbau verändert. Farbige Wände, ein quergestellter Plastikkäfig mit Deckel und veränderte Lichtverhältnisse schaffen eine neue Situation für das Tier. Um sicherzustellen, daß das 
Tier die Umgebung nicht wiedererkennt, wird es über eine 2 minütige Phase ohne Stimulus auf Freezing-Verhalten beobachtet. Darauf folgen zwei Minuten, in denen das bekannte Tonsignal appliziert und währenddessen wiederum das Freezing-Verhalten registriert wird. Ein Fußschock wird in diesem Versuchsabschnitt nicht appliziert.

Zur Auswertung wurden die Basisaktivität und die Erhöhung des Freezing-Verhaltens im kontextbezogenen und stimulusbezogenen Test herangezogen.

\subsection{Magnetresonanztomographie}

Aus den Experimentalgruppen wurden je 7 Tiere zufällig ausgewählt und die Magnetresonanztomographie durchgeführt. Es wurde ein 2.35 T MRBR 4.7/400 mm Magnet (Magnex Scientific, Abingdon, England) mit BGA20 Gradienten (100 mT m $\left.{ }^{-1}\right)$ verwendet. Die Datenverarbeitung erfolgte auf einem DBX System (Bruker Biospin, Ettlingen, Deutschland). Zur Einleitung der Untersuchung werden die Tiere intubiert und mit 1.0-1.5\% Halothan in einem Lachgas/Sauerstoff-Gemisch narkotisiert (70:30 $\left.\mathrm{NO}_{2}: \mathrm{O}_{2}\right)$. Danach wird der Kopf des Tieres auf einem speziell gefertigten Stereotakten fixiert und eine Helmholtz Spule (ф100 mm) sowie eine elliptisch geformte Oberflächenspule (ф $20 \mathrm{~mm}$ anterior-posterior, 12 mm links-rechts) über dem Kopf des Tieres montiert. Erstere dient der Radiofrequenzerzeugung, letztere der Signalaufnahme. Während der Messung wird die Körpertemperatur rektal gemessen und durch Warmwasserschläuche auf dem Körper des Tieres bei $37 \pm 1^{\circ} \mathrm{C}$ gehalten.

Verwendete Sequenz Erfaßt wurden $\mathrm{T}_{1}$-gewichtete Bilder mit einer 3D FLASH Sequenz, deren Parameter auf der folgenden Seite in Tabelle 2.1 angegeben sind.

Gewebeentnahme Nach Ende der Datenerfassung wird des Tier noch in Narkose von der Beatmung getrennt und dekapitiert. Eine Blutprobe wird gewonnen und das Gehirn entnommen. Die Weiterverarbeitung des Gewebes und der Blutproben ist in den Abschnitten 2.5.1 und 2.5.2 ab Seite 28 beschrieben. 


\begin{tabular}{ll}
\hline Repetitionszeit & $17 \mathrm{~ms}$ \\
Echozeit & $7.6 \mathrm{~ms}$ \\
Aufnahmebandbreite & $12.5 \mathrm{kHz}$ \\
Kippwinkel & $25^{\circ}$ \\
Meßfeld & $15 \times 15 \times 15 \mathrm{~mm}^{3}$ \\
Bildauflösung & $117 \times 117 \times 117 \mu \mathrm{m}^{3}$ \\
Datenakkumulationen & 32 \\
Meßzeit & 84 Minuten \\
\hline
\end{tabular}

Tabelle 2.1: Parameter der 3D FLASH Sequenz nach Natt et al. (2002)

\subsubsection{Darstellung der Läsion}

Im Anschluß an die Datenerfassung wurde versucht, die Läsion darzustellen; der Experimentator war gegenüber der Gruppenzugehörigkeit der Tiere geblindet. Es wurden Transversalschnitte betrachtet und der Schnitt mit der besten Ausprägung der Läsion für jedes Tier dokumentiert. Zusätzlich wurde eine Schnittebene tangential zur Hirnoberfläche gewählt, die den Kortex im Läsionsgebiet schneidet. So konnte ein Vorhandensein der Läsion gesichert beziehungsweise ausgeschlossen werden.

\subsubsection{Volumetrie}

Nach der qualitativen Auswertung der Bilder sollten morphologische Auswirkungen der Läsion quantitativ beschrieben werden.

Auf den Aufnahmen wurden folgende Strukturen volumetrisch ausgewertet:

- Seitenventrikel rechts und links

- Hippokampi rechts und links

- Hirngesamtvolumen.

$\mathrm{Zu}$ diesem Zweck wurden die genannten Strukturen manuell umfahren (siehe Abb. 2.4 Seite 28) und die gemessenen Flächen pro Schnittbild notiert. Ausgewertet wurden Transversalschnitte beginnend unterhalb der Kalotte bis hin zu dem Schnittbild, auf dem die Hypophyse nicht mehr sichtbar ist. Die Hypophyse wurde als Endpunkt gewählt, da sie als sehr helle Struktur in der $\mathrm{T}_{1}$-Wichtung einfach und reproduzierbar aufzufinden ist. Über die Messungen in den circa 50 pro Tier ausgewerteten Schnittbildern wurde summiert und das 


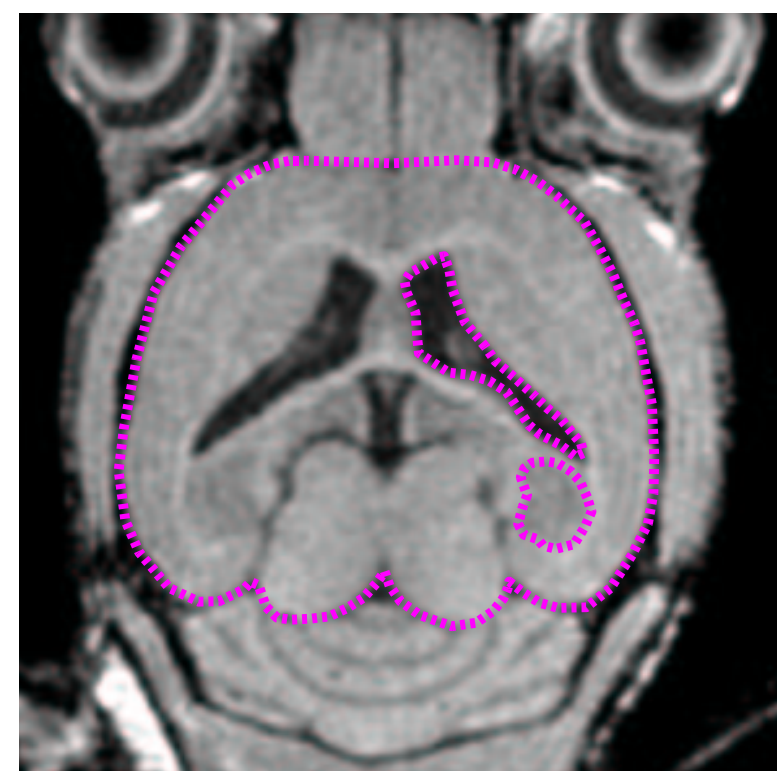

Abbildung 2.4: Darstellung der volumetrisch evaluierten Areale im Transversalschnitt. Exemplarisch ist im rechten Bildteil der laterale Ventrikel und der Hippokampus wie in der volumetrischen Auswertung markiert. Im linken Bildteil ist die Markierung nicht vorhanden, um den guten Weichteilkontrast der $\mathrm{T}_{1}$-Wichtung darzustellen.

Ergebnis in Voxeln errechnet. Das Hirngesamtvolumen wurde unter Ausschluß der sichtbaren Anteile von Cerebellum, Bulbus olfactorius, Rückenmark und Medulla oblongata bestimmt. Die Umrechnung in Kubikmillimeter erfolgte über das bekannte Voxelvolumen von $1.6 \times 10^{-3} \mathrm{~mm}^{3}$. Untersucht wurden Gruppen- sowie Seitenunterschiede im Hippokampusund Ventrikelvolumen absolut und bezogen auf das Gesamthirnvolumen, außerdem Gruppenunterschiede im Gesamthirnvolumen. Die auswertende Person war bis zur statistischen Auswertung gegenüber der Gruppenzugehörigkeit der Tiere geblindet.

\subsection{Gewebsaufbereitung}

\subsubsection{Verarbeitung der Blutproben}

Die Blutentnahme erfolgte retrobulbär mittels einer Glaskapillare. Das gewonnene Blut wurde in einem EDTA-beschichteten Röhrchen (Probengefäß 1.3 ml, Sarstedt AG \& Co, Nümbrecht, Deutschland) aufgefangen und die Blutmenge mit $200 \mu \mathrm{l}$ minimal gehalten. Die Bestimmung des Hämoglobin- und Hämatokritwertes erfolgte mittels eines automati- 
schen Analyse-Geräts $\left(A^{c} T^{\complement} 5\right.$ diff Hämatologie-Analysegerät, Beckman-Coulter, Krefeld, Deutschland).

\subsubsection{Präparation des Hirngewebes}

Alle Tiere wurden in tiefer Narkose dekapitiert, danach das Gehirn entnommen. Das Gehirn wurde direkt nach Entnahme auf 4\% Paraformaldehydlösung in PBS ( $\mathrm{pH}=7.4)$ gegeben und 24 Stunden bei $4^{\circ} \mathrm{C}$ gelagert.

Fixierung Danach wurde das Gewebe in einem Einbettautomaten (TP 1020, Leica, Deutschland) fixiert. Das Gerät führte die Fixierung mit folgenden Lösungen und Zeitdauern durch:

Je 60 Minuten:

- $50 \%$-Ethanol

- $70 \%$-Ethanol

- $90 \%$-Ethanol

- $90 \%$-Ethanol

- $90 \%$-Ethanol

Je 90 Minuten:

- $100 \%$-Ethanol

- $100 \%$-Ethanol

- $100 \%$-Ethanol

- Xylol

- Xylol

Je 120 Minuten:

- flüssiges Paraffin

- flüssiges Paraffin

Alle Lösungen bis auf das Paraffin hatten Raumtemperatur, das flüssige Paraffin war $60^{\circ} \mathrm{C}$ warm.

Das fixierte Gewebe wurde anschließend an einer Ausgießstation (Histocentre 2, Shandon GmbH, Frankfurt a.M., Deutschland) im flüssigen Paraffin auf Biopsiekapseln plaziert und 
das Paraffin zum Aushärten gebracht. An einem Mikrotom (HN 40, Jung AG, Heidelberg, Deutschland) wurden $7 \mu \mathrm{m}$ Gewebsschnitte erstellt, und diese wurden auf Objektträger (SuperFrost ${ }^{\circledR}$ Plus, Menzel-Gläser, Deutschland) aufgezogen.

\subsubsection{Routinefärbungen}

Auf Höhe der Läsion wurden 2-3 repräsentative Schnitte mit der Hämatoxylin-EosinMethode gefärbt. Dabei wurde nach folgendem Protokoll vorgegangen:

Dreimal je 3 Minuten Xylol, dann kurz in Isoxylol waschen.

Je 2 Minuten:

- $100 \%$-Ethanol

- $100 \%$-Ethanol

- $90 \%$-Ethanol

- $70 \%$-Ethanol

- $50 \%$-Ethanol

- $\mathrm{H}_{2} \mathrm{O}$

Es folgten 8 Minuten in Hämalaunlösung, kurze Differenzierung in HCl-Ethanol und 10 Minuten Spülen unter Leitungswasser. Danach wurden die Schnitte für 5 Minuten in Eosinlösung gegeben. Zur Herstellung der Lösungen siehe Abschnitt 2.1.

Dann jeweils 2 Minuten:

- $\mathrm{H}_{2} \mathrm{O}$

- $50 \%$-Ethanol

- $70 \%$-Ethanol

- $90 \%$-Ethanol

- $100 \%$-Ethanol

- $100 \%$-Ethanol

Es folgten dreimal je 3 Minuten Xylol. Die gefärbten Schnitte wurden mit EUKITT ${ }^{\circledR}$ (O. Zindler GmbH \& Co, Freiburg, Deutschland) und Objektglas geschützt. 


\subsection{Auswertung der Standardhistologie}

Aus den weiter hinten beschriebenen Experimentalgruppen wurden für das Protokoll 3 (siehe Seite 32) Tiere zufällig ausgewählt (Sham + Placebo $n=7$; Läsion + Placebo $n=6$; Läsion + EPO n=7) und von jedem Tier 6-8 Objektträger ausgewertet. Dazu wurde das Vorhandensein der Läsion beurteilt und ihre Lokalisation mit einem StandardhistologieAtlas (Rosen et al. 2000) überprüft. Dann wurde jeweils in Höhe des dorsalen Hippokampus im Bereich der Hilus-Region des Gyrus dentatus ein Blickfeld mit 20-facher Vergrößerung dargestellt. Gezählt wurde in diesem Feld die Anzahl der morphologisch intakt erscheinenden pyramidalen Zellen erst auf der ipsi-, dann auf der kontralateralen Seite. Für jedes Tier wurden der Mittelwert und Standardfehler für die ausgewerteten Objektträger berechnet. Die Umrechnung auf Zellen pro $\mathrm{mm}^{2}$ erfolgte durch die bekannte Blickfeldfläche von $0.175 \mathrm{~mm}^{2}$.

\subsection{Untersuchung der Blut-Hirn-Schrankenfunktion}

Im Rahmen der Frage nach der Wirksamkeit von Erythropoietin war der Einfluß auf die Blut-Hirn-Schranke von Bedeutung. Es wurden Tiere nach dem oben beschriebenen Protokoll läsioniert und entweder mit Placebo oder mit EPO behandelt; die Injektion erfolgte direkt im Anschluß an die Läsionierung. Ein Teil der Tiere wurde nach 30 Minuten mit $0.4 \mathrm{ml}$ Evans-Blue-Lösung intramuskulär injiziert und weitere 30 Minuten später noch in Narkose perfundiert. Eine zweite Gruppe von Tieren wurde erst nach 6 Stunden mit EvansBlue-Lösung injiziert und entweder ebenfalls 30 Minuten später oder erst nach weiteren 18 Stunden (also insgesamt 24 Stunden) perfundiert. Eine dritte Tiergruppe wurde nach 24 Stunden mit Evans-Blue injiziert und nach weiteren 30 Minuten perfundiert.

\begin{tabular}{cccc} 
& \multicolumn{3}{c}{ Zeitpunkt der Hirnentnahme } \\
\cline { 2 - 4 } & 1 Stunde & 6 Stunden & 24 Stunden \\
\hline EPO & 4 & 4 & $4+4$ \\
Placebo & 4 & 4 & $4+4$ \\
\hline
\end{tabular}

Tabelle 2.2: Zeitpunkte der Hirnentnahme nach Evans-Blue-Injektion. Nach 24 Stunden je 4 Tiere mit Evans-Blue-Injektion 18 Stunden und 4 Tiere mit Injektion 30 Minuten vor der Hirnentnahme.

Die Perfusion erfolgte mit $0.9 \%$ NaCl-Lösung, die 5000 Einheiten Heparin (Liquemin ${ }^{\circledR}$, 
Hoffmann-LaRoche AG, Grenzach-Wyhlen, Deutschland) enthielt. Dazu wurde der Thorax eröffnet und eine Nadel direkt im linken Ventrikel des Herzens plaziert, dann wurde die Vena cava inferior eröffnet und das Blut aus dem Kreislauf gespült. Im Anschluß an die Ausblutung wurde für 5 Minuten mit 4\% PFA-Lösung perfundiert und das Hirn nach Entnahme ebenfalls über Nacht in PFA-Lösung fixiert. Danach wurde das Gewebe in PBS gewaschen und in einer aufsteigenden Glycerolreihe (15\%,30\%,60\%,75\%,80\%) in PBS geklärt (jeweils 24 Stunden pro genannter Konzentration). Zur Herstellung der genannten Lösungen siehe Abschnitt 2.1.

Der übergetretene blaue Farbstoff war im geklärten Gewebe durch Digitalaufnahmen in der Aufsicht und nach Transversalschnitt durch die Läsion sichtbar. Ein Vorhandensein des Farbstoffs wurde von einem geblindeteten Experimentator dokumentiert und semiquantitativ in die Kategorien „nicht vorhanden“, „,gering“ und „stark“ unterteilt.

\subsection{Experimentalgruppen}

Im Folgenden werden eine Auflistung der Experimentalgruppen und das Design der Studie dargelegt (schematisch dargestellt in Abbildung 2.5 auf Seite 34).

Untersuchung der hämatopoietischen Effekte Zur Abgrenzung des hämatopoietischen Effekts der Erythropoietingabe wurde einer kleinen Gruppe Tiere mehrfach Blut entnommen. Dazu wurden nicht-läsionierte Tiere in 2- und 4-wöchigen Abständen vormittags mit Avertin (400 mg/kg KG) narkotisiert und es wurde retrobulbär Blut entnommen. Die Tiere wurden bis zum Wiedererwachen gewärmt und auf Verletzungen hin beobachtet. Die Weiterverarbeitung der Proben erfolgte nach oben beschriebenem Protokoll (siehe 2.5.1 Seite 28). Untersucht wurde, ob die Erythropoietinapplikation einen hämatopoietischen Effekt hatte und in welchem Ausmaß und Zeitraum er auftrat. Diese Tiere wurden für keine der weiteren Experimente verwendet.

Läsionsprotokolle In vollem Umfang wurden die Verhaltensexperimente, die Magnetresonanztomographie und die Histologie in drei verschiedenen Protokollen durchgeführt. Die folgende Tabelle 2.4 gibt Aufschluß über Experimental- und Kontrollgruppen; die Schemazeichnung 2.5 auf Seite 34 veranschaulicht den zeitlichen Ablauf. Jede der benannten Gruppen bestand aus 10 Tieren. 
fünfmalige Blutabnahme

\begin{tabular}{|r|c|c|c|}
\hline & \multicolumn{3}{|c|}{ Art der Injektionen } \\
\cline { 2 - 4 } & EPO & Placebo & keine \\
\hline $\begin{array}{r}\text { Anzahl } \\
\text { der Tiere }\end{array}$ & 3 & 2 & 2 \\
\hline
\end{tabular}

$0,2,4,8,12$ Wochen nach Ende der Injektionen dreimalige Blutabnahme

\begin{tabular}{|r|c|c|c|}
\hline \multirow{2}{*}{} & \multicolumn{3}{|c|}{ Art der Injektionen } \\
\cline { 2 - 4 } & EPO & Placebo & keine \\
\hline $\begin{array}{r}\text { Anzahl } \\
\text { der Tiere }\end{array}$ & 3 & 2 & 2 \\
\hline \multicolumn{3}{|c}{$0,8,12$ Wochen } \\
nach Ende der Injektionen
\end{tabular}

Tabelle 2.3: Zeitpunkte der Blutentnahme und Gruppengröße. Aufgeführt sind hier nur die Tiere, denen mehrfach Blut entnommen wurde und die für keine der weiteren Experimente verwendet wurden.

\begin{tabular}{cccc} 
Protokoll & \multicolumn{3}{c}{ Gruppen } \\
\hline \hline 1 & Naiv + EPO & Naiv + Placebo & Naiv \\
\hline \multicolumn{4}{c}{} \\
\hline & Sham + EPO & Sham + Placebo & Naiv \\
\hline 3 & Läsion + EPO & Läsion + Placebo & Sham + Placebo \\
\hline \hline
\end{tabular}

Tabelle 2.4: Läsionsprotokolle und Versuchsgruppen. Naiv bedeutet hierbei keine Narkose und Operation, sham Operation und Narkose, aber keine Läsion; die Therapie beinhaltet entweder keine Injektionen oder Injektion von Erythropoietin bzw. lediglich der Trägersubstanz als Placebo-Präparat. 


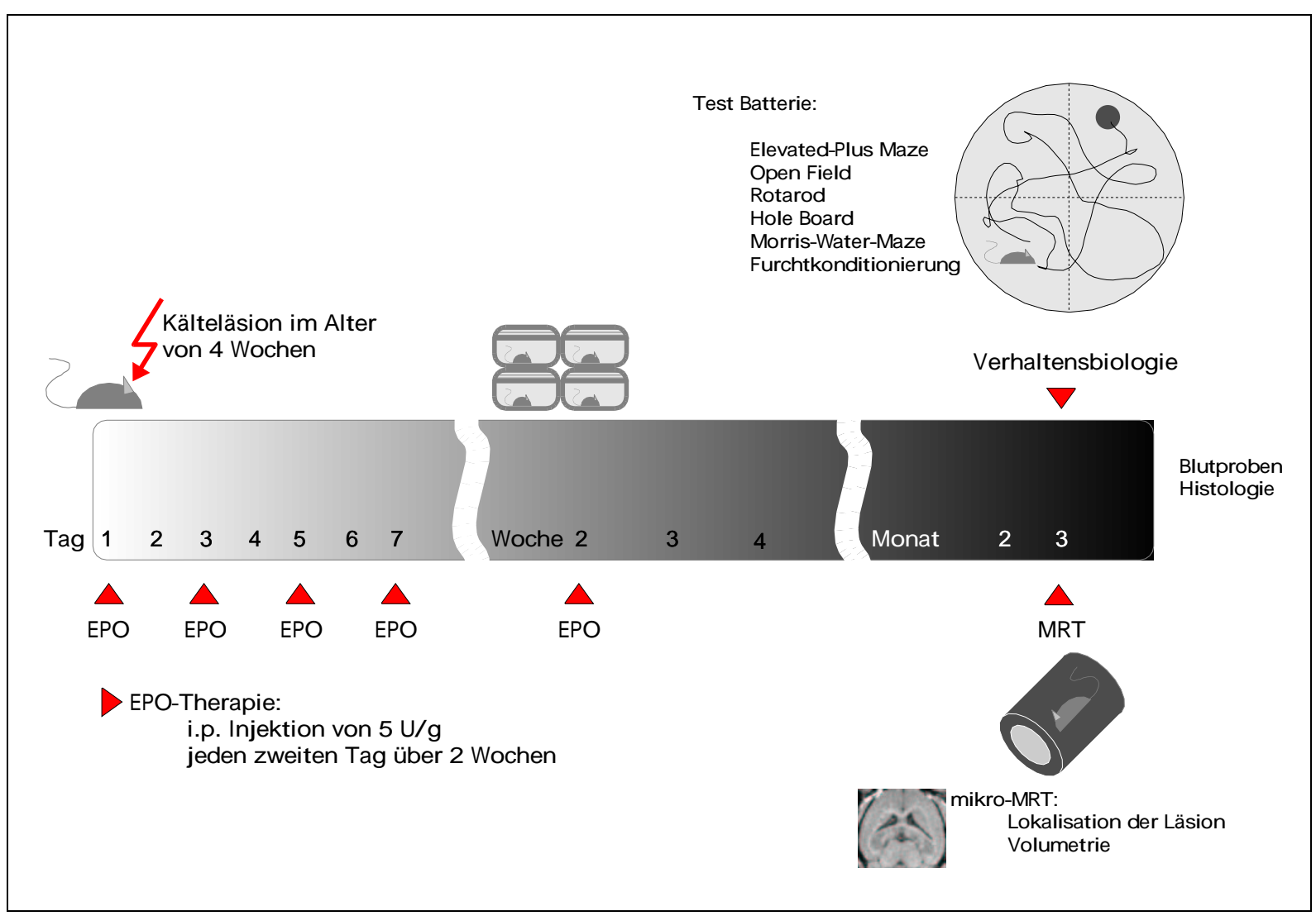

Abbildung 2.5: Zeitlicher Ablauf der Experimente. Zur Verdeutlichung ist ein Schema der Reihenfolge und Zeitpunkte der verschiedenen Elemente der Therapiestudie angegeben. Für sham-Tiere wurde lediglich eine Operation, aber keine Läsion durchgeführt; für Placebo-Tiere wurde lediglich die Trägerlösung ohne Erythropoietin injiziiert. Die Gruppengröße beträgt jeweils $n=10$; für die MRT ist $n=7$. 
Mit diesen Experimenten war es möglich, sehr genau zwischen den Einflußgrößen zu differenzieren. Protokoll 1 ermöglicht es, die Auswirkungen der Injektionen auf das Verhalten zu beurteilen und zwischen der Injektion von EPO und Placebo zu unterscheiden. In Protokoll 2 war es möglich, zusätzlich den Operationsstreß zu beurteilen und auch hier eine eventuelle EPO-Wirkung zu erkennen. Schließlich sollte Protokoll 3 die wichtigste Frage klären, ob EPO einen Effekt auf die Läsion zeigt.

Protokolle 1-3 wurden durchgeführt; die Tiere wurden 3 Monate nach der Läsionierung der Verhaltenstestung und Magnetresonanztomographie zugeführt und die Hirne wurden entnommen (Vorgehen wie oben beschrieben). Im Rahmen einer Pilotstudie nach Protokoll 2 wurden Tiere läsioniert und direkt nach der letzten Injektion (2 Wochen nach Läsion) in der Verhaltensbatterie getestet, um akute Auswirkungen oder Beeinträchtigungen zu erfassen. Während dieser Pilotstudie wurde keine Magnetresonanztomographie, aber Blutentnahmen und Histologie im oben beschriebenen Rahmen durchgeführt.

\subsection{Statistik}

Die Auswertung der erhobenen Daten erfolgte mit SPSS in der Version 11.0 auf einem PC. Bei der Analyse der hämatologischen Auswirkungen von EPO wurde zu den einzelnen Zeitpunkten ein t-Test auf dem Signifikanzniveau 5\% durchgeführt. Für jedes verhaltensbiologische Experiment wurde mit einer einfaktoriellen ANOVA auf Gruppenunterschiede in der Verhaltensuntersuchung und anschließend für die mit der Magnetresonanztomographie volumetrisch erhobenen Areale getestet; das Signifikanzniveau betrug $5 \%$. Im Anschluß an die ANOVA wurde ein post-hoc-Test nach Duncan durchgeführt. Normalverteilung wurde durch den Test nach Kolmogorov-Smirnov sichergestellt. Das gleiche Vorgehen wurde für die Auswertung der Standardhistologie verwendet.

Die Verlaufsdaten des Water-Maze-Test nach Morris wurden mittels einer ANOVA mit Meßwiederholungen auf Gruppenunterschiede getestet. Der Probe-Trial wurde durch paarweise t-Tests der Zeit- und Distanzanteile im Zielquadranten gegen die anderen Quadranten ausgewertet. Ein signifikant erhöhter Aufenthalt im Zielquadrant gegenüber allen anderen Quadranten wurde als Lernerfolg gewertet. Auch in diesem Falle betrug das Signifikanzniveau $5 \%$. 


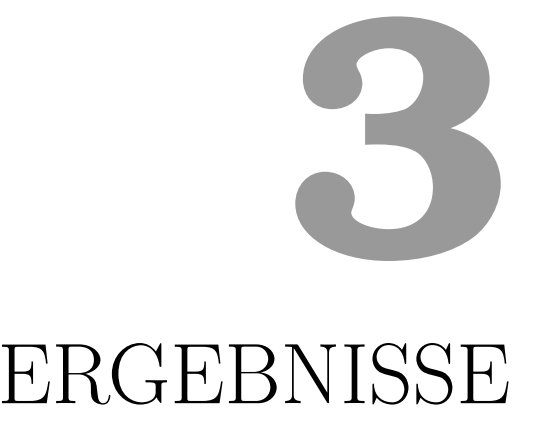

\subsection{Hämatologische Auswirkungen der Erythropoietinapplikation}

Im Folgenden werden die Ergebnisse der wiederholten Blutentnahmen zum Test der Wirksamkeit und Praktikabilität der geplanten Erythropoietinapplikation dargestellt.

Während der Applikation ergab sich keine Komplikation wie beispielsweise Infektionen durch wiederholte intraperitoneale Injektionen. Als Indikator wurde die gleichmäßige Gewichtszunahme der Tiere verwendet, die keine Unterschiede zwischen den Tieren mit und ohne Injektionen zeigten. Die Wirksamkeit des Präparates im Tiermodell ließ sich durch signifikant erhöhte Hämatokrit- und Hämoglobinwerte am Ende der Injektionsreihe beweisen. Auch im Anschluß an die Injektionen traten keine Komplikationen auf, die beispielsweise durch den erhöhten Hämatokrit hätten verursacht werden können.

Im Zeitverlauf ergab sich ein Abklingen der hämatopoietischen Wirkung des Erythropoietins, so daß die veränderten Blutwerte 4 Wochen nach Läsion wieder normalisiert waren. 
Auch eine beschleunigte Normalisierung durch wiederholten Blutverlust wurde durch weniger häufige Entnahmen ausgeschlossen (vergleiche hierzu nochmals Tabelle 2.3). Die Tiere mit häufigeren Blutentnahmen zeigten keinen Unterschied im Rückgang des Hämatokrits und Hämoglobinwertes im Vergleich mit den Tieren, denen seltener Blut entnommen wurde. Zum Zeitpunkt der Verhaltenstests (3 Monate nach Läsion) war folglich keine hämatologische Wirkung der Therapie mehr zu erwarten. Die Blutproben, die nach den Verhaltenstests entnommen wurden, zeigten in Übereinstimmung mit den Mehrfachentnahmen keinen Unterschied zwischen den Experimentalgruppen. In den Abbildungen 3.1 und 3.2 sind die Ergebnisse der Hämatokrit- und Hämoglobinmessungen graphisch und tabellarisch dargestellt.

Signifikant veränderte Werte sind durch Fettdruck markiert, das Signifikanzniveau für den durchgeführten t-Test betrug $5 \%$.

\begin{tabular}{|c|c|c|c|c|}
\hline \multirow{2}{*}{ Woche } & \multicolumn{2}{|c|}{ Naiv + EPO } & \multicolumn{2}{c|}{ Naiv (keine Injektionen) } \\
\cline { 2 - 5 } & Hämatokrit [\%] & Hämoglobin [g/dl] & Hämatokrit [\%] & Hämoglobin [g/dl] \\
\hline 0 & $\mathbf{5 6 . 5 0} \pm \mathbf{2 . 7 7}$ & $\mathbf{1 9 . 0 0} \pm \mathbf{1 . 0 2}$ & $38.42 \pm 0.91$ & $14.56 \pm 0.25$ \\
2 & $\mathbf{4 1 . 3 3} \pm \mathbf{1 . 3 3}$ & $\mathbf{1 5 . 2 5} \pm \mathbf{0 . 2 8}$ & $37.00 \pm 1.08$ & $13.68 \pm 0.18$ \\
4 & $38.22 \pm 2.00$ & $13.25 \pm 0.37$ & $40.17 \pm 1.82$ & $13.67 \pm 0.33$ \\
8 & $41.93 \pm 0.67$ & $13.37 \pm 0.18$ & $43.28 \pm 0.73$ & $13.83 \pm 0.21$ \\
12 & $40.10 \pm 1.94$ & $13.04 \pm 0.44$ & $39.23 \pm 1.20$ & $12.90 \pm 0.37$ \\
\hline
\end{tabular}
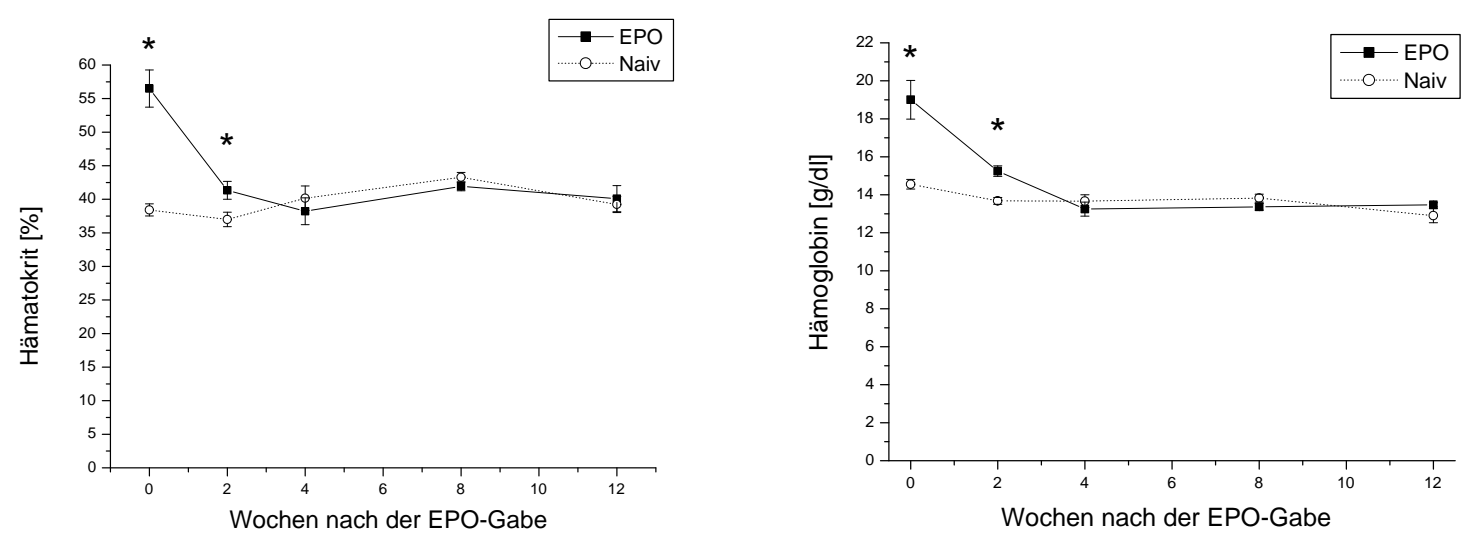

Abbildung 3.1: Darstellung der hämatologischen Verlaufsparameter. Zeitlicher Verlauf nach Abschluß der Injektionen. $\mathrm{n}=3-6$, dargestellt sind Mittelwerte $\pm \mathrm{SE}$; signifikante Unterschiede sind durch Fettdruck kenntlich gemacht, $\left(^{*}\right)$ indiziert $\mathrm{p}<0.05$. 

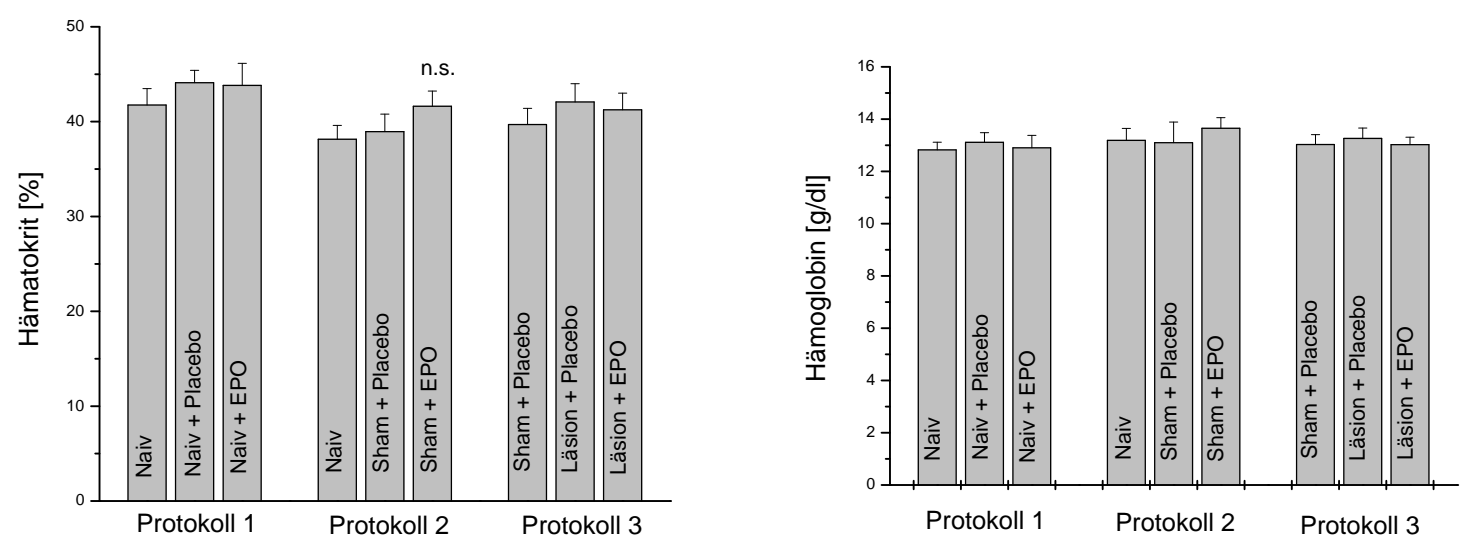

\begin{tabular}{|c|l|c|c|}
\hline Protokoll & Gruppe & Hämatokrit [\%] & Hämoglobin [g/dl] \\
\hline \multirow{3}{*}{1} & Naiv & $41.74 \pm 1.73$ & $12.80 \pm 0.29$ \\
& Naiv + Placebo & $44.10 \pm 1.31$ & $13.11 \pm 0.37$ \\
& Naiv + EPO & $43.81 \pm 2.33$ & $12.90 \pm 0.48$ \\
\hline \multirow{2}{*}{2} & Naiv & $35.67 \pm 2.59$ & $12.50 \pm 0.79$ \\
& Sham + Placebo & $35.96 \pm 2.52$ & $12.59 \pm 0.86$ \\
& Sham + EPO & $41.63 \pm 1.60$ & $13.65 \pm 0.40$ \\
\hline \multirow{3}{*}{3} & Sham + Placebo & $39.70 \pm 1.70$ & $13.03 \pm 0.38$ \\
& Läsion + Placebo & $42.08 \pm 1.93$ & $13.26 \pm 0.40$ \\
& Läsion + EPO & $41.25 \pm 1.76$ & $13.03 \pm 0.28$ \\
\hline \hline 3 & Sham + Placebo & $43.39 \pm 0.79$ & $13.87 \pm 0.11$ \\
akut & Läsion + Placebo & $43.50 \pm 0.61$ & $13.87 \pm 0.16$ \\
& Läsion + EPO & $43.01 \pm 0.79$ & $13.80 \pm 0.19$ \\
\hline
\end{tabular}

Abbildung 3.2: Darstellung der hämatologischen Parameter in den Läsionsprotokollen. Dargestellt sind die Werte der Experimentalgruppen bei Blutentnahmen direkt nach Abschluß der Untersuchungen, vor der Dekapitation. In den Diagrammen sind die Werte der akuten Experimentalgruppe nicht abgebildet. $n=10$ für jede Gruppe; alle Werte sind Mittelwerte \pm SE, es ergaben sich keine signifikanten Unterschiede.

\subsection{Verhaltensbiologie}

In diesem Abschnitt sollen die Ergebnisse der Verhaltenstestung dargestellt werden. Eine Zusammenstellung von Abbildungen und wichtigen Versuchsparametern mit Ergebnissen der statistischen Auswertung in Tabellenform ab Seite 41 dient der Vollständigkeit. Auf eine ausdrückliche Erwähnung nicht signifikanter Unterschiede wird deshalb im Folgenden verzichtet.

Protokoll 1 Auf den Seiten 41 ff. werden die Auswirkungen der Injektionen nach Protokoll 1 gezeigt. In der ANOVA zeigten sich keine Gruppenunterschiede dadurch, daß die 
Tiere im Alter von 4 Wochen für 2 Wochen jeden zweiten Tag injiziert wurden. Auffällig sind allein die paarweisen t-Tests der Zeitanteile im Probe-Trial des Morris-Water-MazeTests. Die Tiere, die mit Placebo injiziert wurden, verbrachten durchschnittlich am meisten Zeit in dem Quadranten links des Zielquadranten. Einzig die mit EPO injizierten Tiere verbrachten signifikant mehr Zeit im Zielquadranten als in allen anderen Quadranten; die Kontrollgruppe nicht injizierter Tiere tat dies jedoch nicht.

Protokoll 2 Für die Kontrolle der Operations- und Injektionsauswirkungen in Protokoll 2 werden die Ergebnisse ab Seite 46 dargestellt. Auch hier zeigten sich wenig Effekte der „Streßkomponente“ des Experimentes. Die Ergebnisse der durchgeführten einfaktoriellen ANOVA ergaben keine Gruppenunterschiede. Erwartungsgemäß zeigten die Tiere Lernverhalten im Sinne der Definitionen sowohl in der Furchtkonditionierung und Präferenz für den Zielquadranten im Probe-Trial des Water-Maze-Tests nach Morris, das im Falle der Gruppe Sham + Placebo knapp das Signifikanzniveau von 5\% verfehlte.

Protokoll 3 nach Abschluß der Injektionen Die Daten der Tiere nach Protokoll 3, die direkt nach den Injektionen im Alter von 6 Wochen getestet wurden, sind auf den Seiten $51 \mathrm{ff}$. dargestellt. Die sehr jungen Tiere zeigten sich aufgrund der hohen motorischen Aktivität nur begrenzt für die verhaltensbiologischen Tests geeignet. Im Rotarod hielten sie sich bereits am ersten Tag sehr lange auf der Walze, so daß ein Lerneffekt am zweiten Tag nicht darstellbar war. Auch die nicht abgebildete Gesamtdistanz im Open-field war gegenüber den anderen Experimenten erhöht, ebenso das Explorationsverhalten im HoleBoard. Im Morris-Water-Maze-Test zeigten die Tiere im Zeitverlauf durchaus Lernverhalten und verkürzten die Latenz bis zum Erreichen der Plattform, im Probe-Trial zeigte jedoch keine der Gruppen eine Präferenz für den Zielquadranten.

Protokoll 3 nach 3 Monaten Wurden die Tiere nach Protokoll 3 erst nach 3 Monaten getestet (Abbildungen ab Seite 56), so zeigten sich Auswirkungen der Läsion. Im HoleBoard zeigten die Läsionstiere mit Placebo eine erhöhte Exploration, signifikant erhöht gegenüber den Läsionstieren mit EPO, aber nicht signifikant gegenüber den Sham-Kontrollen. Ein ähnliches Bild ergab sich für die Zeitanteile in den Arealen des Elevated-Plus-Maze. Die placebo-behandelten Läsionstiere verbrachten mehr Zeit in den offenen Armen, signifikant erhöht gegenüber den EPO-behandelten Läsionstieren. 
Ein Läsionseffekt ergab sich auch im Falle des prozentualen Anteils der Eintritte in die offenen Arme an den Gesamteintritten in Arme. Dieser Parameter wird als der Hauptindikator für angstverwandte Verhaltensweisen angesehen. Die Zahl der Gesamteintritte in Arme ist hingegen ein Maß für die motorische Aktivität. Die motorische Grundaktivität unterschied sich in den Gruppen nicht, jedoch explorierten die Tiere der Gruppe Läsion + Placebo signifikant häufiger als alle anderen die offenen Arme. Die mit EPO behandelten Läsionstiere zeigten diese Verhaltensauffälligkeit ebensowenig wie die Kontrolltiere der Gruppe Sham + Placebo. Im Hippokampus-vermittelten räumlichen Lerntest nach Morris lernten alle Tiere die Aufgabe und zeigten eine Präferenz für den Zielquadranten im Probe-Trial, auch die Furchtkonditionierung als Lerntest blieb unauffällig. Die Läsion beeinträchtigte also Hippokampus-Funktionen zu diesem Zeitpunkt zumindest nicht im detektierbaren Rahmen. 

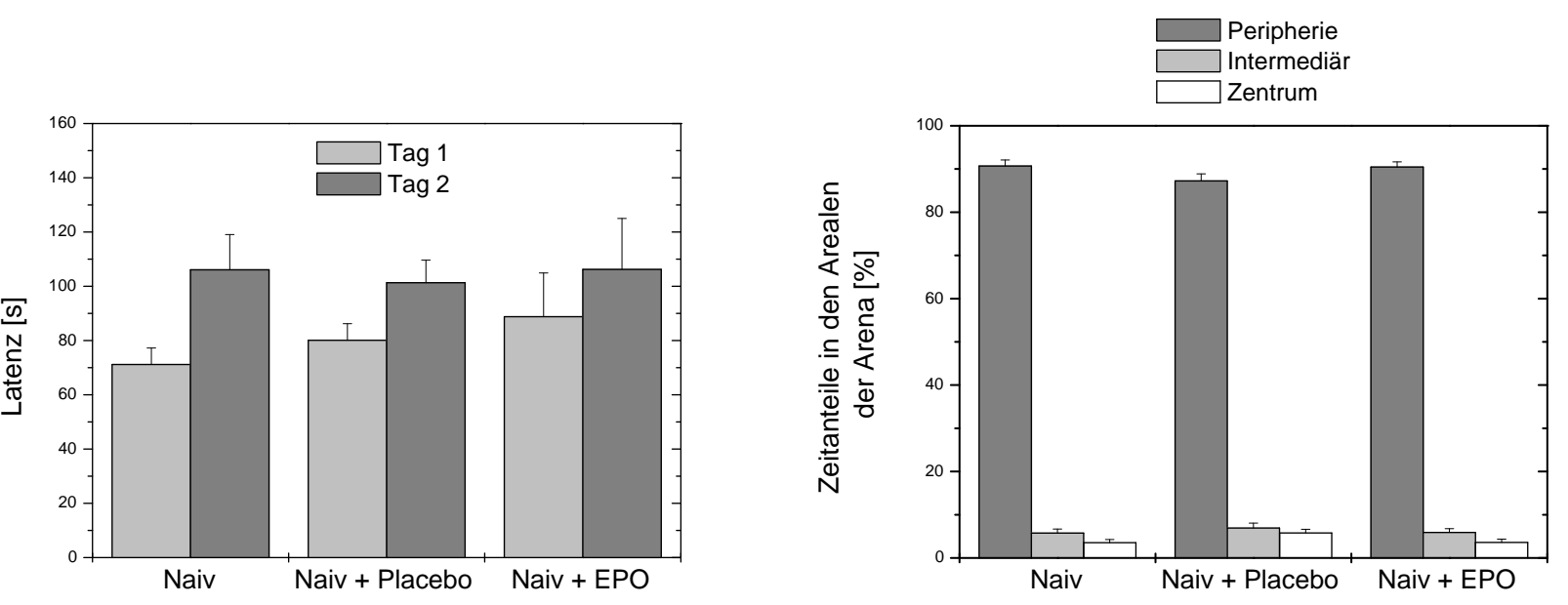

Abbildung 3.3: Rotarod- und Open-field-Daten für Protokoll 1. links: RotarodLatenzen in Sekunden (bis zum Herunterfallen der Tiere) an zwei aufeinanderfolgenden Tagen, rechts: Anteile des Aufenthalts in verschiedenen Arealen der Open-Field-Arena; die Gesamtzeit betrug 5 Minuten. Dargestellt sind Daten der Tiere aus Protokoll 1 als Mittelwert $\pm \mathrm{SE}$, für jede Gruppe ist $\mathrm{n}=10$.

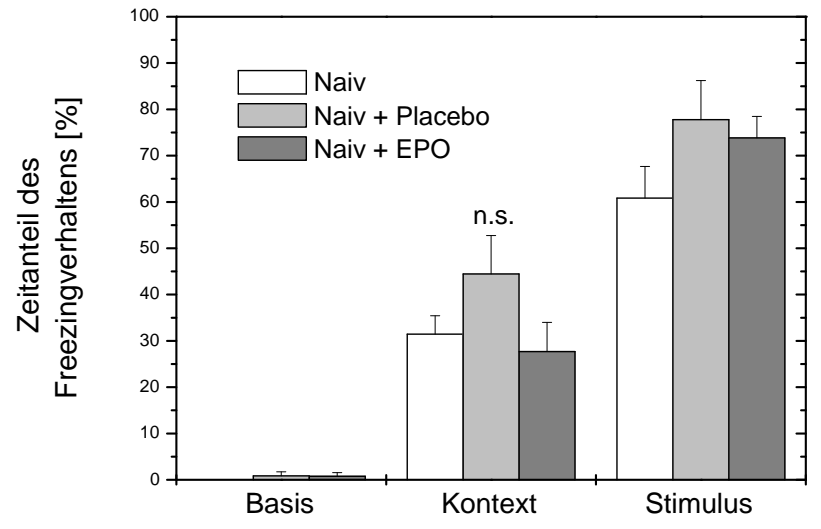

Abbildung 3.4: Darstellung des Freezing-Verhaltens in der Furchtkonditionierung für Protokoll 1. Im Gruppenvergleich werden der Basis-Furchtlevel und das Verhalten bei Präsentation des Kontextes sowie des Tones (Stimulus) ohne aversiven Reiz abgebildet. Die Abwesenheit jeglicher Bewegung außer Atmung wird als Freezing bezeichnet. Dargestellt sind Daten der Tiere aus Protokoll 1 als Mittelwert \pm SE, für jede Gruppe ist $n=10$. 

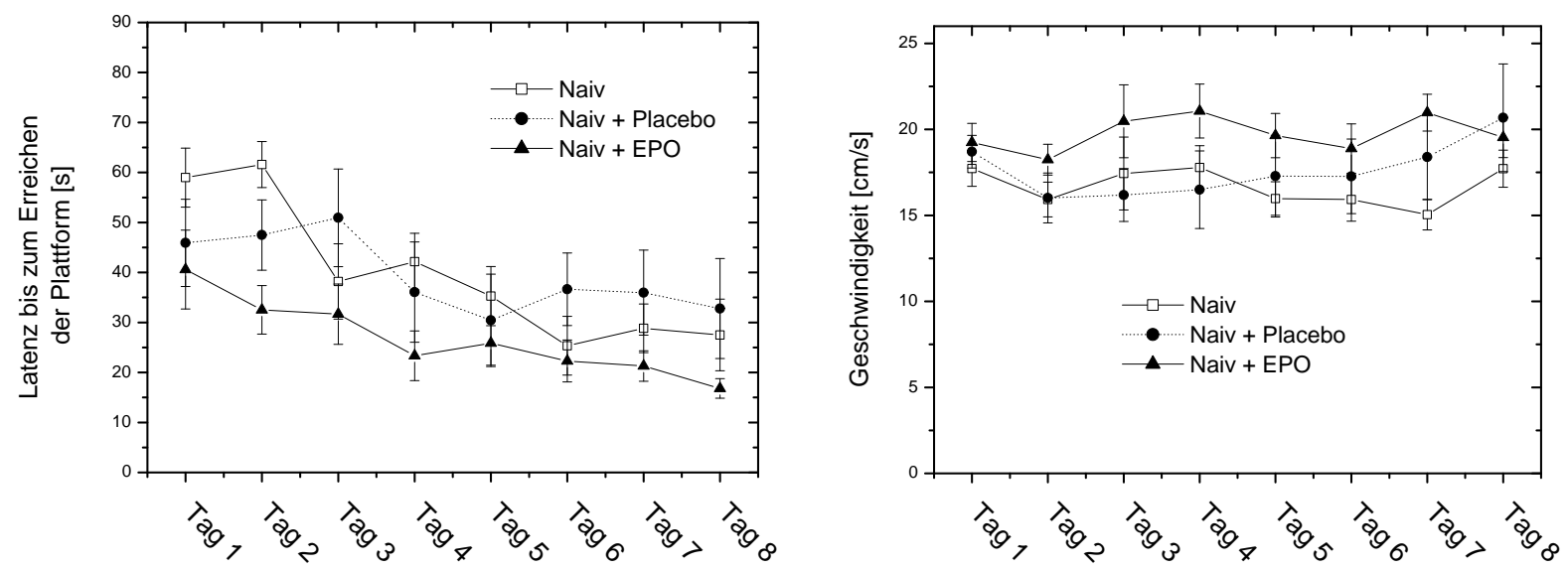

Abbildung 3.5: Verlauf der Latenzen im Water-Maze-Test nach Morris bis zum Erreichen der Plattform und Schwimmgeschwindigkeiten für Protokoll 1. Es sind nur Werte für den Versuchsabschnitt mit unsichtbarer Plattform abgebildet, der räumliches Lernverhalten der Tiere testet. links: Verlauf der Latenzen bis zum Erreichen der Plattform, das Tier hatte maximal 90 Sekunden zur Verfügung. rechts: Schwimmgeschwindigkeiten über 8 Tage. Nicht dargestellt sind die ebenfalls erhobenen zurückgelegten Distanzen bis zum Erreichen der Plattform. Dargestellt sind Daten der Tiere aus Protokoll 1 als Mittelwert \pm SE, für jede Gruppe ist $n=10$.

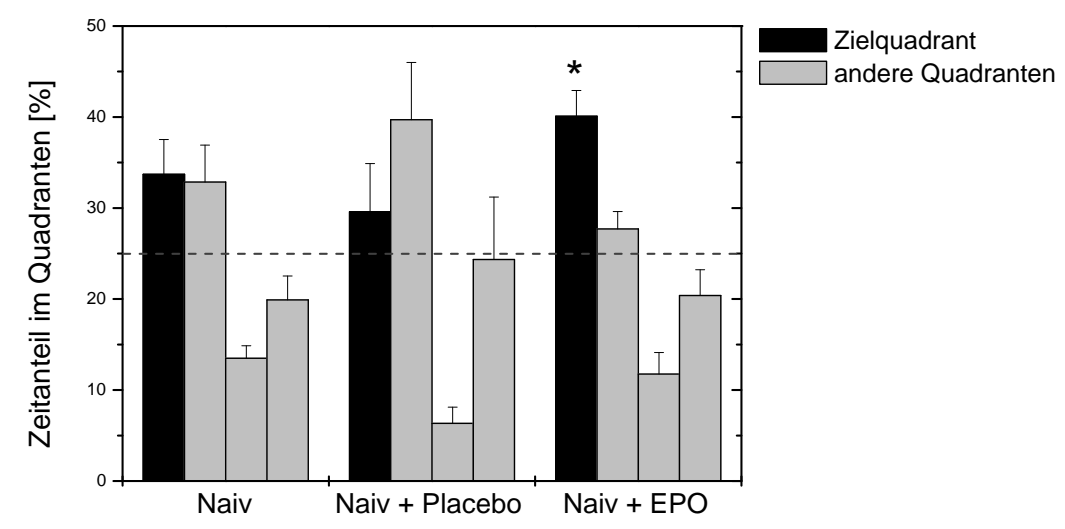

Abbildung 3.6: Abschlußtest im Water-Maze-Test nach Morris für Protokoll 1. Im letzten Durchgang des Testes wird die Plattform entfernt, und die Tiere haben 90 Sekunden für die Suche. Dargestellt sind Zeitanteile in den verschiedenen Quadranten (Balken: Zielquadrant, links, rechts und gegenüber dem Zielquadranten gelegen); die Linie indiziert den zu erwartenden Zufallsanteil von 25\%. Dargestellt sind Daten der Tiere aus Protokoll 1 als Mittelwert \pm SE, für jede Gruppe ist $n=10,\left(^{*}\right) \mathrm{p}<0.05$ in paarweisen t-Tests mit den anderen Quadranten. 


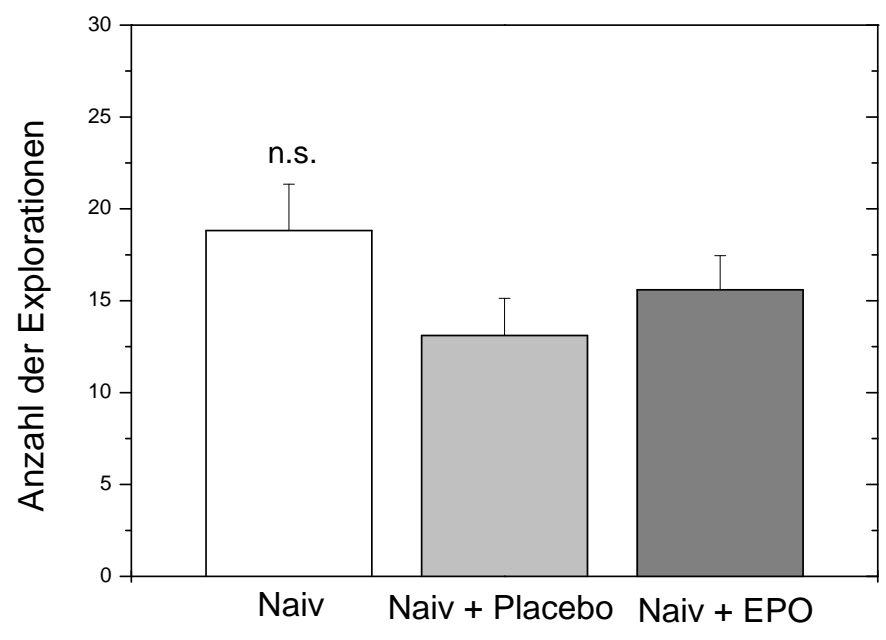

Abbildung 3.7: Anzahl der explorierten Löcher im Hole-Board für Protokoll 1. Während der 3-minütigen Testphase wird die Anzahl der explorierten Löcher gezählt. Dargestellt sind Daten der Tiere aus Protokoll 1 als Mittelwert \pm SE, für jede Gruppe ist $\mathrm{n}=10$.
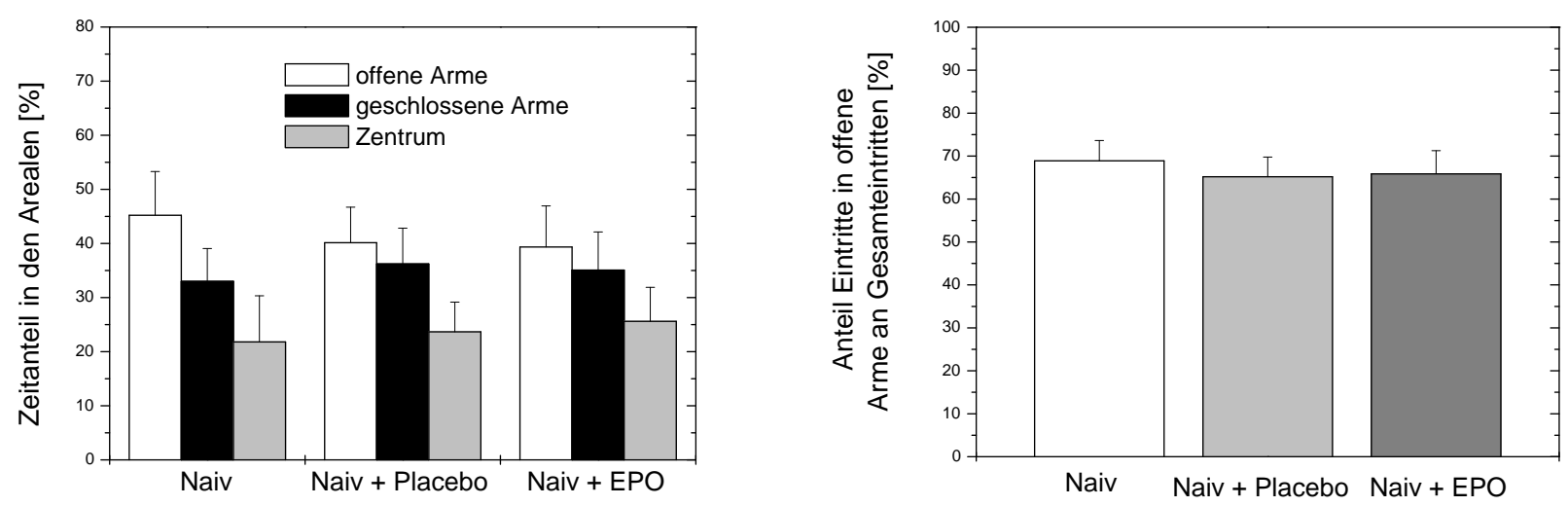

Abbildung 3.8: Verhalten im Elevated-Plus-Maze für Protokoll 1. links: Zeitanteile, die in den verschiedenen Arealen des Maze verbracht wurden. Ebenfalls erhobene Distanzanteile bestätigen in allen Fällen diese Daten. rechts: Anteil der Eintritte in offene Arme an den insgesamt betretenen Armen. Die Gesamtanzahl der betretenen Arme als Maß für die motorische Aktivität wird in Beziehung zum Eintritt in die offenen Arme als Parameter für ängstliches Verhalten gesetzt. Dargestellt sind Daten der Tiere aus Protokoll 1 als Mittelwert \pm SE, für jede Gruppe ist $n=10$. 
Elevated-Plus-Maze

\begin{tabular}{lccc}
\hline & $\begin{array}{c}\text { Zeitanteil in } \\
\text { offenen Armen [\%] }\end{array}$ & Gesamteintritte & $\begin{array}{c}\text { Anteil Eintritte } \\
\text { in offene Arme [\%] }\end{array}$ \\
\hline Naiv & $45.21 \pm 8.09$ & $20.09 \pm 2.35$ & $68.89 \pm 4.74$ \\
Naiv + Placebo & $40.14 \pm 6.58$ & $19.22 \pm 1.82$ & $65.20 \pm 4.58$ \\
Naiv + EPO & $39.34 \pm 7.59$ & $20.90 \pm 1.95$ & $65.87 \pm 5.40$ \\
\hline \hline & $(\mathrm{F}=0.19, \mathrm{p}=0.83)$ & $(\mathrm{F}=0.15, \mathrm{p}=0.86)$ & $(\mathrm{F}=0.16, \mathrm{p}=0.85)$
\end{tabular}

\begin{tabular}{lcc} 
Rotarod & & \\
\hline Latenz $[s]$ & Tag 1 & Tag 2 \\
& $71.18 \pm 6.05$ & $106.09 \pm 12.96$ \\
Naiv & $80.10 \pm 6.10$ & $101.33 \pm 8.31$ \\
Naiv + Placebo & $88.78 \pm 16.14$ & $106.22 \pm 18.76$ \\
Naiv + EPO & $(\mathrm{F}=0.70, \mathrm{p}=0.51)$ & $(\mathrm{F}=0.32, \mathrm{p}=0.73)$
\end{tabular}

\begin{tabular}{lccc} 
Open-field & & & \\
\hline Zeitanteil [\%] & & & \\
& Peripherie & Intermediär & Zentrum \\
\hline Naiv & $90.68 \pm 1.40$ & $5.76 \pm 0.94$ & $3.52 \pm 0.73$ \\
Naiv + Placebo & $87.24 \pm 1.64$ & $6.92 \pm 1.15$ & $5.78 \pm 0.85$ \\
Naiv + EPO & $90.44 \pm 1.22$ & $5.91 \pm 0.87$ & $3.58 \pm 0.76$ \\
\hline \hline & $(\mathrm{F}=0.58, \mathrm{p}=0.57)$ & $(\mathrm{F}=0.20, \mathrm{p}=0.82)$ & $(\mathrm{F}=1.00, \mathrm{p}=0.38)$
\end{tabular}

\begin{tabular}{lc} 
Holeboard & \\
\hline & Explorationen \\
\hline Naiv & $18.82 \pm 2.53$ \\
Naiv + Placebo & $13.11 \pm 2.02$ \\
Naiv + EPO & $15.60 \pm 1.86$ \\
\hline & $(\mathrm{F}=1.70, \mathrm{p}=0.20)$
\end{tabular}

Furchtkonditionierung

\begin{tabular}{lccc}
\hline \multicolumn{1}{l}{ Freezing-Zeitanteil [\%] } & Kasis & Kontext & Stimulus \\
\hline Naiv & $0.00 \pm 0.00$ & $31.47 \pm 3.94$ & $60.84 \pm 6.84$ \\
Naiv + Placebo & $0.85 \pm 0.85$ & $44.44 \pm 8.29$ & $77.78 \pm 8.45$ \\
Naiv + EPO & $0.77 \pm 0.77$ & $27.69 \pm 6.30$ & $73.85 \pm 4.62$ \\
\hline \hline
\end{tabular}

Tabelle 3.1: Übersicht über die abgebildeten Verhaltensparameter für Protokoll 1. Unter den Tabellen werden jeweils der F-Wert und die zugehörige Fehlerwahrscheinlichkeit p angegeben. Auf Gruppenunterschiede wurde durch einfaktorielle ANOVA getestet; das Signifikanzniveau betrug $5 \%$. Dargestellt sind Daten der Tiere aus Protokoll 1 , für jede Gruppe ist $n=10$. 


\begin{tabular}{|c|c|c|c|c|c|c|}
\hline \multicolumn{7}{|c|}{ Morris-Water-Maze } \\
\hline & \multicolumn{2}{|c|}{ Latenz $[s]$} & \multicolumn{2}{|c|}{$\overline{\operatorname{Distanz}}[\mathrm{cm}]$} & \multicolumn{2}{|c|}{ Geschwindigkeit $[\mathrm{cm} / \mathrm{s}]$} \\
\hline & Tag 1 & Tag 2 & Tag 1 & Tag 2 & Tag 1 & Tag 2 \\
\hline Naiv & 43.02 & 17.33 & 719.89 & 331.96 & 18.13 & 19.62 \\
\hline Naiv + Placebo & 33.31 & 24.63 & 610.47 & 425.96 & 19.12 & 20.24 \\
\hline Naiv + EPO & 46.41 & 20.28 & 771.62 & 398.77 & 16.96 & 21.17 \\
\hline
\end{tabular}

\begin{tabular}{lcccccccc}
\multicolumn{8}{c}{ Latenz [s] } & \multicolumn{7}{c}{ unsichtbare Plattform } \\
& Tag 1 & Tag 2 & Tag 3 & Tag 4 & Tag 5 & Tag 6 & Tag 7 & Tag 8 \\
\hline Naiv & 58.97 & 61.57 & 38.20 & 42.17 & 35.28 & 25.34 & 28.84 & 27.50 \\
Naiv + Placebo & 45.92 & 47.50 & 50.93 & 36.07 & 30.43 & 36.64 & 35.96 & 32.79 \\
Naiv + EPO & 40.58 & 32.53 & 31.66 & 23.35 & 25.84 & 22.30 & 21.29 & 16.80 \\
\hline \hline
\end{tabular}

\begin{tabular}{lcccccccc} 
Distanz $[\mathrm{cm}]$ & & & & & & & \\
& Tag 1 & Tag 2 & Tag 3 & Tag 4 & Tag 5 & Tag 6 & Tag 7 & Tag 8 \\
\hline Naiv & 1028.33 & 952.93 & 573.96 & 702.20 & 536.53 & 352.75 & 458.59 & 458.50 \\
Naiv + Placebo & 823.65 & 708.04 & 717.26 & 462.43 & 374.47 & 556.64 & 539.13 & 476.26 \\
Naiv + EPO & 738.03 & 580.38 & 558.75 & 420.55 & 476.04 & 430.19 & 423.39 & 310.52 \\
\hline \hline
\end{tabular}

\begin{tabular}{lcccccccc}
\multicolumn{2}{l}{ Geschwindigkeit $[\mathrm{cm} / \mathrm{s}]$} & & & & & & & \\
& Tag 1 & Tag 2 & Tag 3 & Tag 4 & Tag 5 & Tag 6 & Tag 7 & Tag 8 \\
\hline Naiv & 17.73 & 15.92 & 17.43 & 17.78 & 15.98 & 15.92 & 15.04 & 17.71 \\
Naiv + Placebo & 18.70 & 16.01 & 16.19 & 16.49 & 17.28 & 17.27 & 18.39 & 20.68 \\
Naiv + EPO & 19.24 & 18.24 & 20.47 & 21.07 & 19.64 & 18.88 & 20.97 & 19.53 \\
\hline \hline
\end{tabular}

\begin{tabular}{lcccc} 
Zeitanteil [\%] & \multicolumn{4}{c}{ Probetrial } \\
& Ziel & links & rechts & gegenüber \\
\hline Naiv & $33.71 \pm 3.82$ & $32.85 \pm 4.06$ & $13.49 \pm 1.37$ & $19.91 \pm 2.62$ \\
Naiv + Placebo & $29.58 \pm 5.30$ & $39.70 \pm 6.30$ & $6.34 \pm 1.78$ & $24.34 \pm 6.87$ \\
Naiv + EPO & $\mathbf{4 0 . 0 9} \pm \mathbf{2 . 8 3}$ & $27.70 \pm 1.91$ & $11.76 \pm 2.36$ & $20.39 \pm 2.83$ \\
\hline \hline
\end{tabular}

Tabelle 3.2: Evaluierte -Parameter des Morris-Water-Maze-Tests für Protokoll 1. oben: Darstellung des Versuchsabschnittes mit sichtbarer Plattform über 2 Tage. Mitte: Verlauf der Parameter über 8 Tage mit unsichtbarer Plattform. Auf Gruppenunterschiede wurde durch ANOVA mit Meßwiederholung getestet. unten: Das Suchverhalten im Probe-Trial wurde durch Registrierung von Zeit- und Distanzanteilen (nicht dargestellt) im Zielquadranten beschrieben. Der Zielquadrant wurde paarweise im t-Test mit den anderen Quadranten verglichen. Das Signifikanzniveau für alle Tests war 5\%; signifikante Unterschiede sind fett gedruckt. Dargestellt sind Daten der Tiere aus Protokoll 1, für jede Gruppe ist $n=10$. 

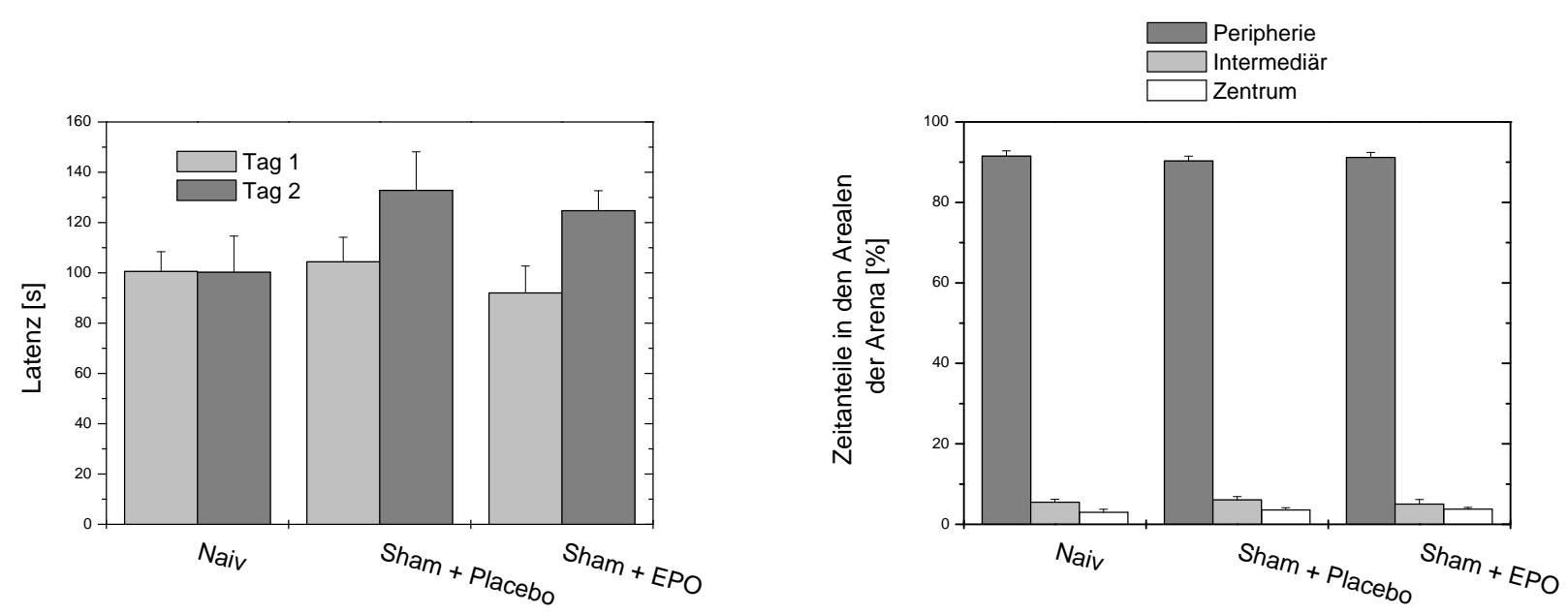

Abbildung 3.9: Rotarod- und Open-field-Daten für Protokoll 2. links: RotarodLatenzen in Sekunden (bis zum Herunterfallen der Tiere) an zwei aufeinanderfolgenden Tagen. rechts: Anteile des Aufenthalts in verschiedenen Arealen der Open-Field-Arena; die Gesamtzeit betrug 5 Minuten. Dargestellt sind Daten der Tiere aus Protokoll 2 als Mittelwert $\pm \mathrm{SE}$, für jede Gruppe ist $\mathrm{n}=10$.

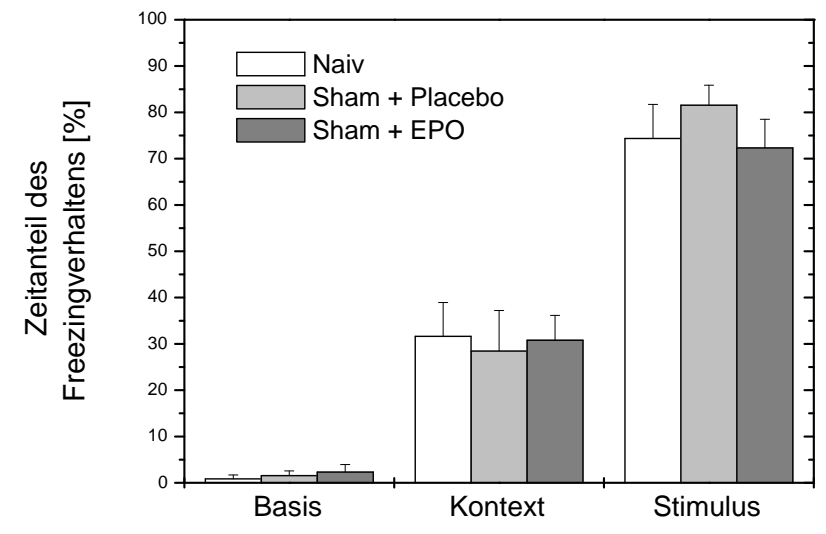

Abbildung 3.10: Darstellung des Freezing-Verhaltens in der Furchtkonditionierung für Protokoll 2. Im Gruppenvergleich werden der Basis-Furchtlevel und das Verhalten bei Präsentation des Kontextes sowie des Tones (Stimulus) ohne aversiven Reiz abgebildet. Die Abwesenheit jeglicher Bewegung außer Atmung wird als Freezing bezeichnet. Dargestellt sind Daten der Tiere aus Protokoll 2 als Mittelwert \pm SE, für jede Gruppe ist $n=10$. 

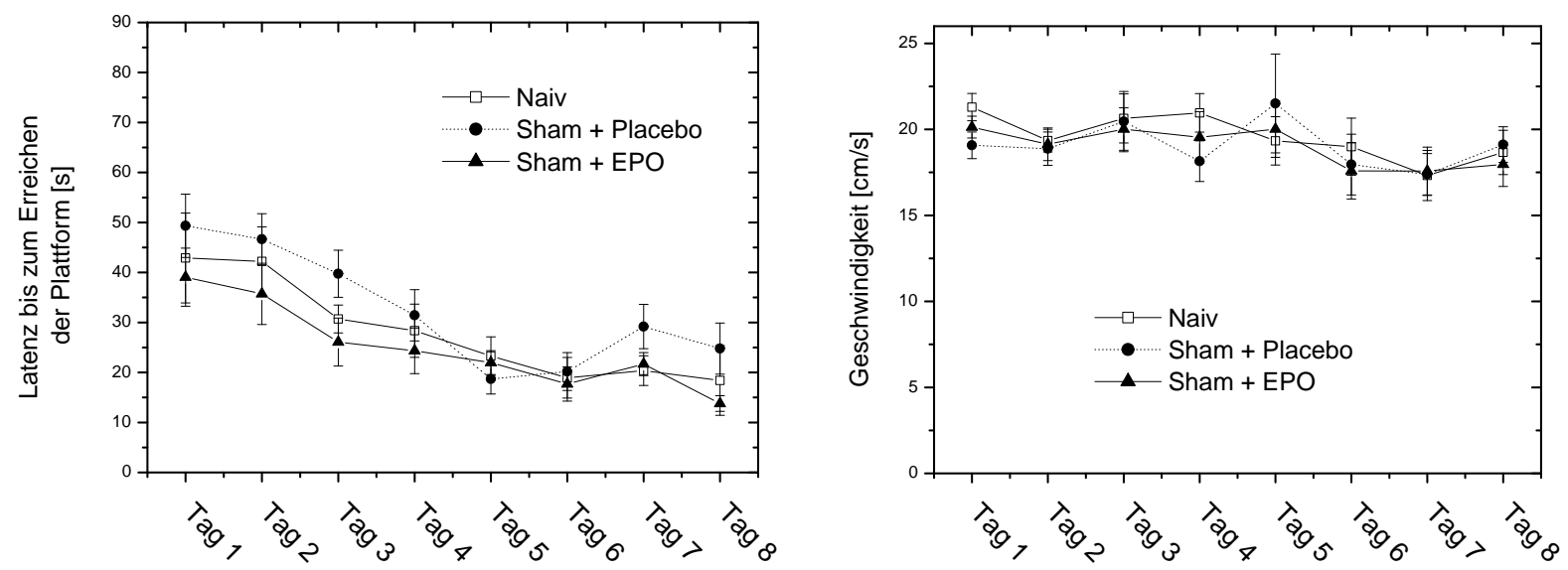

Abbildung 3.11: Verlauf der Latenzen im Water-Maze-Test nach Morris bis zum Erreichen der Plattform und Schwimmgeschwindigkeiten für Protokoll 2. Es sind nur Werte für den Versuchsabschnitt mit unsichtbarer Plattform abgebildet, der räumliches Lernverhalten der Tiere testet. links: Verlauf der Latenzen bis zum Erreichen der Plattform, das Tier hatte maximal 90 Sekunden zur Verfügung. rechts: Schwimmgeschwindigkeiten über 8 Tage. Nicht dargestellt sind die ebenfalls erhobenen zurückgelegten Distanzen bis zum Erreichen der Plattform. Dargestellt sind Daten der Tiere aus Protokoll 2 als Mittelwert \pm SE, für jede Gruppe ist $n=10$.

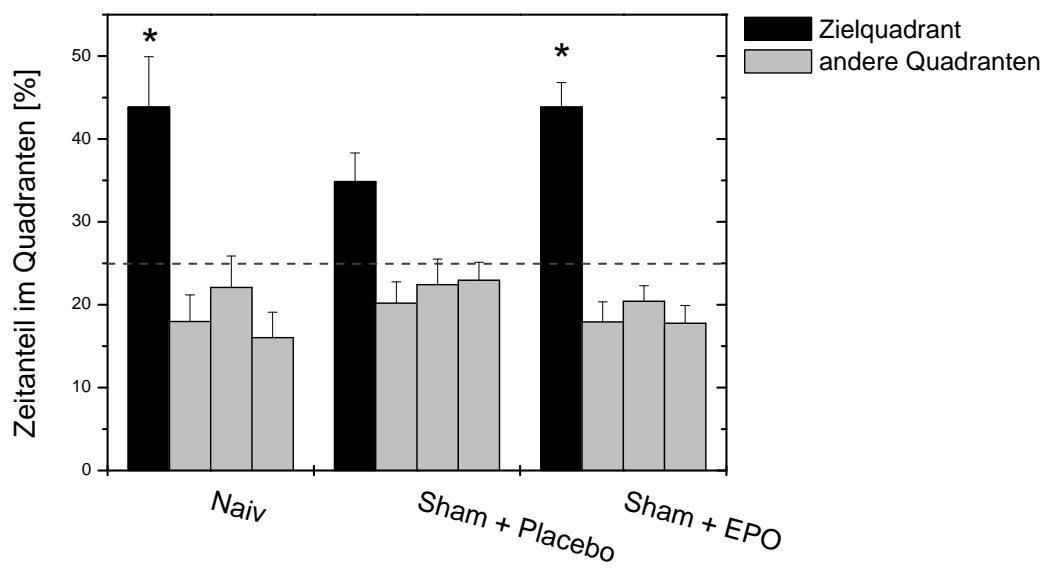

Abbildung 3.12: Abschlußtest im Water-Maze-Test nach Morris für Protokoll 2. Im letzten Durchgang des Testes wird die Plattform entfernt, und die Tiere haben 90 Sekunden für die Suche. Dargestellt sind Zeitanteile in den verschiedenen Quadranten (Balken: Zielquadrant, links, rechts und gegenüber dem Zielquadranten gelegen); die Linie indiziert den zu erwartenden Zufallsanteil von 25\%. Dargestellt sind Daten der Tiere aus Protokoll 2 als Mittelwert $\pm \mathrm{SE}$, für jede Gruppe ist $n=10,\left(^{*}\right) \mathrm{p}<0.05$ in paarweisen t-Tests mit anderen Quadranten. 


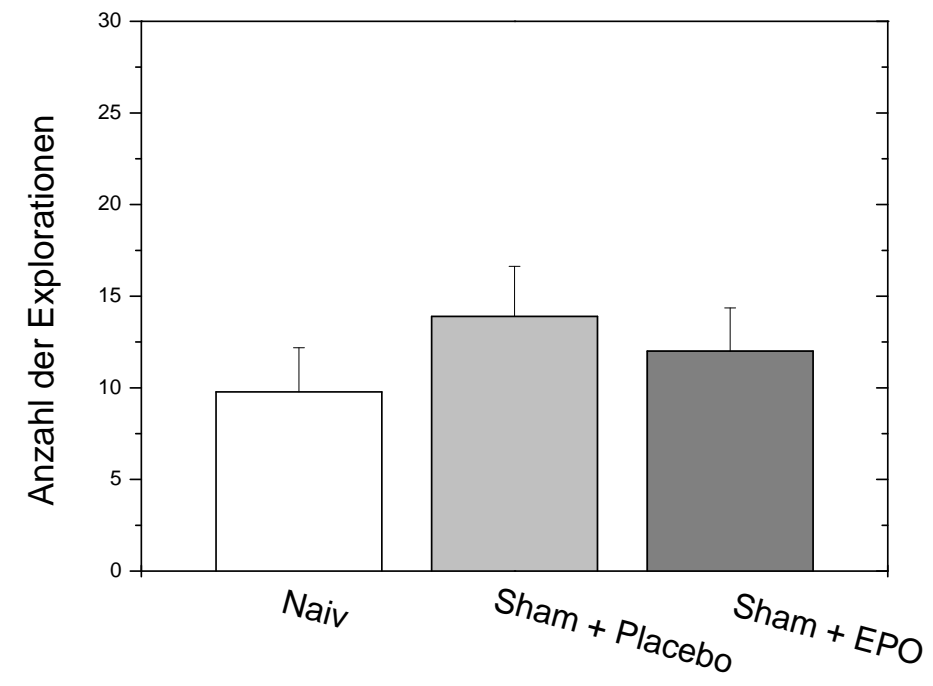

Abbildung 3.13: Anzahl der explorierten Löcher im Hole-Board für Protokoll 2. Während der 3 minütigen Testphase wird die Anzahl der explorierten Löcher gezählt. Dargestellt sind Daten der Tiere aus Protokoll 2 als Mittelwert \pm SE, für jede Gruppe ist $\mathrm{n}=10$.
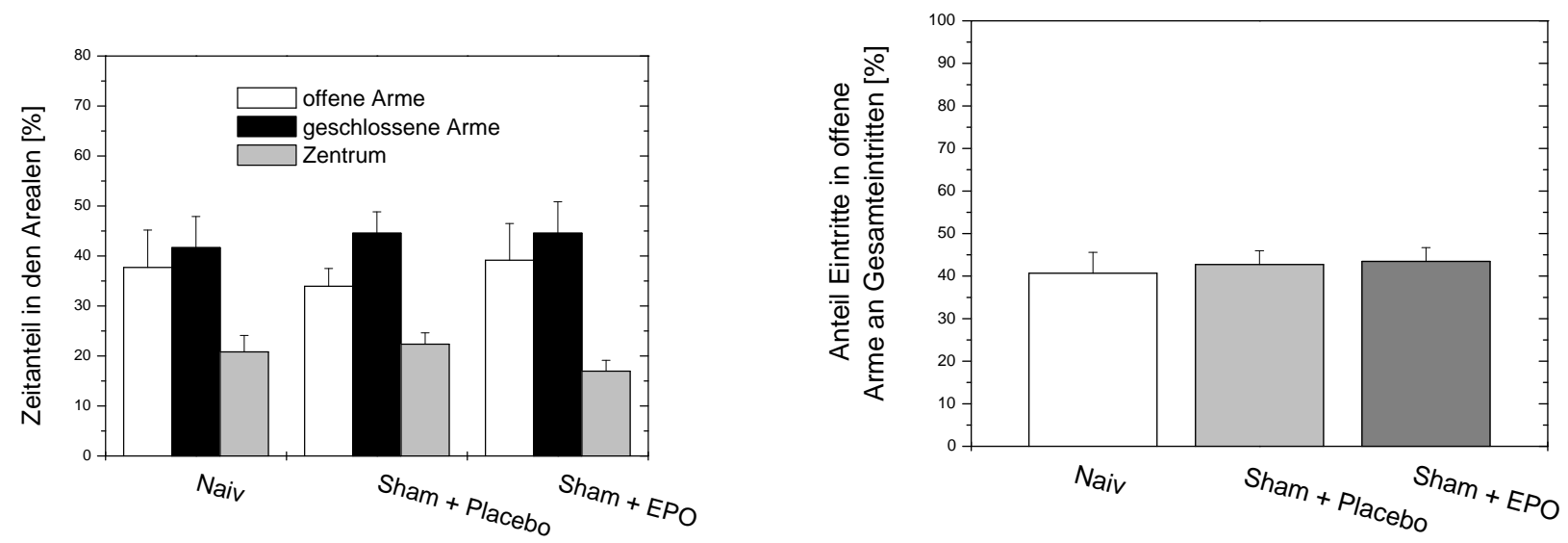

Abbildung 3.14: Verhalten im Elevated-Plus-Maze für Protokoll 2. links: Zeitanteile, die in den verschiedenen Arealen des Maze verbracht wurden. Ebenfalls erhobene Distanzanteile bestätigen in allen Fällen diese Daten. rechts: Anteil der Eintritte in offene Arme an den insgesamt betretenen Armen. Die Gesamtanzahl der betretenen Arme als Maß für die motorische Aktivität wird in Beziehung zum Eintritt in die offenen Arme als Parameter für ängstliches Verhalten gesetzt. Dargestellt sind Daten der Tiere aus Protokoll 2 als Mittelwert \pm SE, für jede Gruppe ist $n=10$. 
Elevated-Plus-Maze

\begin{tabular}{lccc}
\hline & $\begin{array}{c}\text { Zeitanteil in } \\
\text { offenen Armen [\%] }\end{array}$ & Gesamteintritte & $\begin{array}{c}\text { Anteil Eintritte } \\
\text { in offene Arme [\%] }\end{array}$ \\
\hline Naiv & $37.70 \pm 7.49$ & $24.22 \pm 3.28$ & $40.68 \pm 4.90$ \\
Sham + Placebo & $33.95 \pm 3.54$ & $24.50 \pm 1.16$ & $42.74 \pm 3.23$ \\
Sham + EPO & $39.15 \pm 7.35$ & $22.10 \pm 1.75$ & $43.46 \pm 3.24$ \\
\hline \hline & $(\mathrm{F}=0.19, \mathrm{p}=0.83)$ & $(\mathrm{F}=0.38, \mathrm{p}=0.69)$ & $(\mathrm{F}=0.14, \mathrm{p}=0.87)$
\end{tabular}

\begin{tabular}{lcc} 
Rotarod & & \\
\hline Latenz $[s]$ & Tag 1 & Tag 2 \\
\hline Naiv & $100.56 \pm 7.85$ & $100.22 \pm 14.42$ \\
Sham + Placebo & $104.40 \pm 9.74$ & $132.80 \pm 15.35$ \\
Sham + EPO & $92.00 \pm 10.70$ & $124.70 \pm 7.95$ \\
\hline & $(\mathrm{F}=0.45, \mathrm{p}=0.64)$ & $(\mathrm{F}=1.67, \mathrm{p}=0.21)$
\end{tabular}

\begin{tabular}{lccc} 
Open-field & & & \\
\hline Zeitanteil [\%] & & & \\
& Peripherie & Intermediär & Zentrum \\
\hline Naiv & $91.49 \pm 1.33$ & $5.48 \pm 0.75$ & $2.97 \pm 0.76$ \\
Sham + Placebo & $90.29 \pm 1.22$ & $6.08 \pm 0.81$ & $3.56 \pm 0.55$ \\
Sham + EPO & $91.18 \pm 1.26$ & $5.01 \pm 1.15$ & $3.76 \pm 0.44$ \\
\hline \hline & $(\mathrm{F}=0.18, \mathrm{p}=0.84)$ & $(\mathrm{F}=0.25, \mathrm{p}=0.79)$ & $(\mathrm{F}=0.47, \mathrm{p}=0.63)$
\end{tabular}

\section{Holeboard}

\begin{tabular}{lc}
\hline & Explorationen \\
\hline Naiv & $9.78 \pm 2.41$ \\
Sham + Placebo & $13.90 \pm 2.73$ \\
Sham + EPO & $12.00 \pm 2.36$ \\
\hline & $(\mathrm{F}=0.66, \mathrm{p}=0.53)$
\end{tabular}

Furchtkonditionierung

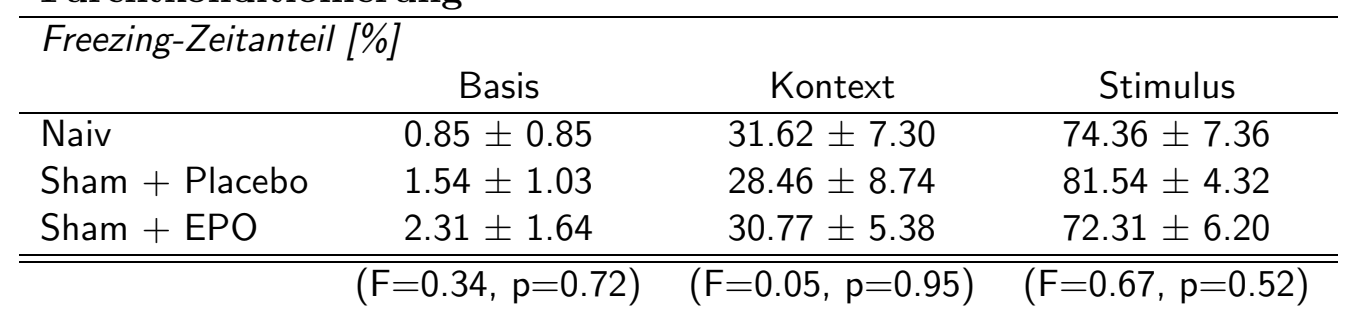

Tabelle 3.3: Übersicht über die abgebildeten Verhaltensparameter für Protokoll 2. Unter den Tabellen werden jeweils der F-Wert und die zugehörige Fehlerwahrscheinlichkeit p angegeben. Auf Gruppenunterschiede wurde durch einfaktorielle ANOVA getestet, das Signifikanzniveau betrug $5 \%$. Dargestellt sind Daten der Tiere aus Protokoll 2 , für jede Gruppe ist $n=10$. 
Morris-Water-Maze

\begin{tabular}{lccccccc} 
& \multicolumn{4}{c}{ sichtbare Plattform } \\
\cline { 5 - 7 } & Latenz $[\mathrm{s}]$ & & \multicolumn{2}{c}{ Distanz $[\mathrm{cm}]$} & \multicolumn{2}{c}{ Geschwindigkeit $[\mathrm{cm} / \mathrm{s}]$} \\
& Tag 1 & Tag 2 & Tag 1 & Tag 2 & Tag 1 & Tag 2 \\
\hline Naiv & 48.22 & 17.49 & 951.43 & 378.15 & 20.18 & 21.79 \\
Sham + Placebo & 44.04 & 12.06 & 768.27 & 371.39 & 18.62 & 20.54 \\
Sham + EPO & 43.93 & 18.23 & 755.10 & 261.47 & 18.79 & 21.49 \\
\hline \hline
\end{tabular}

\begin{tabular}{lllllllll}
\hline & \multicolumn{8}{c}{ unsichtbare Plattform } \\
Latenz [s] & Tag 1 & Tag 2 & Tag 3 & Tag 4 & Tag 5 & Tag 6 & Tag 7 & Tag 8 \\
\hline Naiv & 42.89 & 42.22 & 30.71 & 28.35 & 23.28 & 18.93 & 20.37 & 18.39 \\
Sham + Placebo & 49.35 & 46.65 & 39.74 & 31.43 & 18.68 & 20.18 & 29.18 & 24.78 \\
Sham + EPO & 39.06 & 35.72 & 26.08 & 24.33 & 21.97 & 17.70 & 21.68 & 13.78 \\
\hline \hline
\end{tabular}

Distanz [cm]

\begin{tabular}{lcccccccc} 
& Tag 1 & Tag 2 & Tag 3 & Tag 4 & Tag 5 & Tag 6 & Tag 7 & Tag 8 \\
\hline Naiv & 868.97 & 800.67 & 622.91 & 575.20 & 463.64 & 335.06 & 371.21 & 329.57 \\
Sham + Placebo & 951.14 & 852.54 & 721.56 & 538.57 & 342.44 & 351.55 & 538.33 & 489.88 \\
Sham + EPO & 797.63 & 670.42 & 493.61 & 430.39 & 424.49 & 310.67 & 376.29 & 235.66 \\
\hline \hline
\end{tabular}

Geschwindigkeit [cm/s]

\begin{tabular}{lllllllll} 
& Tag 1 & Tag 2 & Tag 3 & Tag 4 & Tag 5 & Tag 6 & Tag 7 & Tag 8 \\
\hline Naiv & 21.29 & 19.34 & 20.64 & 20.96 & 19.33 & 18.99 & 17.32 & 18.66 \\
Sham + Placebo & 19.07 & 18.88 & 20.45 & 18.15 & 21.51 & 17.95 & 17.38 & 19.11 \\
Sham + EPO & 20.13 & 19.14 & 20.02 & 19.53 & 20.01 & 17.58 & 17.57 & 17.96 \\
\hline \hline
\end{tabular}

\begin{tabular}{|c|c|c|c|c|}
\hline \multirow{2}{*}{ Zeitanteil [\%] } & \multicolumn{3}{|c|}{ Probetrial } & \multirow{2}{*}{ gegenüber } \\
\hline & Ziel & links & rechts & \\
\hline Naiv & $43.86 \pm 6.06$ & $17.98 \pm 3.20$ & $22.08 \pm 3.80$ & $16.03 \pm 3.07$ \\
\hline Sham + Placebo & $34.35 \pm 3.46$ & $20.19 \pm 2.57$ & $22.42 \pm 3.09$ & $22.95 \pm 2.17$ \\
\hline Sham + EPO & $43.85 \pm 2.96$ & $17.92 \pm 2.43$ & $20.41 \pm 1.89$ & $17.76 \pm 2.15$ \\
\hline
\end{tabular}

Tabelle 3.4: Evaluierte Parameter des Morris-Water-Maze-Tests für Protokoll 2. oben: Darstellung des Versuchsabschnittes mit sichtbarer Plattform über 2 Tage. Mitte: Verlauf der Parameter über 8 Tage mit unsichtbarer Plattform. Auf Gruppenunterschiede wurde durch ANOVA mit Meßwiederholung getestet. unten: Das Suchverhalten im Probe-Trial wurde durch Registrierung von Zeit- und Distanzanteilen (nicht dargestellt) im Zielquadranten beschrieben. Der Zielquadrant wurde paarweise im t-Test mit den anderen Quadranten verglichen. Das Signifikanzniveau für alle Tests war 5\%, signifikante Unterschiede sind fett gedruckt. Dargestellt sind Daten der Tiere aus Protokoll 2, für jede Gruppe ist $n=10$. 

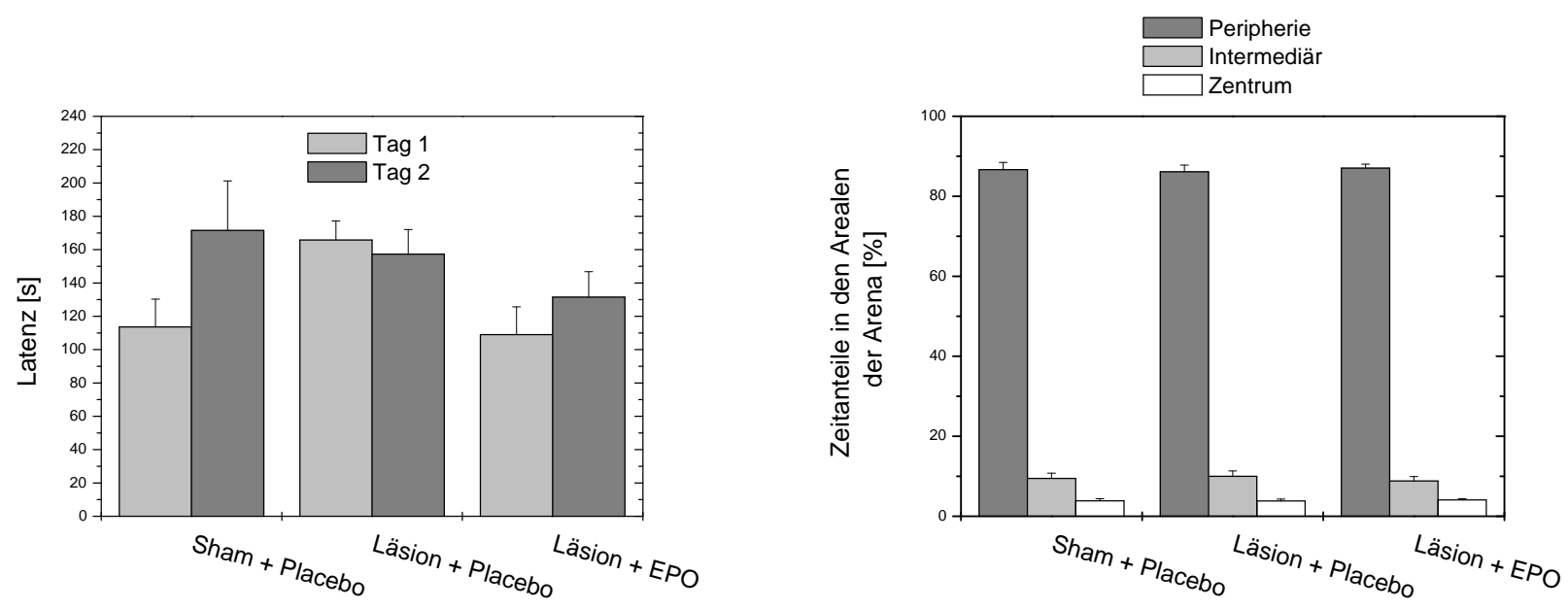

Abbildung 3.15: Rotarod- und Open-field-Daten für Protokoll 3 nach Abschluß der Injektionen. links: Rotarod-Latenzen in Sekunden (bis zum Herunterfallen der Tiere) an zwei aufeinanderfolgenden Tagen. rechts: Anteile des Aufenthaltes in verschiedenen Arealen der Open-Field-Arena; die Gesamtzeit betrug 5 Minuten. Dargestellt sind Daten der Tiere aus Protokoll 3 als Mittelwert \pm SE, für jede Gruppe ist $n=10$. Beachte die geänderte Skalierung gegenüber der Darstellung anderer Gruppen.

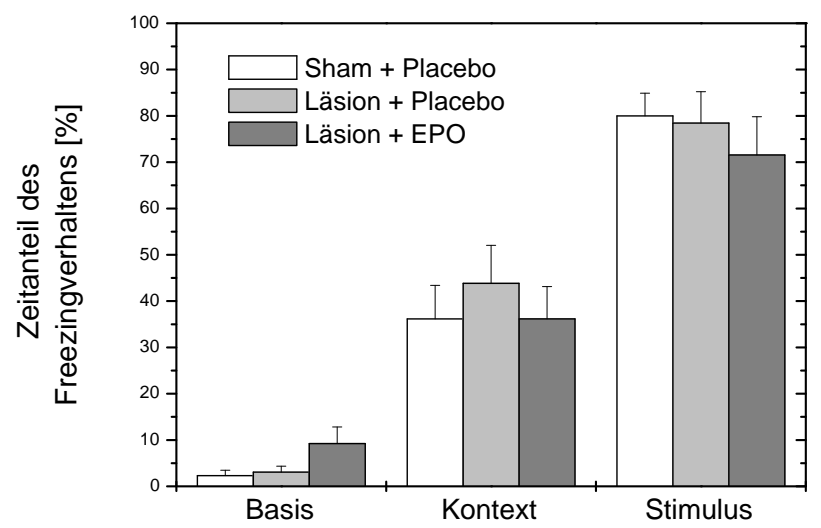

Abbildung 3.16: Darstellung des Freezing-Verhaltens in der Furchtkonditionierung für Protokoll 3 nach Abschluß der Injektionen. Im Gruppenvergleich werden der Basis-Furchtlevel und das Verhalten bei Präsentation des Kontextes sowie des Tones (Stimulus) ohne aversiven Reiz abgebildet. Die Abwesenheit jeglicher Bewegung außer Atmung wird als Freezing bezeichnet. Dargestellt sind Daten der Tiere aus Protokoll 3 als Mittelwert \pm SE, für jede Gruppe ist $n=10$. 

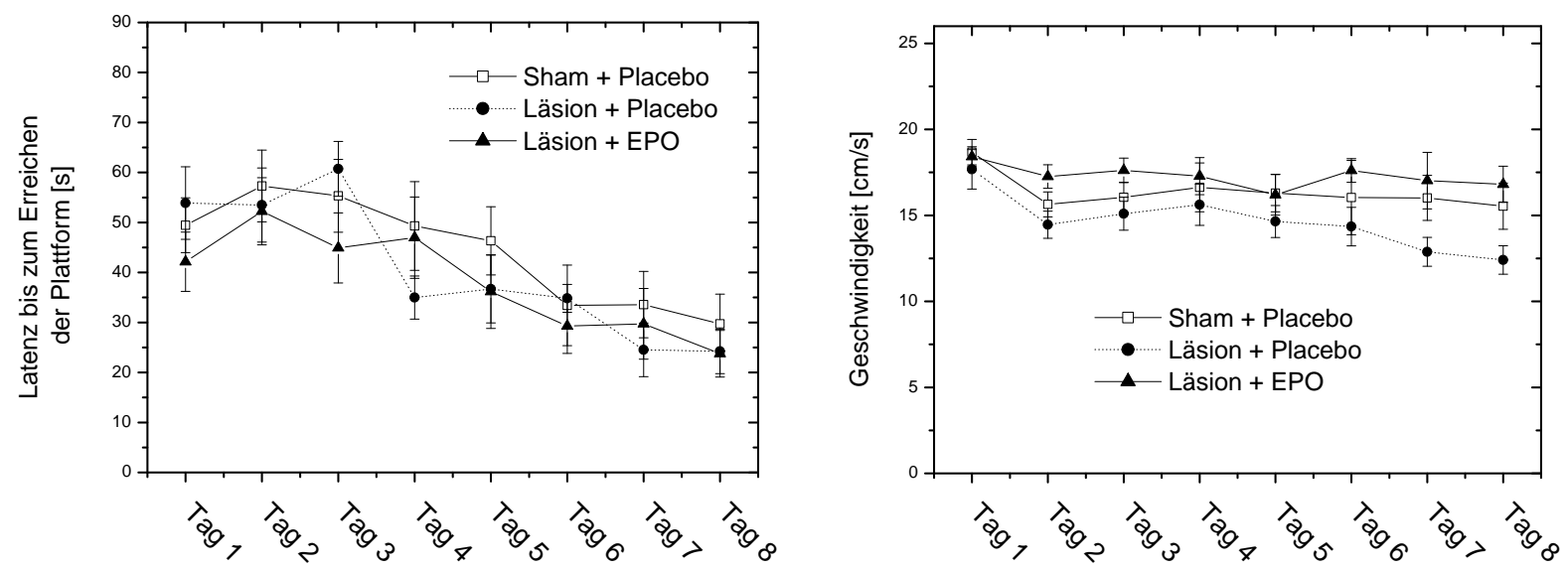

Abbildung 3.17: Verlauf der Latenzen im Water-Maze-Test nach Morris bis zum Erreichen der Plattform und Schwimmgeschwindigkeiten für Protokoll 3 nach Abschluß der Injektionen. Es sind nur Werte für den Versuchsabschnitt mit unsichtbarer Plattform abgebildet, der räumliches Lernverhalten der Tiere testet. links: Verlauf der Latenzen bis zum Erreichen der Plattform, das Tier hatte maximal 90 Sekunden zur Verfügung. rechts: Schwimmgeschwindigkeiten über 8 Tage. Nicht dargestellt sind die ebenfalls erhobenen zurückgelegten Distanzen bis zum Erreichen der Plattform. Dargestellt sind Daten der Tiere aus Protokoll 3 als Mittelwert \pm SE, für jede Gruppe ist $\mathrm{n}=10$.

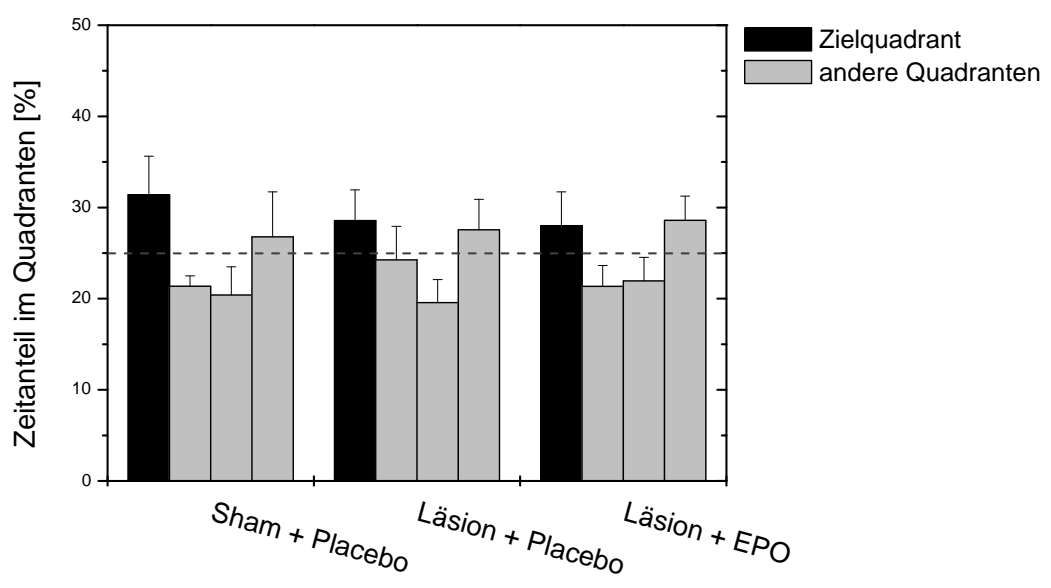

Abbildung 3.18: Abschlußtest im Water-Maze-Test nach Morris für Protokoll 3 nach Abschluß der Injektionen. Im letzten Durchgang des Testes wird die Plattform entfernt und die Tiere haben 90 Sekunden für die Suche. Dargestellt sind Zeitanteile in den verschiedenen Quadranten (Balken: Zielquadrant, links, rechts und gegenüber dem Zielquadranten gelegen), die Linie indiziert den zu erwartenden Zufallsanteil von $25 \%$. Dargestellt sind Daten der Tiere aus Protokoll 3 als Mittelwert \pm SE, für jede Gruppe ist $\mathrm{n}=10$. 


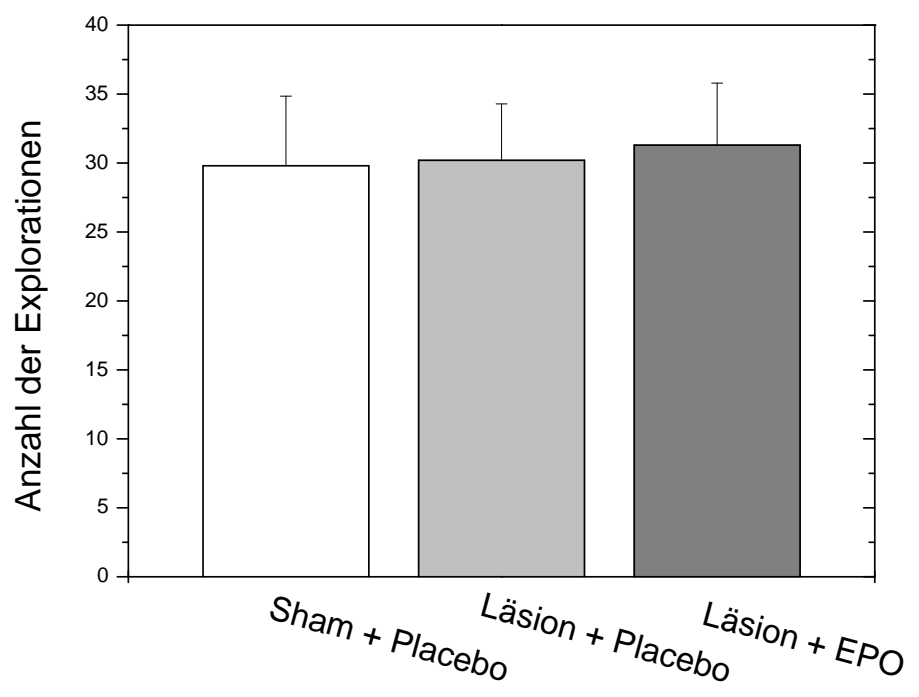

Abbildung 3.19: Anzahl der explorierten Löcher im Hole-Board für Protokoll 3 nach Abschluß der Injektionen. Während der 3 minütigen Testphase wird die Anzahl der explorierten Löcher gezählt. Dargestellt sind Daten der Tiere aus Protokoll 3 als Mittelwert \pm SE, für jede Gruppe ist $n=10$. Beachte die geänderte Skalierung aufgrund der hohen Aktivität der jungen Tiere.
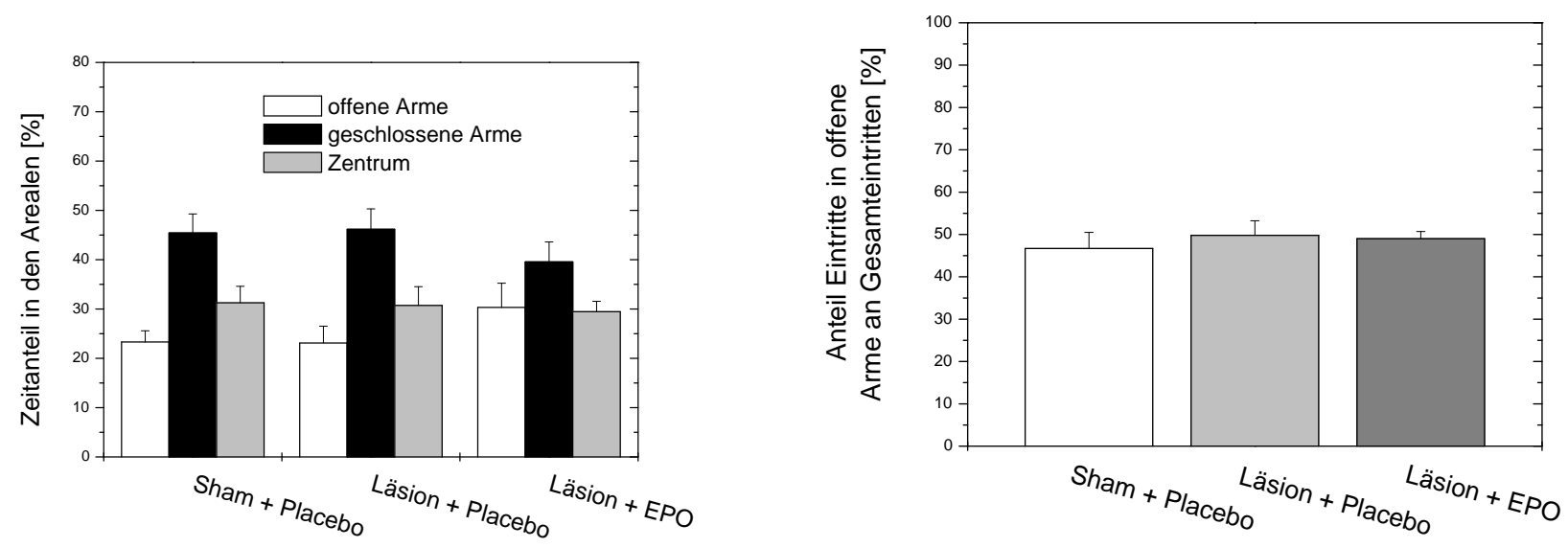

Abbildung 3.20: Verhalten im Elevated-Plus-Maze für Protokoll 3 nach Abschluß der Injektionen. links: Zeitanteile, die in den verschiedenen Arealen des Maze verbracht wurden. Ebenfalls erhobene Distanzanteile bestätigen in allen Fällen diese Daten. rechts: Anteil der Eintritte in offene Arme an den insgesamt betretenen Armen. Die Gesamtanzahl der betretenen Arme als Maß für die motorische Aktivität wird in Beziehung zum Eintritt in die offenen Arme als Parameter für ängstliches Verhalten gesetzt. Dargestellt sind Daten der Tiere aus Protokoll 3 als Mittelwert \pm SE, für jede Gruppe ist $\mathrm{n}=10$. 
Elevated-Plus-Maze

\begin{tabular}{lccc}
\hline & $\begin{array}{c}\text { Zeitanteil in } \\
\text { offenen Armen [\%] }\end{array}$ & Gesamteintritte & $\begin{array}{c}\text { Anteil Eintritte } \\
\text { in offene Arme [\%] }\end{array}$ \\
\hline Sham + Placebo & $23.31 \pm 2.27$ & $28.60 \pm 1.8$ & $46.71 \pm 3.78$ \\
Läsion + Placebo & $23.10 \pm 3.41$ & $30.30 \pm 1.65$ & $49.79 \pm 3.44$ \\
Läsion + EPO & $30.32 \pm 4.90$ & $32.60 \pm 1.07$ & $49.02 \pm 1.67$ \\
\hline \hline & $(\mathrm{F}=1.24, \mathrm{p}=0.31)$ & $(\mathrm{F}=1.20, \mathrm{p}=0.32)$ & $(\mathrm{F}=0.27, \mathrm{p}=0.77)$
\end{tabular}

\begin{tabular}{lcc} 
Rotarod & & \\
\hline Latenz $[s]$ & Tag 1 & Tag 2 \\
\hline Sham + Placebo & $113.60 \pm 16.72$ & $171.50 \pm 29.72$ \\
Läsion + Placebo & $165.80 \pm 11.37$ & $157.30 \pm 14.79$ \\
Läsion + EPO & $109.00 \pm 16.70$ & $131.50 \pm 15.26$ \\
\hline & $(\mathbf{F}=\mathbf{4 . 3 4}, \mathbf{p}=\mathbf{0 . 0 2})$ & $(\mathrm{F}=0.92, \mathbf{p}=0.41)$ \\
& siehe Abb.3.15 S.51 &
\end{tabular}

\begin{tabular}{lccc} 
Open-field & & & \\
\hline Zeitanteil [\%] & & & \\
& Peripherie & Intermediär & Zentrum \\
\hline Sham + Placebo & $86.64 \pm 1.81$ & $9.46 \pm 1.31$ & $3.85 \pm 0.53$ \\
Läsion + Placebo & $86.13 \pm 1.65$ & $9.98 \pm 1.34$ & $3.84 \pm 0.46$ \\
Läsion + EPO & $87.04 \pm 0.99$ & $8.82 \pm 1.12$ & $4.09 \pm 0.32$ \\
\hline \hline & $(\mathrm{F}=0.09, \mathrm{p}=0.92)$ & $(\mathrm{F}=0.21, \mathrm{p}=0.81)$ & $(\mathrm{F}=0.11, \mathrm{p}=0.90)$
\end{tabular}

\begin{tabular}{lc} 
Holeboard & \\
\hline & Explorationen \\
\hline Sham + Placebo & $29.80 \pm 5.05$ \\
Läsion + Placebo & $30.20 \pm 4.09$ \\
Läsion + EPO & $31.30 \pm 4.50$ \\
\hline & $(\mathrm{F}=0.03, \mathrm{p}=0.97)$
\end{tabular}

Furchtkonditionierung

\begin{tabular}{lccc}
\hline Freezing-Zeitanteil [\%] & Basis & Kontext & Stimulus \\
\hline Sham + Placebo & $2.31 \pm 1.18$ & $36.15 \pm 7.26$ & $80.00 \pm 4.89$ \\
Läsion + Placebo & $3.08 \pm 1.26$ & $43.85 \pm 8.19$ & $78.46 \pm 6.76$ \\
Läsion + EPO & $9.23 \pm 3.59$ & $36.15 \pm 6.98$ & $71.54 \pm 8.27$ \\
\hline \hline & $(\mathrm{F}=2.73, \mathrm{p}=0.08)$ & $(\mathrm{F}=0.35, \mathrm{p}=0.71)$ & $(\mathrm{F}=0.44, \mathrm{p}=0.65)$
\end{tabular}

Tabelle 3.5: Übersicht über die abgebildeten Verhaltensparameter für Protokoll 3 nach Abschluß der Injektionen. Unter den Tabellen werden jeweils der F-Wert und die zugehörige Fehlerwahrscheinlichkeit p angegeben. Auf Gruppenunterschiede wurde durch einfaktorielle ANOVA getestet, das Signifikanzniveau betrug 5\%; signifikante Unterschiede sind fett gedruckt. Dargestellt sind Daten der Tiere aus Protokoll 3, für jede Gruppe ist $n=10$. 
Morris-Water-Maze

\begin{tabular}{lcccccc} 
& \multicolumn{4}{c}{ sichtbare Plattform } & & \\
& Latenz $[\mathrm{s}]$ & & \multicolumn{2}{c}{ Distanz $[\mathrm{cm}]$} & \multicolumn{2}{c}{ Geschwindigkeit [cm/s] } \\
& Tag 1 & Tag 2 & Tag 1 & Tag 2 & Tag 1 & Tag 2 \\
\hline Sham + Placebo & 21.76 & 9.33 & 495.24 & 188.94 & 21.82 & 19.82 \\
Läsion + Placebo & 32.03 & 17.13 & 608.89 & 282.28 & 21.25 & 17.97 \\
Läsion + EPO & 22.22 & 10.83 & 457.02 & 209.36 & 22.34 & 18.96 \\
\hline \hline
\end{tabular}

\begin{tabular}{lcccccccc} 
Latenz $[$ s] & & & & & & & \\
& Tag 1 & Tag 2 & Tag 3 & Tag 4 & Tag 5 & Tag 6 & Tag 7 & Tag 8 \\
\hline Sham + Placebo & 49.45 & 57.30 & 55.32 & 49.30 & 46.33 & 33.42 & 33.58 & 29.73 \\
Läsion + Placebo & 53.89 & 53.49 & 60.73 & 34.99 & 36.69 & 34.83 & 24.53 & 24.22 \\
Läsion + EPO & 42.14 & 52.24 & 44.94 & 46.96 & 36.18 & 29.27 & 29.73 & 23.75 \\
\hline \hline
\end{tabular}

unsichtbare Plattform

\begin{tabular}{lcccccccc} 
Distanz $[\mathrm{cm}]$ & & & & & & & \\
& Tag 1 & Tag 2 & Tag 3 & Tag 4 & Tag 5 & Tag 6 & Tag 7 & Tag 8 \\
\hline Sham + Placebo & 890.29 & 892.60 & 869.50 & 784.72 & 766.23 & 484.70 & 536.88 & 474.54 \\
Läsion + Placebo & 922.47 & 813.95 & 915.32 & 576.18 & 583.68 & 551.96 & 325.14 & 328.82 \\
Läsion + EPO & 796.17 & 909.06 & 784.11 & 793.78 & 606.90 & 520.76 & 537.43 & 421.09 \\
\hline \hline
\end{tabular}

\begin{tabular}{|c|c|c|c|c|c|c|c|c|c|}
\hline \multicolumn{10}{|c|}{ Geschwindigkeit $[\mathrm{cm} / \mathrm{s}]$} \\
\hline & \multicolumn{2}{|c|}{ Tag 1} & Tag 2 & Tag 3 & Tag 4 & Tag 5 & Tag 6 & Tag 7 & 1 \\
\hline Sham + Placebo & \multicolumn{2}{|c|}{18.67} & 15.64 & 16.05 & 16.63 & 16.29 & 16.03 & 16.02 & \\
\hline Läsion + Placebo & \multicolumn{2}{|c|}{17.67} & 14.46 & 15.10 & 15.62 & 14.64 & 14.35 & 12.88 & 1 \\
\hline Läsion + EPO & \multicolumn{2}{|c|}{18.41} & 17.26 & 17.62 & 17.28 & 16.20 & 17.61 & 17.02 & \\
\hline \multirow{2}{*}{\multicolumn{10}{|c|}{ Probetrial }} \\
\hline & & & & & & & & & \\
\hline & \multicolumn{3}{|r|}{ Ziel } & \multicolumn{2}{|c|}{ links } & \multicolumn{2}{|c|}{ rechts } & \multicolumn{2}{|l|}{ gegenüber } \\
\hline \multicolumn{2}{|c|}{ Sham + Placebo } & \multicolumn{2}{|c|}{$31.40 \pm 4.23$} & \multicolumn{2}{|c|}{$21.36 \pm 1.15$} & \multicolumn{2}{|c|}{$20.40 \pm 3.10$} & \multicolumn{2}{|l|}{$26.78 \pm 4.93$} \\
\hline \multicolumn{2}{|c|}{ Läsion + Placebo } & \multicolumn{2}{|c|}{$28.56 \pm 3.37$} & \multicolumn{2}{|c|}{$24.25 \pm 3.68$} & \multicolumn{2}{|c|}{$19.57 \pm 2.53$} & \multicolumn{2}{|l|}{$27.56 \pm 3.34$} \\
\hline \multicolumn{2}{|l|}{ Läsion + EPO } & \multicolumn{2}{|c|}{$28.01 \pm 3.71$} & \multicolumn{2}{|c|}{$21.35 \pm 2.29$} & \multicolumn{2}{|c|}{$21.95 \pm 2.58$} & \multicolumn{2}{|l|}{$28.59 \pm 2.66$} \\
\hline
\end{tabular}

Tabelle 3.6: Evaluierte Parameter des Morris-Water-Maze-Tests für Protokoll 3 nach Abschluß der Injektionen. oben: Darstellung des Versuchsabschnittes mit sichtbarer Plattform über 2 Tage. Mitte: Verlauf der Parameter über 8 Tage mit unsichtbarer Plattform. Auf Gruppenunterschiede wurde durch ANOVA mit Meßwiederholung getestet. unten: Das Suchverhalten im Probe-Trial wurde durch Registrierung von Zeitund Distanzanteilen (nicht dargestellt) im Zielquadranten beschrieben. Der Zielquadrant wurde paarweise im t-Test mit den anderen Quadranten verglichen. Das Signifikanzniveau für alle Tests war 5\%. Dargestellt sind Daten der Tiere aus Protokoll 3, für jede Gruppe ist $n=10$. 

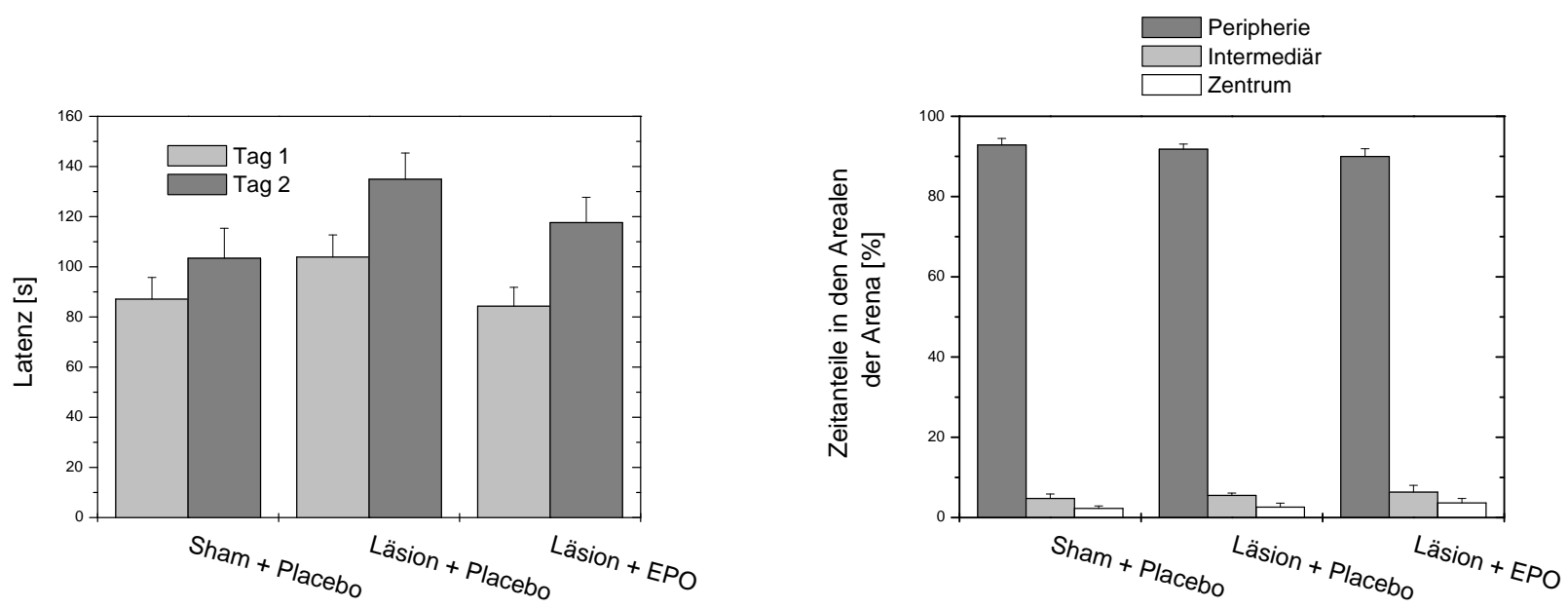

Abbildung 3.21: Rotarod- und Open-field-Daten für Protokoll 3 nach 3 Monaten. links: Rotarod-Latenzen in Sekunden (bis zum Herunterfallen der Tiere) an zwei aufeinanderfolgenden Tagen. rechts: Anteile des Aufenthalts in verschiedenen Arealen der Open-Field-Arena; die Gesamtzeit betrug 5 Minuten. Dargestellt sind Daten der Tiere aus Protokoll 3 als Mittelwert \pm SE, für jede Gruppe ist $n=10$.

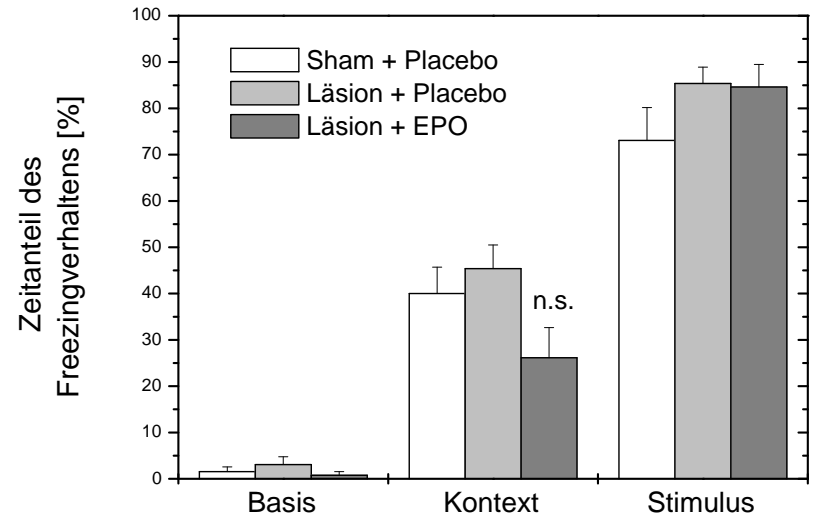

Abbildung 3.22: Darstellung des Freezing-Verhaltens in der Furchtkonditionierung für Protokoll 3 nach 3 Monaten. Im Gruppenvergleich wird der BasisFurchtlevel und das Verhalten bei Präsentation des Kontextes sowie des Tones (Stimulus) ohne aversiven Reiz abgebildet. Die Abwesenheit jeglicher Bewegung außer Atmung wird als Freezing bezeichnet. Dargestellt sind Daten der Tiere aus Protokoll 3 als Mittelwert $\pm \mathrm{SE}$, für jede Gruppe ist $n=10$. 

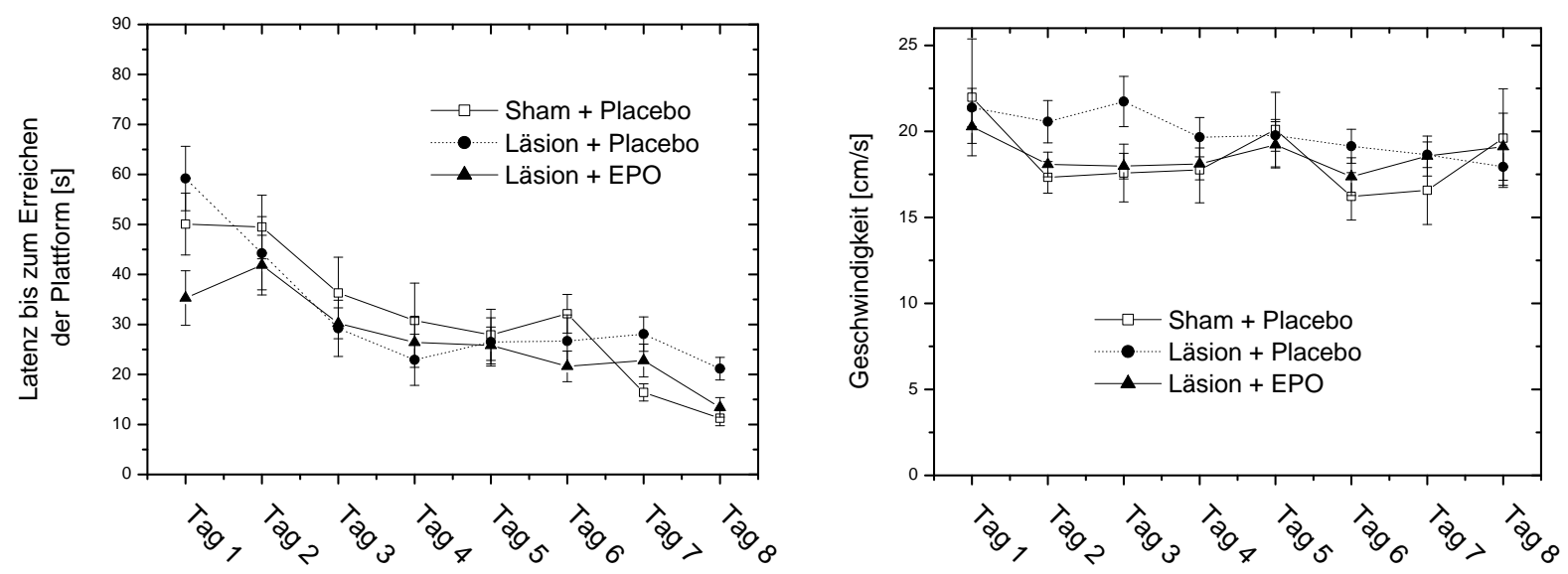

Abbildung 3.23: Verlauf der Latenzen im Water-Maze-Test nach Morris bis zum Erreichen der Plattform und Schwimmgeschwindigkeiten für Protokoll 3 nach 3 Monaten. Es sind nur Werte für den Versuchsabschnitt mit unsichtbarer Plattform abgebildet, der räumliches Lernverhalten der Tiere testet. links: Verlauf der Latenzen bis zum Erreichen der Plattform, das Tier hatte maximal 90 Sekunden zur Verfügung. rechts: Schwimmgeschwindigkeiten über 8 Tage. Nicht dargestellt sind die ebenfalls erhobenen zurückgelegten Distanzen bis zum Erreichen der Plattform. Dargestellt sind Daten der Tiere aus Protokoll 3 als Mittelwert \pm SE, für jede Gruppe ist $n=10$.

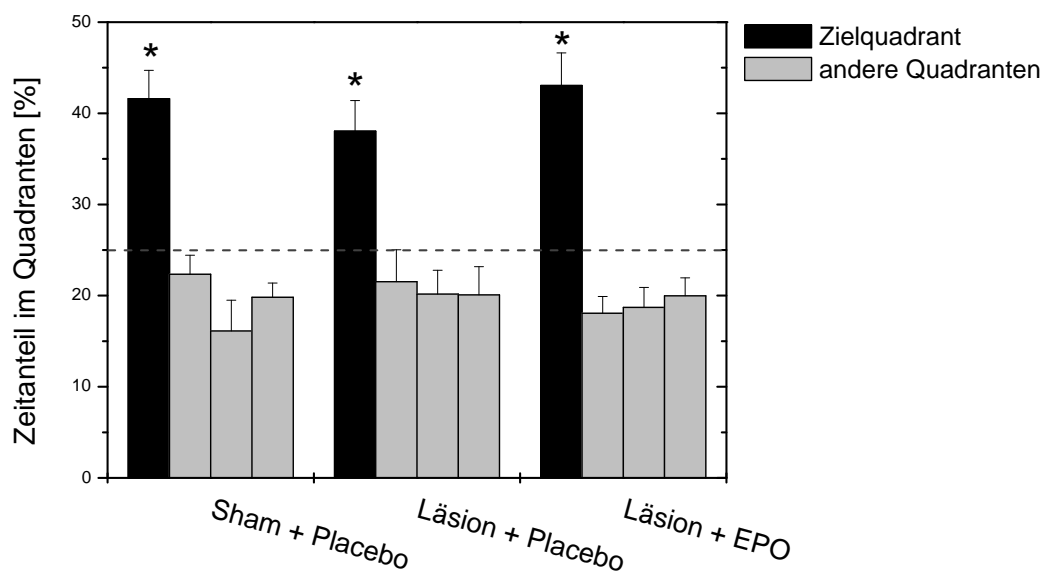

Abbildung 3.24: Abschlußtest im Water-Maze-Test nach Morris für Protokoll 3 nach 3 Monaten. Im letzten Durchgang des Testes wird die Plattform entfernt und die Tiere haben 90 Sekunden für die Suche. Dargestellt sind Zeitanteile in den verschiedenen Quadranten (Balken: Zielquadrant, links, rechts und gegenüber dem Zielquadranten gelegen); die Linie indiziert den zu erwartenden Zufallsanteil von 25\%. Dargestellt sind Daten der Tiere aus Protokoll 3 als Mittelwert \pm SE, für jede Gruppe ist $n=10,\left(^{*}\right)$ $\mathrm{p}<0.05$ in paarweisen t-Tests mit den anderen Quadranten. 


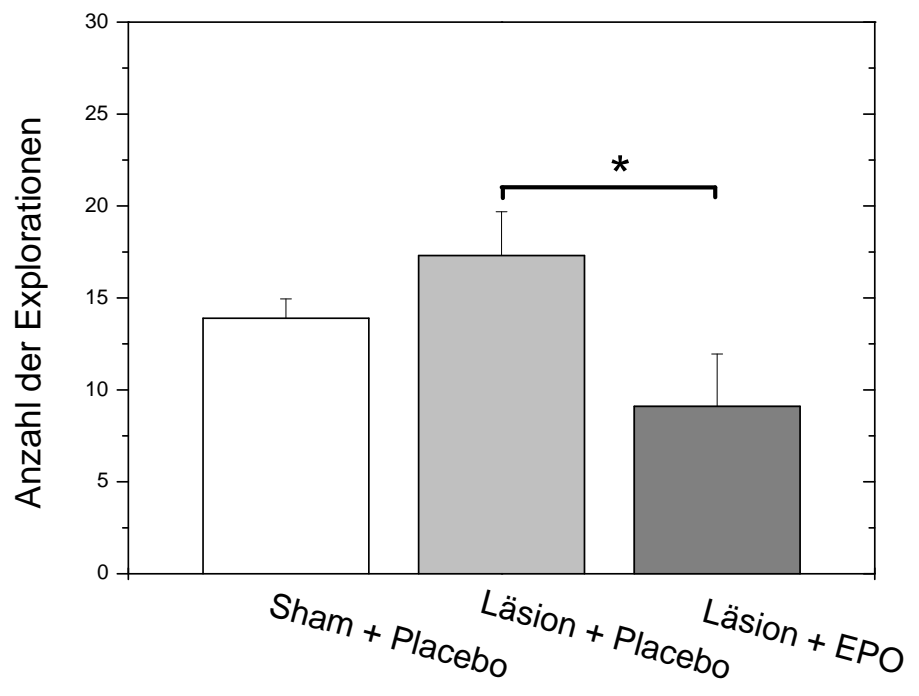

Abbildung 3.25: Anzahl der explorierten Löcher im Hole-Board für Protokoll 3 nach 3 Monaten. Während der 3 minütigen Testphase wird die Anzahl der explorierten Löcher gezählt. Dargestellt sind Daten der Tiere aus Protokoll 3 als Mittelwert \pm SE, für jede Gruppe ist $n=10,\left(^{*}\right) \mathrm{p}<0.05$ im post-hoc Test nach Duncan.
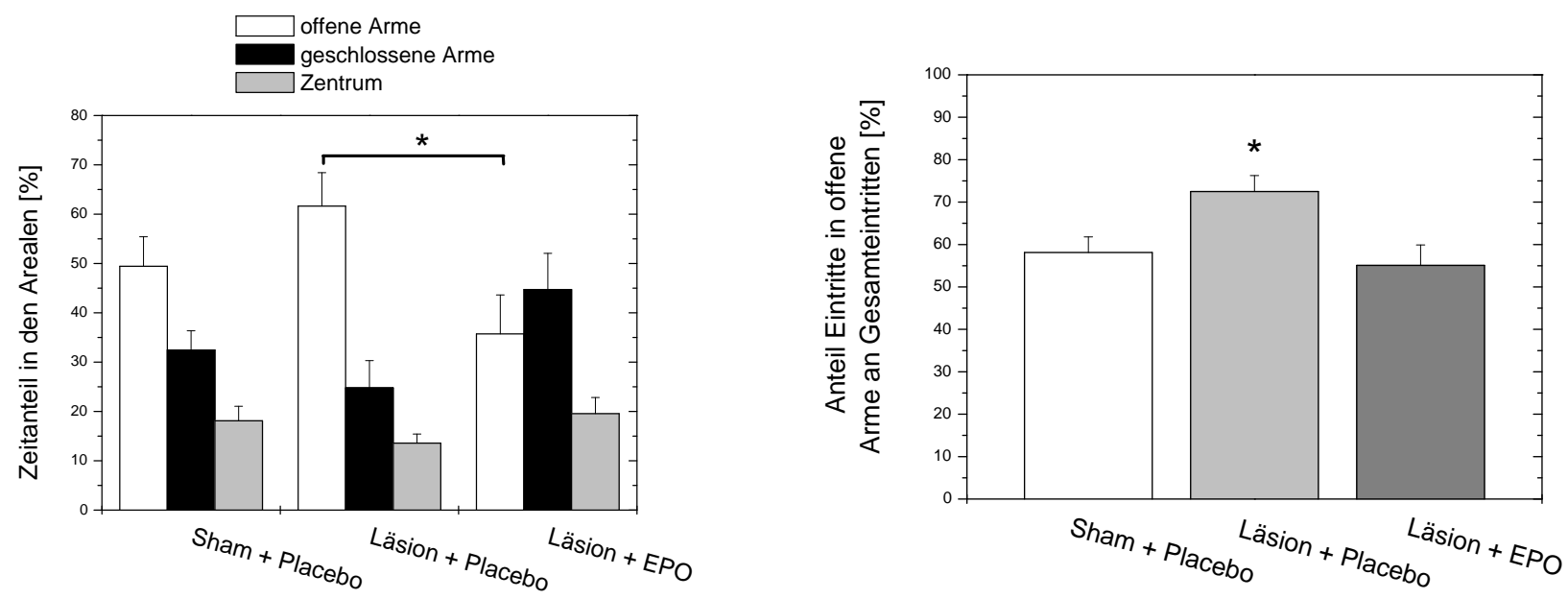

\section{Abbildung 3.26: Verhalten im Elevated-Plus-Maze für Protokoll 3 nach 3 Mo-} naten. links: Zeitanteile, die in den verschiedenen Arealen des Maze verbracht wurden. Ebenfalls erhobene Distanzanteile bestätigen in allen Fällen diese Daten. rechts: Anteil der Eintritte in offene Arme an den insgesamt betretenen Armen. Die Gesamtanzahl der betretenen Arme als Maß für die motorische Aktivität wird in Beziehung zum Eintritt in die offenen Arme als Parameter für ängstliches Verhalten gesetzt. Dargestellt sind Daten der Tiere aus Protokoll 3 als Mittelwert \pm SE, für jede Gruppe ist $n=10,\left(^{*}\right) \mathrm{p}<0.05$ im post-hoc Test nach Duncan. 
Elevated-Plus-Maze

\begin{tabular}{lccc}
\hline & $\begin{array}{c}\text { Zeitanteil in } \\
\text { offenen Armen [\%] }\end{array}$ & Gesamteintritte & $\begin{array}{c}\text { Anteil Eintritte } \\
\text { in offene Arme [\%] }\end{array}$ \\
\hline Sham + Placebo & $49.45 \pm 5.97$ & $22.50 \pm 2.13$ & $58.11 \pm 3.69$ \\
Läsion + Placebo & $61.63 \pm 6.79$ & $19.20 \pm 2.39$ & $72.49 \pm 3.75$ \\
Läsion + EPO & $35.73 \pm 7.89$ & $22.40 \pm 1.44$ & $55.08 \pm 4.82$ \\
\hline \hline & $\begin{array}{c}(\mathbf{F}=3.49, \mathbf{p}=\mathbf{0 . 0 4 5}) \\
\text { siehe Abb.3.26 Seite 58 }\end{array}$ & $(\mathrm{F}=0.86, \mathbf{p}=0.44)$ & $\mathbf{( F = 5 . 1 0 , p = 0 . 0 1 3 )}$ \\
\end{tabular}

Rotarod

\begin{tabular}{lcc}
\hline Latenz $[s]$ & Tag 1 & Tag 2 \\
\hline Sham + Placebo & $87.10 \pm 8.63$ & $103.40 \pm 11.99$ \\
Läsion + Placebo & $103.90 \pm 8.80$ & $134.90 \pm 10.46$ \\
Läsion + EPO & $84.30 \pm 7.50$ & $117.60 \pm 10.13$ \\
\hline & $(\mathrm{F}=1.62, \mathrm{p}=0.22)$ & $(\mathrm{F}=2.10, \mathrm{p}=0.14)$
\end{tabular}

\begin{tabular}{lccc} 
Open-field & & & \\
\hline Zeitanteil [\%] & & & \\
& Peripherie & Intermediär & Zentrum \\
\hline Sham + Placebo & $92.85 \pm 1.63$ & $4.77 \pm 1.10$ & $2.29 \pm 0.60$ \\
Läsion + Placebo & $91.80 \pm 1.29$ & $5.53 \pm 0.56$ & $2.61 \pm 0.97$ \\
Läsion + EPO & $89.97 \pm 1.93$ & $6.34 \pm 1.69$ & $3.64 \pm 1.11$ \\
\hline \hline & $(\mathrm{F}=0.80, \mathrm{p}=0.46)$ & $(\mathrm{F}=0.42, \mathrm{p}=0.66)$ & $(\mathrm{F}=0.59, \mathrm{p}=0.56)$
\end{tabular}

Holeboard

\begin{tabular}{lc}
\hline & Explorationen \\
\hline Sham + Placebo & $13.90 \pm 1.05$ \\
Läsion + Placebo & $17.30 \pm 2.39$ \\
Läsion + EPO & $9.1 \pm 2.85$ \\
\hline & $\mathbf{( F = 3 . 4 0 , p = 0 . 0 4 8 )}$
\end{tabular}

siehe Abb.3.25 S.58

\section{Furchtkonditionierung}

\begin{tabular}{lccc}
\hline Freezing-Zeitanteil [\%] & Basis & Kontext & Stimulus \\
\hline Sham + Placebo & $1.54 \pm 1.03$ & $40.00 \pm 5.71$ & $73.08 \pm 7.09$ \\
Läsion + Placebo & $3.07 \pm 1.70$ & $45.38 \pm 5.13$ & $85.38 \pm 3.53$ \\
Läsion + EPO & $0.77 \pm 0.77$ & $26.15 \pm 6.51$ & $84.62 \pm 4.87$ \\
\hline \hline & $(\mathrm{F}=0.91, \mathrm{p}=0.41)$ & $(\mathrm{F}=0.16, \mathrm{p}=0.86)$ & $(\mathrm{F}=1.65, \mathrm{p}=0.21)$
\end{tabular}

Tabelle 3.7: Übersicht über die abgebildeten Verhaltensparameter für Protokoll 3 nach 3 Monaten. Unter den Tabellen wird jeweils der F-Wert und die zugehörige Fehlerwahrscheinlichkeit p angegeben. Auf Gruppenunterschiede wurde durch einfaktorielle ANOVA getestet, das Signifikanzniveau betrug 5\%. Dargestellt sind Daten der Tiere aus Protokoll 3, für jede Gruppe ist $n=10$. Fett markiert sind signifikant unterschiedliche Werte. 


\begin{tabular}{lcccccc} 
Morris-Water-Maze & \multicolumn{4}{c}{ sichtbare Plattform } \\
\cline { 3 - 6 } & & \multicolumn{4}{c}{ Distanz $[\mathrm{cm}]$} & Geschwindigkeit [cm/s] \\
& Tag 1 & Tag 2 & Tag 1 & Tag 2 & Tag 1 & Tag 2 \\
\hline Sham + Placebo & 39.40 & 23.92 & 750.71 & 468.49 & 22.35 & 21.52 \\
Läsion + Placebo & 32.73 & 18.27 & 634.74 & 403.65 & 21.90 & 23.65 \\
Läsion + EPO & 28.95 & 19.61 & 543.92 & 376.77 & 19.88 & 20.50 \\
\hline \hline
\end{tabular}

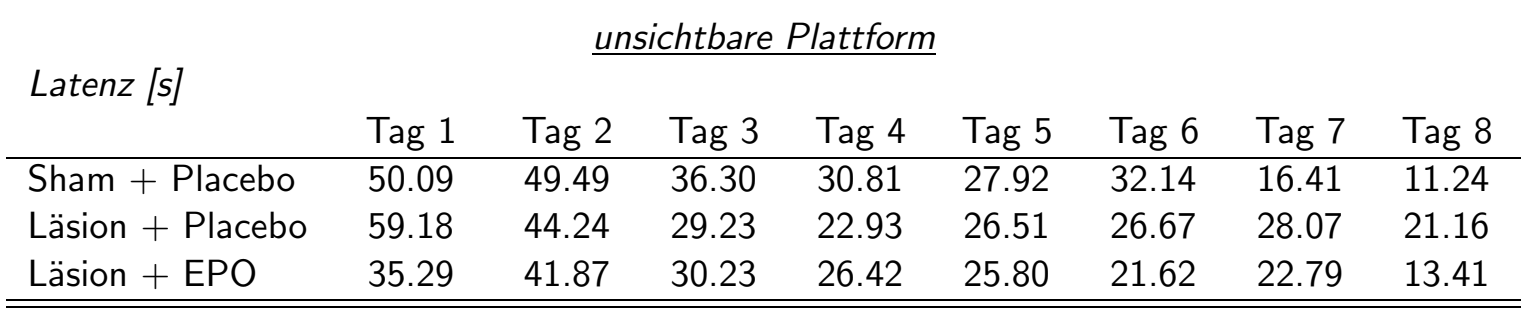

\begin{tabular}{lcccccccc} 
Distanz $[\mathrm{cm}]$ & & & & & & \\
& Tag 1 & Tag 2 & Tag 3 & Tag 4 & Tag 5 & Tag 6 & Tag 7 & Tag 8 \\
\hline Sham + Placebo & 916.42 & 828.95 & 547.73 & 444.15 & 460.49 & 562.26 & 307.46 & 212.51 \\
Läsion + Placebo & 1184.10 & 854.75 & 578.97 & 439.21 & 520.93 & 521.49 & 533.04 & 398.03 \\
Läsion + EPO & 682.86 & 769.75 & 556.92 & 485.31 & 517.13 & 383.49 & 415.65 & 222.49 \\
\hline \hline
\end{tabular}

\begin{tabular}{lllllllll}
\multicolumn{2}{l}{ Geschwindigkeit $[\mathrm{cm} / \mathrm{s}]$} & & & & & \\
& Tag 1 & Tag 2 & Tag 3 & Tag 4 & Tag 5 & Tag 6 & Tag 7 & Tag 8 \\
\hline Sham + Placebo & 21.98 & 17.33 & 17.58 & 17.77 & 20.11 & 16.22 & 18.42 & 21.78 \\
Läsion + Placebo & 21.38 & 20.56 & 21.73 & 19.66 & 19.77 & 19.14 & 18.65 & 17.93 \\
Läsion + EPO & 20.27 & 18.08 & 17.98 & 18.11 & 19.22 & 17.37 & 18.56 & 19.11 \\
\hline \hline
\end{tabular}

\begin{tabular}{lcccc} 
Zeitanteil [\%] & \multicolumn{4}{c}{ Probetrial } \\
& Ziel & links & rechts & gegenüber \\
\hline Sham + Placebo & $\mathbf{4 1 . 6 1} \pm \mathbf{3 . 1 1}$ & $22.34 \pm 2.09$ & $16.12 \pm 3.37$ & $19.81 \pm 1.57$ \\
Läsion + Placebo & $\mathbf{3 8 . 0 4} \pm \mathbf{3 . 3 6}$ & $21.53 \pm 3.50$ & $20.16 \pm 2.62$ & $20.08 \pm 3.09$ \\
Läsion + EPO & $\mathbf{4 3 . 0 5} \pm \mathbf{3 . 5 7}$ & $18.07 \pm 1.84$ & $18.70 \pm 2.20$ & $19.98 \pm 1.97$ \\
\hline \hline & siehe Abb.3.24 S.57
\end{tabular}

Tabelle 3.8: Evaluierte Parameter des Morris-Water-Maze-Tests für Protokoll 3 nach 3 Monaten. oben: Darstellung des Versuchsabschnittes mit sichtbarer Plattform über 2 Tage. Mitte: Verlauf der Parameter über 8 Tage mit unsichtbarer Plattform. Auf Gruppenunterschiede wurde durch ANOVA mit Meßwiederholung getestet. unten: Das Suchverhalten im Probe-Trial wurde durch Registrierung von Zeit- und Distanzanteilen (nicht dargestellt) im Zielquadranten beschrieben. Der Zielquadrant wurde paarweise im t-Test mit den anderen Quadranten verglichen. Das Signifikanzniveau für alle Tests war $5 \%$; signifikante Unterschiede sind fett gedruckt. Dargestellt sind Daten der Tiere aus Protokoll 3, für jede Gruppe ist $n=10$. 


\subsection{Magnetresonanztomographie}

\subsubsection{Darstellung der Läsion}

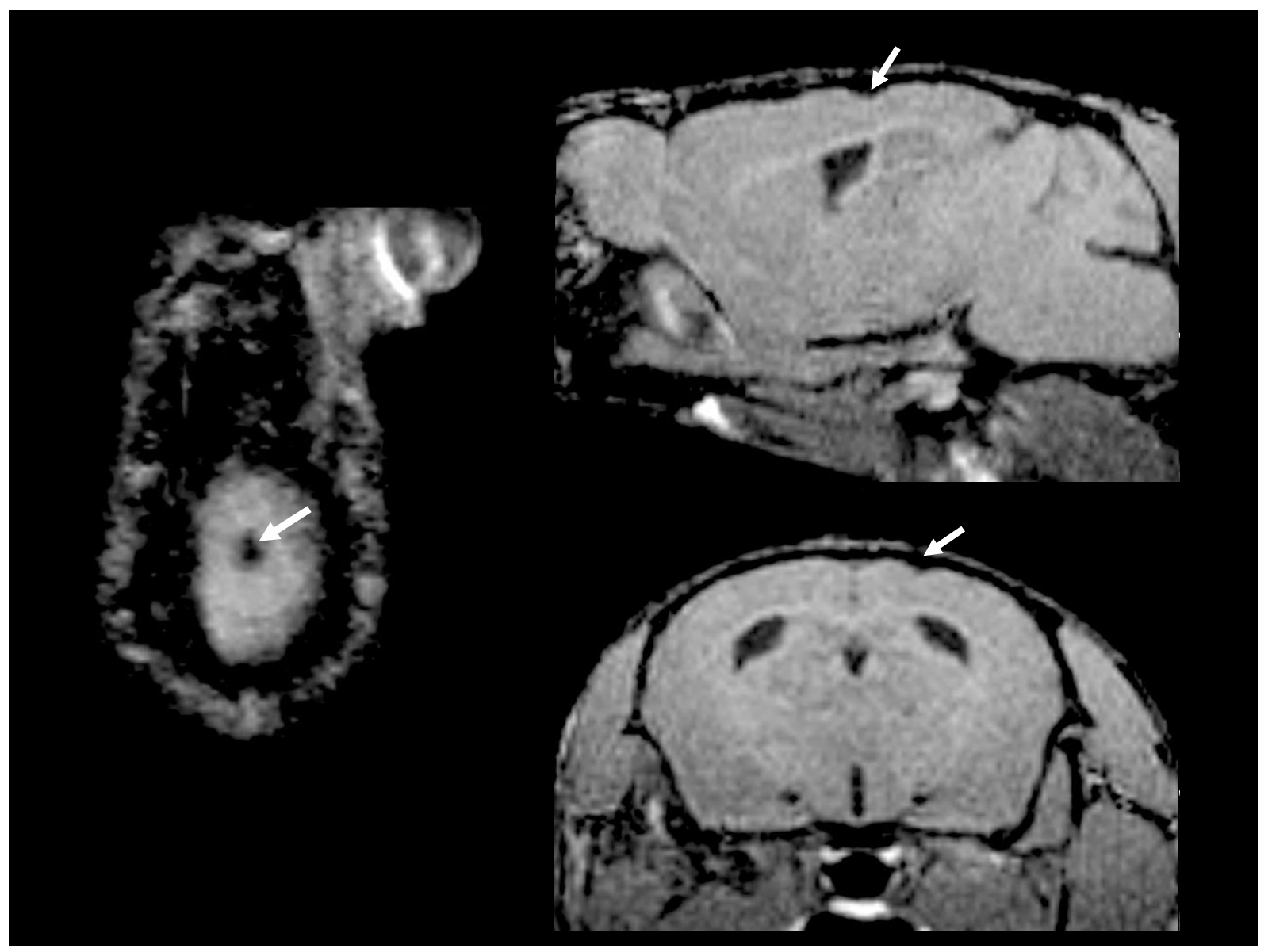

Abbildung 3.27: Darstellung der Kälteläsion in der MRT. Abgebildet sind $\mathrm{T}_{1^{-}}$ gewichtete Bilder einer 3D FLASH MRT. links: tangentialer Schnitt an den Kortex eines läsionierten Tieres. rechts: Die Pfeile deuten auf die Läsion, wie sie sich im sagittalen (oben) und coronaren Schnittbild (unten) darstellt.

Zur qualitativen Beurteilung der Läsion wurde geblindet ein Vorhandensein im Transversalschnitt beurteilt. Von den 7 Läsionen + Placebo wurden alle erkannt, von den 7 Läsionen + EPO nur 5. Ein Tier der Gruppe Sham + Placebo wurde fälschlicherweise als Läsionstier mit falsch positionierter Läsion klassifiziert.

Im Tangentialschnitt waren alle Läsionen $(n=14)$ darstellbar, und bei keinem nicht-läsionierten Tier war eine Läsion nachweisbar. Auch das oben genannte falsch klassifizierte Tier 
war eindeutig als nicht läsioniert zuzuordnen. Die Position der Läsion war reproduzierbar rechts-parietal und die Morphologie nur bei einem der Tiere verändert. Dieses Tier war in den Transversalschnitten als nicht-läsioniert klassifziert worden und in der Gruppe Läsion + EPO.

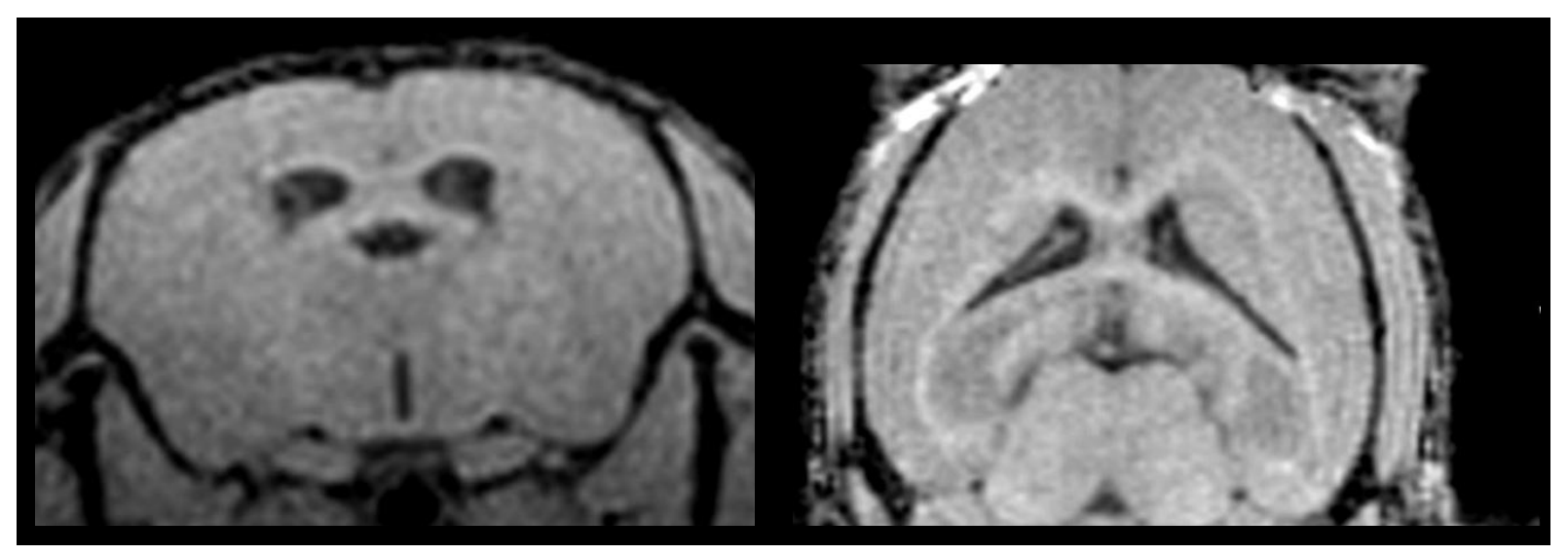

Abbildung 3.28: Darstellung von Kontrolltieren im MRT. links in einer coronaren Schnittführung, rechts ein exemplarischer Transversalschnitt, in dem die Volumetrie durchgeführt wurde.

\subsubsection{Volumetrie}

Die Ergebnisse der Volumetrie in den $\mathrm{T}_{1}$-gewichteten Bildern der 3D FLASH MRT ist folgend in Tabelle 3.9 dargestellt. Für jede Grupe ist $n=7$, dargestellt sind Mittelwerte \pm SE.

\begin{tabular}{cccc} 
Gruppe & $\begin{array}{c}\text { Hirnvolumen } \\
{\left[\mathrm{mm}^{3}\right]}\end{array}$ & $\begin{array}{c}\text { Ventrikelvolumen } \\
{[\%]}\end{array}$ & $\begin{array}{c}\text { Hippokampus- } \\
\text { volumen [\%] }\end{array}$ \\
\hline Naiv & $310.46 \pm 5.33$ & $2.66 \pm 0.19$ & $3.78 \pm 0.12$ \\
Naiv + Placebo & $308.11 \pm 4.01$ & $3.38 \pm 0.48$ & $3.75 \pm 0.06$ \\
Naiv + EPO & $314.00 \pm 4.73$ & $3.25 \pm 0.34$ & $3.73 \pm 0.11$ \\
Sham + Placebo & $307.01 \pm 2.60$ & $2.32 \pm 0.18$ & $3.85 \pm 0.07$ \\
Sham + EPO & $312.83 \pm 4.80$ & $2.34 \pm 0.26$ & $3.93 \pm 0.09$ \\
Läsion + Placebo & $310.41 \pm 4.52$ & $2.67 \pm 0.26$ & $4.10 \pm 0.10$ \\
Läsion + EPO & $303.69 \pm 4.32$ & $2.73 \pm 0.15$ & $3.81 \pm 0.10$ \\
\hline & & 3 & Prozent des Gesamthirnvolumens
\end{tabular}

Tabelle 3.9: Volumetrische Ergebnisse im Gruppenvergleich 
Es ergaben sich in der durchgeführten ANOVA keine Gruppenunterschiede im Hinblick auf diese Parameter. Ebenfalls nicht signifikant waren Seitenvergleiche der Volumen von Hippokampus und Ventrikel im individuellen Vergleich. Die Volumen wurden im Hinblick auf eventuelle Abhängigkeiten vom Gesamthirnvolumen zu diesem in Beziehung gesetzt und als prozentuale Anteile behandelt.

Ein Tier wurde aus der Gruppe Läsion + Placebo ausgeschlossen, da der Hydrozephalus extrem war und eine direkte Verursachung durch die Läsion nicht als wahrscheinlich angesehen wurde. Im Vergleich zur obigen Tabelle die Werte dieses Tieres: Gesamthirnvolumen $334.25 \mathrm{~mm}^{3}$, Ventrikelvolumen 16.90\%, Hippokampus-Volumen 4.08\%. Bei dem Stamm C57BL/6J ist ein Hydrozephalus als kongenitale Fehlbildung bei 1-3\% der Neugeborenen beschrieben (Dagg 1966, 309-328).

\subsection{Routinefärbungen und Zellzahl}

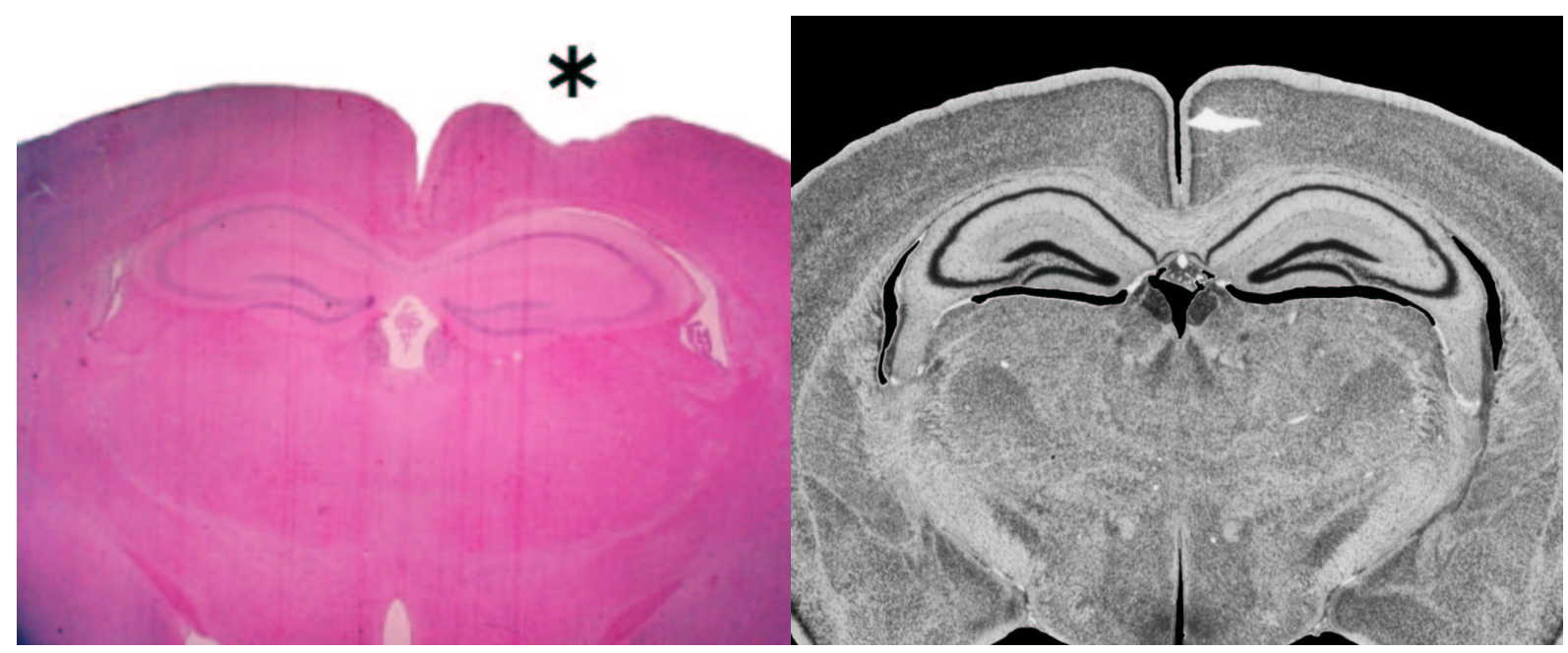

Abbildung 3.29: Routinefärbung des Mausgehirns. Dargestellt ist links ein repräsentativer Schnitt in Hämatoxylin-Eosin-Färbung auf Höhe der Läsion $\left.{ }^{*}\right)$, rechts eine Cresyl-Violett-Färbung $1.64 \mathrm{~mm}$ posterior des Bregmas, entnommen aus dem koronalen C57BL/6-Atlas der Mouse Brain Library (Rosen et al. 2000).

Auf den Hämatoxylin-Eosin-Färbungen wurden das Vorhandensein der Läsion und ihre Lokalisation überprüft. Die Auswertung ergab eine korrekte Läsionslokalisation im Vergleich mit dem Atlas der Mouse Brain Library (Rosen et al. 2000), wie in Abbildung $3.29 \mathrm{zu}$ sehen ist. Damit wurden die Ergebnisse der Magnetresonanztomographie durch konventionelle Methoden bestätigt. 
Die Auswertung der Zellzahlen in der Hilus-Region des Gyrus dentatus ergaben für das Protokoll 3 (3 Monate nach Läsion) eine signifikante Reduktion der Zellzahl durch die Läsion, sowohl auf der ipsi- wie auch auf der zur Läsion kontralateralen Hirnseite. Diese Reduktion konnte von der durchgeführten EPO-Applikation wirkungsvoll verhindert werden; die Zellzahlen blieben in der Gruppe Läsion + EPO auf Kontrollniveau, wie in Abbildung 3.30 zu sehen ist.
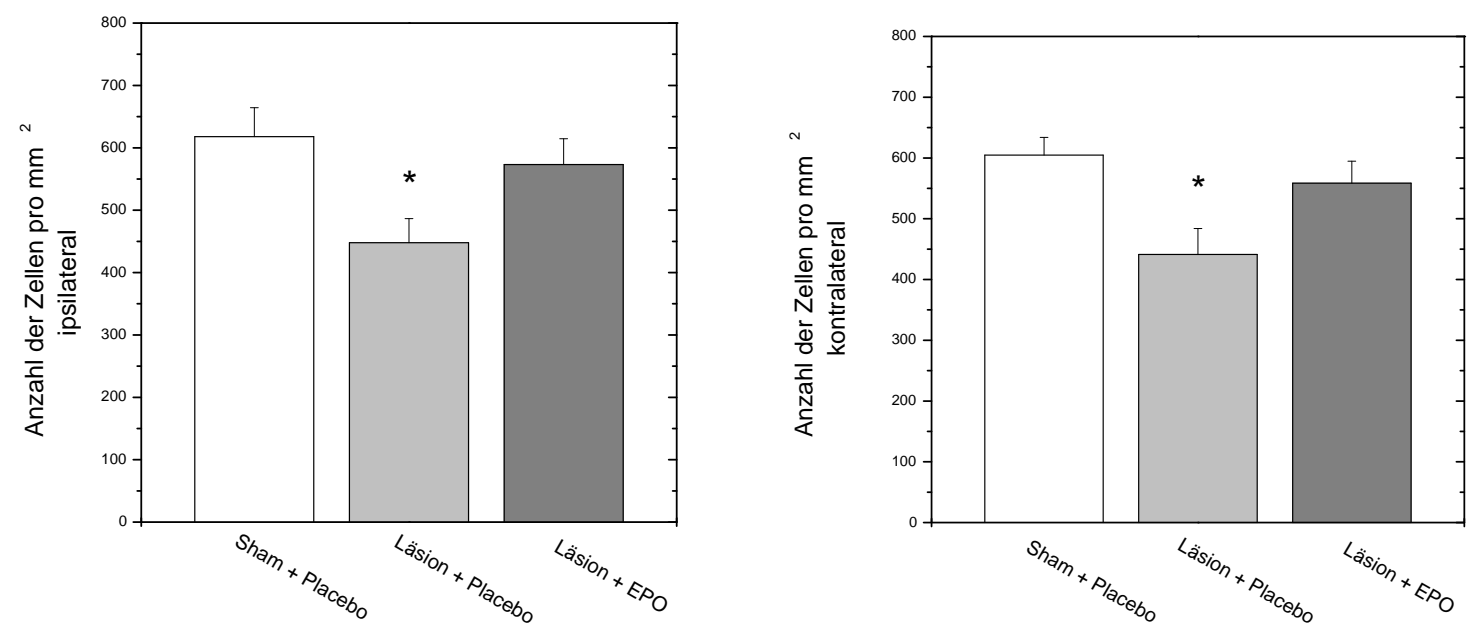

\begin{abstract}
Abbildung 3.30: Zellzahlen der Hilus-Region des Gyrus dentatus. links: Darstellung der Zellzahlen pro $\mathrm{mm}^{2}$ der ipsilateralen Hilus-Region des Gyrus dentatus 3 Monate nach Läsion und Verum- oder Placebotherapie, ausgewertet auf Höhe des dorsalen Hippokampus an 6-8 Gewebsschnitten pro Tier. $\mathrm{n}=7$ für Sham + Placebo und Läsion + $\mathrm{EPO}, \mathrm{n}=6$ für Läsion + Placebo. rechts: die entsprechende Darstellung für das kontralaterale Hirnareal. Die Markierungen $\left({ }^{*}\right)$ zeigen einen Gruppenunterschied in der ANOVA auf beiden Seiten des Gehirns. Der post-hoc Test nach Duncan zeigte eine Reduktion der Zellzahl nur für die Gruppe Läsion + Placebo, $\mathrm{p}<0.05$.
\end{abstract}

\title{
3.5 Blut-Hirn-Schrankenfunktion
}

In der akuten Phase trat blauer Farbstoff innerhalb einer halben Stunde bei allen Tieren $(\mathrm{n}=8)$ über die Blut-Hirn-Schranke und zeigte unabhängig von der Therapie mit Erythropoietin oder Placebo eine gestörte Funktion an. Im Falle der Injektion nach 24 Stunden trat 
nur bei wenigen Tieren innerhalb von 30 Minuten Farbstoff über. Ein Tier der PlaceboGruppe zeigte keinen Farbstoff, die anderen eine sehr dezente Anfärbung des Gewebes. Immerhin 3 Tiere der EPO-Gruppe zeigten überhaupt keine sichtbare Läsion, ein Tier zeigte dezente Anfärbung. Bei Injektion nach 6 Stunden trat innerhalb von einer halben Stunde bei keinem Tier Farbstoff über, aber nach weiteren 18 Stunden zeigten fast alle Tiere eine Anfärbung des Läsionsgebietes. Zwei Tiere der EPO-Gruppe und eines der Placebo-Gruppe zeigten keine Anfärbung. In der Tabelle 3.10 ist die Anzahl der geblindet semiquantitativ klassifizierten Läsionsgrößen wiedergegeben.

\begin{tabular}{|c||c|c|c|c|}
\hline \multirow{2}{*}{ Zeitpunkt der } & Art der & \multicolumn{3}{|c|}{ Farbstoffübertritt } \\
\cline { 3 - 5 } Hirnentnahme & Injektion & kein & gering & stark \\
\hline akut & EPO & 0 & 3 & 1 \\
& Placebo & 0 & 3 & 1 \\
\hline 6 Stunden & EPO & 4 & 0 & 0 \\
& Placebo & 4 & 0 & 0 \\
\hline 24 Stunden & EPO & 3 & 1 & 0 \\
& Placebo & 1 & 3 & 0 \\
\hline \hline kumulativ & EPO & 2 & 1 & 1 \\
24 Stunden & Placebo & 1 & 1 & 2 \\
\hline
\end{tabular}

Tabelle 3.10: Größe der Evans-Blue-Anfärbung. Dargestellt ist die semiquantitativ geblindet bewertete Größe der Evans-Blue-Extravasation. Der Farbstoff wurde jeweils 30 Minuten vor Hirnentnahme injiziert, lediglich in der Kumulativ-Gruppe wurde 6 Stunden nach Läsion injiziert und weitere 18 Stunden bis zur Hirnentnahme gewartet. n=4 pro Gruppe zu jedem Zeitpunkt. 


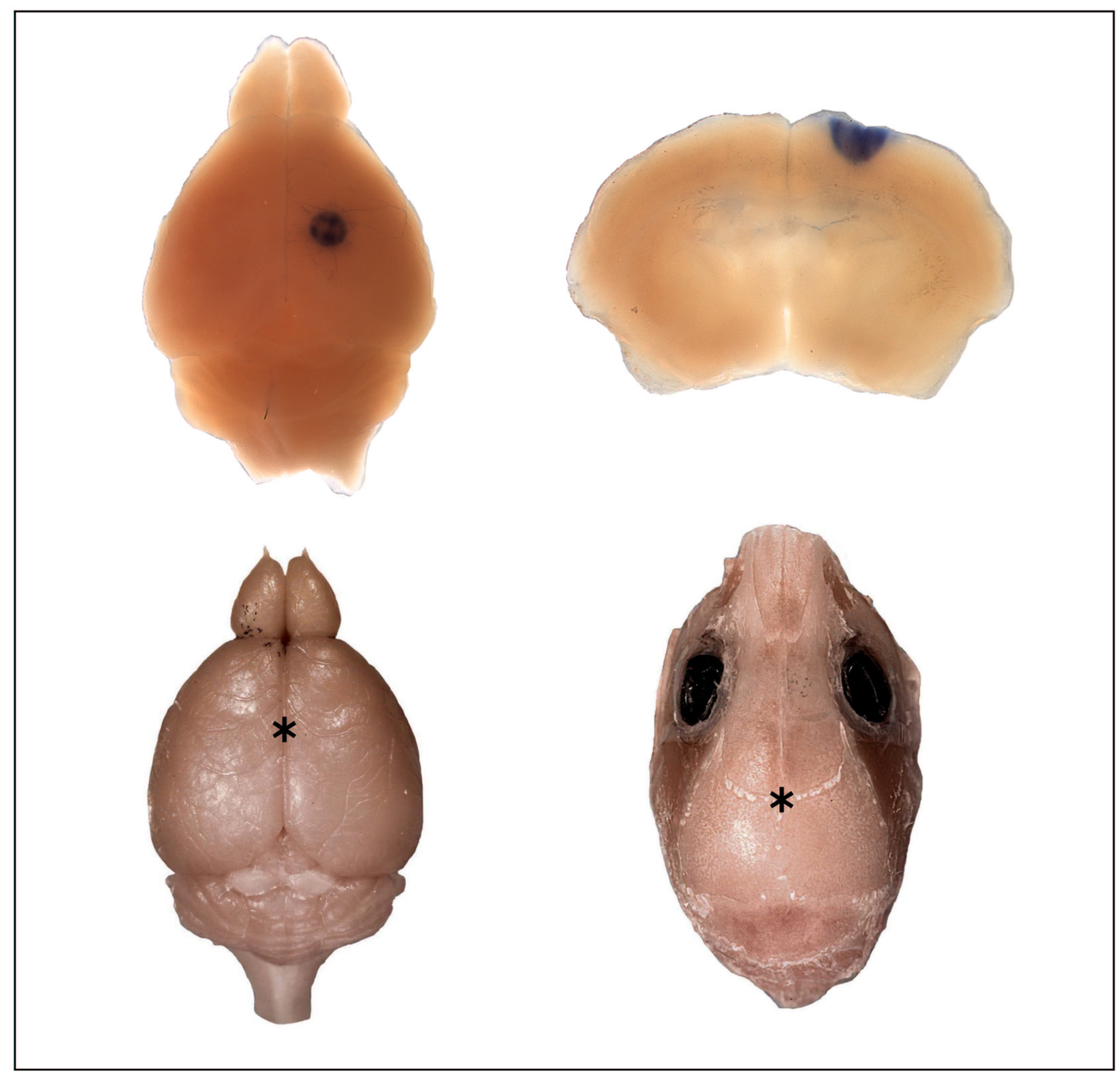

Abbildung 3.31: Evans-Blue-Färbungen der Kälteläsion des Mausgehirns. oben: Dargestellt ist die Extravasation von Evans-Blue eine Stunde nach Läsion bei einem placebo-behandelten Tier, links oben in der Aufsicht und rechts oben in einem Coronarschnitt. unten: Die beiden unteren Bilder zeigen Präparate aus der Mouse Brain Library (Rosen et al. 2000) mit Markierung des Bregmas $\left(^{*}\right)$ links ohne und rechts mit belassener Kalotte. Zu beachten ist der unterschiedliche Größenmaßstab. 


\section{4 \\ DISKUSSION}

\subsection{Zusammenfassung der Ergebnisse}

Die vorliegende Arbeit beschreibt die Auswirkungen einer neuroprotektiven Therapie mit Erythropoietin (EPO) im Kälteläsionsmodell für Neurotrauma bei der Maus. Es konnte gezeigt werden, daß eine 14-tägige systemische EPO-Applikation sofort nach Läsion in der Lage ist, verhaltensbiologische und histologische Auffälligkeiten zu einem späten Zeitpunkt nach Neurotrauma zu verhindern.

Die verwendete Verhaltensbatterie ist geeignet, die Auffälligkeiten zu charakterisieren, und durch das Design der Studie wurde eine Abgrenzung von Artefakten durch Operation und andere Stressoren möglich. Durch die Läsion wird ein pseudo-anxiolytisches Verhalten im Elevated-Plus Maze induziert, welches einhergeht mit Alterationen des Explorationsverhaltens im Sinne einer Aktivitätssteigerung im Hole-Board Test; alle übrigen Tests bleiben zu diesem Zeitpunkt unauffällig. Die Verhaltensänderungen nach Läsion sind durch EPO reversibel.

Die funktionelle Beeinträchtigung durch die Läsion in den verhaltensbiologischen Tests 
wurde den morphologischen Auswirkungen in Histologie sowie Bildgebung und Integrität der Blut-Hirn-Schranke gegenübergestellt. Das Verfahren der Kälteläsion zeigt sich in diesem Zusammenhang als hoch standardisierbar und verursacht eine diskrete kortikale Läsion mit lokalem Zusammenbruch der Blut-Hirn-Schranke. Die korrekte Lokalisation der Läsion konnte anhand der Histologie und der Magnetresonanztomographie bestätigt werden. Läsionsauswirkungen auf die Volumina von ausgewählten Hirnarealen (Seitenventrikel, Hippokampus) oder das Gesamthirnvolumen konnten in der Magnetresonanztomographie 3 Monate nach Läsion nicht deutlich gezeigt werden, obwohl die unilaterale Läsion einen bilateralen Verlust an pyramidalen Zellen in der Hilus-Region des Gyrus dentatus im Hippokampus induziert. Dieser Verlust kann durch eine EPO-Applikation verhindert werden und bildet somit das Korrelat zur Normalisierung der verhaltensbiologischen Auffälligkeiten unter Therapie.

\subsection{Identifikation von Verhaltensänderungen nach Neurotrauma}

Mit der Entwicklung von gentechnischen Methoden ist die Maus als Tiermodell von größtem Interesse. Die Verfahren zur Erzeugung von transgenen und Knock-Out-Tieren haben im Gebiet der Verhaltensforschung eine Adaptation von an der Ratte etablierten Methoden an die Maus motiviert (Crawley 2000). Mit Hilfe einer Batterie von verschiedenen Methoden ist es möglich, diskrete Verhaltensänderungen zu charakterisieren und sie in einem Zusammenhang vieler Parameter zu betrachten.

In der vorliegenden Studie konnte nach Neurotrauma ein pseudo-anxiolytisches Verhalten im Elevated-Plus-Maze dargestellt werden, welches nicht mit einer generellen Hyperaktivität einhergeht. Der Eintritt in die offenen Arme ist ein angstassoziierter Parameter, während die im vorliegenden Fall nicht signifikant geänderte Anzahl der Eintritte und der Anteil der Zeit in den offenen Armen ein aktivitätsassoziierter Parameter ist (Espejo 1997). Vorbeschrieben ist ein starker Effekt von Gewöhnung und Neuartigkeit der Situation auf das Verhalten im Elevated-Plus-Maze bei Hogg (1996), die einen Überblick über viele Studien geben. Unsere Tiere zeigen durch den hohen Zeitanteil in den offenen Armen des Maze schon ohne Läsion ein angstfreies Verhalten. Möglich ist, daß erst durch diesen Zustand eine Differenzierung des pseudo-anxiolytischen Effektes möglich ist, da er bei ängstlichen Tieren, die nicht an Manipulationen gewöhnt waren, nicht meßbar ist, denn diese Tiere ver- 
bringen den größten Teil der Zeit in den geschlossenen Armen (Riechers 2004). Vorstellbar ist hier ein sogenannter „Ceiling“-Effekt, der auch aus anderen Untersuchungen bekannt ist (Hogg 1996) und der bewirkt, daß bei sehr ängstlichen Tieren eine weitere Zunahme des Angstverhaltens nur schwer meßbar ist. Die erhöhte Explorationsaktivität läßt sich in diesem Modell auch im Hole-Board darstellen, wenn eine Therapie und das Handling entfallen; die läsionierten Tiere zeigen unter diesen streßfreien Bedingungen ein signifikant erhöhtes Explorationsverhalten (Riechers 2004).

Die Abwesenheit von multiplen Alterationen in den Verhaltenstests muß in diesem Zusammenhang als großer Vorteil angesehen werden, da erst so eine Charakterisierung des abnormen Verhaltens möglich ist. Wir können in unserem Modell eine intakte Motorik, normales Lernverhalten und unveränderte spontane Lokomotorik zeigen. Eine stärkere Beeinträchtigung durch Neurotrauma wie beispielsweise bei Brines et al. (2000) läßt nur noch ein sogenanntes „Neuroscoring“ zu, das basale Funktionen abtestet, dem aber feine Unterschiede wie kognitive Funktionen naturgemäß unzugänglich sind. Wir konnten zeigen, daß weder die Injektionen noch die Operation in unserer Verhaltensbatterie Auffälligkeiten erzeugen konnten; das abnorme Verhaltensmuster ist also läsionsspezifisch.

Auch beim Menschen können Läsionen des zentralen Nervensystems neben schweren Schäden subtile Veränderungen des Verhaltens hinterlassen (Hofman et al. 2001; Shoumitro et al. 1999). Diese Veränderungen sind vielfach nicht mit der Schwere der eigentlichen Verletzung assoziiert und makroskopisch nicht darstellbar, dennoch sind die Betroffenen stark beeinträchtigt. Auch die Prädisposition für psychiatrische Erkrankungen ist in diesem Zusammenhang interessant, da sie die langfristige Auswirkung einer Läsion impliziert (Reekum et al. 2000; Koponen et al. 2002). Es scheint also neben akuten auch mittel- bis langfristige Mechanismen zu geben, die - getriggert durch eine Läsion - die Vulnerabilität des Gehirns erhöhen und zu gestörter Funktion führen. Wir modellieren diesen Aspekt durch das junge Alter, in dem den Mäusen die Läsion beigebracht wird. So ergibt sich eine lange Phase für Follow-up-Untersuchungen, die von Riechers (2004) bis zu 9 Monate nach Läsion durchgeführt wurden. Zu diesem Zeitpunkt zeigen sich auch Beeinträchtigungen des Lernverhaltens sowie volumetrische Auffälligkeiten im Sinne einer Abnahme des Hirnvolumens (Sirén et al. 2004). 


\subsection{Morphologie und Funktion}

Die Morphologie des Gehirns wird durch eine Läsion nachhaltig beeinflußt, denn neben der Primärläsion werden die Strukturen durch zelltoxische und degenerative Vorgänge verändert. Art und Ausmaß der Veränderungen können histologisch, also post mortem, oder in vivo untersucht werden. Die Histologie bietet durch ihre Genauigkeit große Vorteile, während In-vivo-Untersuchungen durch bildgebende Verfahren in der Lage sind, artefaktfrei Größenverhältnisse und Funktionalität abzubilden. Mit zunehmendem Auflösungsvermögen ist aber auch die Magnetresonanztomographie hilfreich bei der Darstellung mikroskopischer Strukturen (Benveniste und Blackband 2002; Bulte et al. 2002; Natt et al. 2002).

Beim Menschen seit langer Zeit eingesetzt, zeigt dieses Verfahren uneinheitliche Veränderungen nach Neurotrauma (Bešenski 2002). Beschrieben sind Hippokampus-Atrophie (Bigler et al. 1997), Ventrikelerweiterungen (Henry-Feugeas et al. 2000) und Hirnatrophie mit Parenchymverlust (Verger et al. 2001). Bei vielen dieser Studien wurde versucht, bildgebende Verfahren als Prädiktor für klinische Parameter oder Progredienz der Erkrankung einzusetzen, denn die nicht mit einer Strahlenbelastung verbundene Magnetresonanztomographie bietet den Vorteil, daß Longitudinaluntersuchungen ethisch vertretbar sind und somit auch diskrete Veränderungen dokumentierbar werden.

Wir konnten in unserem Modell drei Monate nach Kälteläsion keine volumetrischen Auffälligkeiten darstellen ( $n=7$ pro Experimentalgruppe). Akute Auswirkungen sind von Schneider et al. (2002) bei der Ratte beschrieben worden und zeigen eine auf der Seite der Läsion betonte Ausbreitung des Ödems mit einer ischämischen Komponente durch reduzierten cerebralen Blutfluß. In einer Longitudinalstudie wurde bei C57BL/6J-Mäusen nach experimenteller Ischämie eine Erweiterung der Ventrikelräume und eine Hippokampus-Atrophie mit generalisierter Hirnatrophie beschrieben (McDaniel et al. 2001). Die Beobachtung endete nach fünf Wochen, und daher sind diese Ergebnisse mit unseren nicht direkt vergleichbar. Möglich ist, daß die beschriebene Abnahme der Parenchymmasse in unserem Modell bereits abgeschlossen oder weit fortgeschritten ist oder daß die Änderungen so diskret sind, daß nur intraindividuelle Vergleiche signifikante Veränderungen aufzeigen können. Für die erste Hypothese spricht, daß die von uns gemessenen Hirnvolumina deutlich unter den von McDaniel et al. (2001) publizierten liegen. Die gemessenen Hippokampus-Volumina sind ebenfalls nicht vergleichbar, da offensichtlich die von McDaniel et al. (2001) verwendete Sequenz nach eigenen Angaben nicht in der Lage ist, die Grenzen des Hippokampus korrekt 
darzustellen. Zusätzlich wurde das Volumen der Unterstrukturen nicht für das Gesamthirnvolumen korrigiert und somit sind Artefakte bei McDaniel et al. (2001) nicht auszuschließen. Beim Menschen wurde in einer Longitudinalstudie nach mildem Schädel-Hirn-Trauma eine beschleunigte Hirnatrophie beschrieben, die sich allerdings nur im Verlauf und nicht in punktuellen Aufnahmen signifikant darstellte (MacKenzie et al. 2002).

Die von uns verwendete Sequenz ist in der Lage, auch kleine Strukturen des Mausgehirns darzustellen (Natt et al. 2002). Wir konnten die Läsion in allen placebo-behandelten Tieren lokalisieren, zwei der EPO-behandelten Tiere zeigten im Transversalschnitt zwar Veränderungen der Hirnoberfläche, aber eine strukturell andere Ausbildung. Dies kann nur als Hinweis auf eine unterschiedliche Entwicklung der Läsion gewertet werden, denn in Tangentialschnitten wurde in jedem Fall eine Läsion offensichtlich. Da im Kälteläsionsmodell auch die Regeneration von Hirngefäßen untersucht wurde (Nag 2002) und eine angiogenetische Komponente von EPO bekannt ist (Ribatti et al. 1993), ist hier eventuell der Grund für die Veränderungen zu suchen.

Die in unserem Modell auftretenden verhaltensbiologischen Auffälligkeiten zeigen in Abwesenheit von deutlichen morphologischen Auswirkungen in der Magnetresonanztomographie eine gestörte Funktion an, die mit einem Zellverlust im Hippokampus zusammentriftt. Verschiedene Aspekte müssen hier in Betracht gezogen werden. Der Läsionsort ist nach einer Kortexkartierung der Maus von Caviness (1975) in der Area 3 gelegen. Dieses Gebiet schließt den sogenannten Barell-Kortex mit ein, den somatosensorischen Repräsentationsort für die Barthaare der Maus; ebenfalls in diesem Gebiet liegt die Repräsentation für somatosensorische Afferenzen des Rumpfes und der proximalen Extremitäten. Axonale Verbindungen existieren zur kontralateralen Area 3, zum Thalamus, Putamen und Globus pallidus sowie zum entorhinalen Kortex (Porter und White 1983). Pseudo-anxiolytisches Verhalten könnte also aus gestörter Sensorik sowie unterbrochenen Verbindungen in andere Hirnareale resultieren. Verhaltensänderungen nach Läsionen im Barrel-Kortex sind bei der Maus bereits beschrieben worden (Barnéoud et al. 1991). Bei der Ratte ist nach Parietalkortexläsion ein verbessertes Lernverhalten beschrieben worden (Hogg et al. 1998a;b); in Primatenmodellen wurde eine Unfähigkeit der Differenzierung von verschiedenartigen sensorischen Reizen beschrieben (Zainos et al. 1997). Dies zeigt, wie schwierig die genaue Funktion dieses Hirnareals (auch im Hinblick auf unterschiedliche Spezies) zu charakterisieren ist. Andererseits wurde von Zohar et al. (2003) nach minimalem Schädel-Hirn-Trauma bei Mäusen ein Lerndefizit beschrieben, daß auftrat, ohne daß die Tiere eine makroskopisch sichtbare oder in der Bildgebung darstellbare Läsion zeigten. Ein Zusammenbruch 
der Blut-Hirn-Schranke und Hirnödem blieben aus, trotzdem waren die Defizite auch nach 90 Tagen noch meßbar. Es ist davon auszugehen, daß durch das angewendete mechanische Läsionsmodell bei Zohar et al. (2003) ein diffuser schwer meßbarer Schaden induziert wird, der nicht wie in der vorliegenden Studie streng auf ein kleines kortexareal begrenzt ist. Auf der Grundlage der charakteristischen Verhaltensänderungen nach Kälteläsion kann unser Modell daher zur pathophysiologischen Untersuchung des Schädel-Hirn-Traumas und zur neuropharmakologischen Testung von Substanzen dienen, da keine schwerwiegenden Einschränkungen basaler Fertigkeiten festzustellen waren.

\subsection{Pharmakologische Neuroprotektion}

Mit den oben genannten Grundlagen ist also ein sensitiver verhaltensbiologischer Indikator zur Messung eines Therapieerfolges gegeben. Dieser Parameter muß unterschieden werden von molekularbiologischen Methoden zur Identifizierung von pathologischen Vorgängen nach Neurotrauma. Nach der Charakterisierung einer potentiell neuroprotektiven Substanz in der Zellkultur muß ihre Wirksamkeit im Tierexperiment überprüft werden. Hier scheint am naheliegendsten eine Testung der funktionserhaltenden Wirkung, die nicht unbedingt gleichbedeutend mit einem maximalen Gewebeerhalt ist, vielmehr scheint eine günstige Modulation der Reparations- und Zelltodvorgänge das Ziel einer erfolgreichen neuroprotektiven Therapie zu sein. Wird also Funktionserhalt als Maßstab für den Therapieerfolg gewählt, so ist eine molekularbiologische Charakterisierung von Dynamik und Mechanismus der protektiven Wirkung erst der nachfolgende Schritt. Nach vielen Substanzen, die neuroprotektiv im Tierversuch, aber erfolglos oder zumindest nur bedingt einsetzbar in der Klinik sind (Bullock et al. 1999; Narayan et al. 2002), ist EPO eine Substanz, die viele günstige Eigenschaften mitbringt. Vielleicht an erster Stelle steht die lange klinische Erfahrung mit EPO, die einen schnellen Einsatz bei erfolgreichen Human-Studien mit sich bringen würde.

Erythropoietin wurde in vielen Zellkulturmodellen (siehe Seite 10) und Tiermodellen (siehe Tab. 1.1 auf Seite 13) als neuroprotektive Substanz identifiziert. Eine Modellierung der funktionserhaltenden Wirkung höherer Funktionen hat jedoch nur vereinzelt stattgefunden (Buemi et al. 2000; Catania et al. 2002; Sadamoto et al. 1998; Sakanaka et al. 1998; Wen et al. 2002) und ist bisher nicht systematisch im Sinne einer Batterie von verhaltensbiologischen Tests durchgeführt worden. Die vorliegende Studie beschäftigt sich mit den Folgen zu einem späten Zeitpunkt nach Neurotrauma, was in der tierexperimentellen 
Literatur unterrepräsentiert ist; nur wenige der In-vivo-Studien mit Erythropoietin haben sich mit Zeiträumen größer als vier Wochen nach induziertem Schaden beschäftigt (siehe Tab.1.1 auf Seite 13). Wir haben jedoch diesen Zeitpunkt gewählt, um Interferenz mit der akut hämatologischen Wirkung von EPO zu vermeiden und um eine direkte Aussage über funktionelle Auswirkungen der Therapie zu erhalten. Die gewebserhaltenden Funktionen wie in Ischämiemodellen (Brines et al. 2000; Bernaudin et al. 1999; Sirén et al. 2001a) kommen dafür in unserem Modell nicht zum Tragen. Möglich ist, daß die Primärläsion obwohl sehr klein - im Verhältnis zur Sekundärläsion groß ist, da wir nur ein mildes Trauma mit lokalem Zusammenbruch der Blut-Hirn-Schranke erzeugen. Die Regenerationsfähigkeit und Narbenbildung ist bei der C57BL/6-Maus sehr ausgeprägt (Steward et al. 1999) und Sekundärschäden fern der Primärläsion sind im Kälteläsionsmodell nur gering ausgeprägt (Murakami et al. 1997; 1999), wodurch der histologisch sichtbare Effekt von EPO limitiert sein könnte. Es ist aber auch möglich, daß Schäden im Gehirn erst zu einem sehr späten Zeitpunkt sichtbar werden, nachdem persistierende Degenerationsvorgänge durch das Neurotrauma getriggert wurden. Es ist also davon auszugehen, daß der in unserem Modell sichtbare Schutz vor Neuronenverlust im Hippokampus durch EPO für die Normalisierung der Verhaltenstests verantwortlich ist, obwohl Alterationen in der Volumetrie nicht für großräumigen Gewebsverlust sprechen.

Eine kognitive Komponente der EPO-Behandlung im Sinne einer verbesserten Lernleistung, wie sie zum Beispiel Hengemihle et al. (1996) zeigen, konnten wir nicht klar bestätigen. Drei Monate nach den Injektionen fällt auf, daß lediglich die EPO-injizierten Tiere ohne Operation den Probe-Trial im Water-Maze bewältigen, und im Protokoll 2 lernen außer der naiven Gruppe nur die mit EPO injizierten Operations-Kontrollen (Sham + EPO), nicht aber die Operations-Kontrollen mit Placebo-Behandlung. Dieser Effekt lange nach der EPO-Applikation wäre eventuell zu einem früheren Zeitpunkt deutlicher, ist jedoch in unserem Modell nicht darstellbar, da die Tiere direkt nach Abschluß der Therapie zu jung und damit nicht für die Paradigmen der Verhaltenstestung geeignet sind.

\subsection{Grundlagen gestörter Neuronenfunktion}

Die Forschung auf dem Gebiet der Erkankungen des zentralen Nervensystems hat inzwischen einige Mechanismen identifiziert, die im Sinne einer gemeinsamen Endstrecke vieler schädigender Einflüsse aktiviert werden. Dazu zählen unter anderem die Aktivierung von Caspasen im Zuge der Apoptose, Ausschüttung von inflammatorischen Zytokinen und 
Einwanderung von Zellen des Immunsystems, Produktion von Radikalen sowie zelltoxische Wirkung von überschießender Besetzung des NMDA-Rezeptors durch Glutamat. Ein Einblick in die Modulation dieser Vorgänge würde protektive Eingriffe in das komplexe System vereinfachen. Zunehmend wird deutlich, daß einzelne Veränderungen des Systems nur Anhaltspunkte sein können, und es wird beispielsweise mit Hilfe der Microarraytechnik versucht, das Zusammenspiel verschiedener Faktoren gleichzeitig zu dokumentieren und zu analysieren (Mirnics 2001; Marciano et al. 2002).

Im Kälteläsionsmodell wurde diese Technik bis dato nicht verwendet, aber viele Faktoren, die die Entwicklung der Läsion beeinflussen, sind identifiziert. Die veränderte Generation von reaktiven Sauerstoffspezies wurde in transgenen und Knock-Out-Modellen beschrieben (Murakami et al. 1999; Chan et al. 1991; Giralt et al. 2002; Flentjar et al. 2002), und ein verminderter oxidativer Streß resultierte in vermindertem Ödem, verbesserter Blut-HirnSchrankenintegrität und verkleinerter Läsion. Die Zahl der Apoptosen in der traumatischen Pänumbra stieg, und es wurde weniger Mikrogliaaktivierung beobachtet, was mit verminderter Gliose einherging. Eine veränderte inflammatorische Reaktion zeigte sich bei IL-6 defizienten Tieren (Penkowa et al. 1999) durch reduzierte Makrophageninvasion; beobachtet wurden auch weniger geschädigte Neurone und aktivierte Mikroglia. Ein Antagonist des Bradykinin-Rezeptors 2 konnte das Ödem nach Kälteläsion vermindern (Görlach et al. 2001). Bei strahleninduzierter gestörter Regeneration der Mikrogefäße und Unterdrückung der Entzündungsreaktion im Läsionsgebiet zeigte sich eine gestörte Rückbildung des Ödems und eine verlangsamte Abräumreaktion durch Makrophagen (Olson et al. 1987).

Der Zusammenbruch der Bluthirnschranke wurde von Klatzo et al. (1958) beschrieben und im Zeitverlauf charakterisiert. Unsere Ergebnisse zur gestörten Funktion bei der Maus sind in Übereinstimmung mit den Ergebnissen von Murakami et al. (1997), die ebenfalls eine Kumulativextravasation bis 24 Stunden nach Läsion beschreiben. Wir konnten allerdings dokumentieren, daß innerhalb einer halben Stunde nur akut nach Läsion Evans-Blue immer über die Blut-Hirn-Schranke tritt, zu späteren Zeitpunkten nur in sehr wenigen Fällen. Vermutlich sind bei diesen Tieren größere Gefäße verletzt worden und der Übertritt des Farbstoffs findet nicht durch Ödembildung, sondern durch Blutung statt. Daher konnten wir nicht klar zeigen, daß EPO die Dynamik der Wiederherstellung der Blut-Hirn-Schranke beeinflussen kann, wie im In-vitro-Modell vermutet (Martinez-Estrada et al. 2003). Es ist somit möglich, daß durch den Einfluß von EPO das Ödemvolumen vermindert wird und die metabolische Versorgung des Läsionsgebietes länger erhalten oder schneller wieder hergestellt werden konnte; dies war aber mit den dargestellten Ergebnissen nicht zwingend 
zu belegen.

Eine Erstellung des Genexpressionsprofils nach Kälteläsion, wie es im Falle anderer Läsionen bereits durchgeführt wurde (Kobori et al. 2002), wäre wünschenswert und könnte das Zusammenspiel der beschriebenen Vorgänge verdeutlichen. Die Veränderungen nach transgener Überexpression von humanem Erythropoietin in der Maus sind mit der Microarraytechnik charakterisiert (Maurer et al. 2002) und könnten zusammen mit der Läsions- auch die Therapieauswirkungen beschreiben helfen. In unserem Modell der späten Auswirkungen eines Neurotraumas ist außerdem zu erwarten, daß eine engere Eingrenzung der Gene, die an langfristig neurodegenerativen Vorgängen beteiligt sind, stattfinden kann, da die oben beschriebenen akuten Prozesse zu diesem Zeitpunkt abgeschlossen sein sollten. 


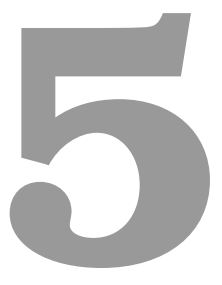

ZUSAMMENFASSUNG 
Auch milde Traumata des Schädels können beim Menschen persistierende und klinisch relevante Beschwerden verursachen. Die vorliegende Arbeit stellt in einem Modell des SchädelHirn-Traumas der Maus die läsionsspezifischen Charakteristika auf verhaltensbiologischer und morphologischer Ebene dar und beschreibt die Auswirkungen eines Therapieversuchs mit systemischer Erythropoietinapplikation.

Es wurde bei insgesamt über 90 juvenilen Mäusen (C57BL/6J männlich, Alter 4 Wochen) eine standardisierte Kälteläsion mittels Stereotaxie im rechtsparietalen Kortex appliziert (1.5 mm posterolateral des Bregmas, Durchmesser $1 \mathrm{~mm}$, Applikationsdauer $60 \mathrm{~s}$ ). Die Erythropoietintherapie wurde direkt nach der Läsion begonnen und systemisch (i.p. jeden zweiten Tag mit $5 \mathrm{U} / \mathrm{g}$ KG) über 2 Wochen fortgeführt; Therapie- (Placebo) sowie Operationskontrollen (Sham) waren vorhanden. Die Tiere wurden im Alter von 3 Monaten in einer verhaltensbiologischen Testbatterie sowie magnetresonanztomographischer Volumetrie ( $\mathrm{T}_{1}$-gewichtete 3D FLASH Sequenz) untersucht und das Gewebe histologisch aufbereitet.

Es konnte gezeigt werden, daß die strikt kortikale Kälteläsion reproduzierbar einen lokalen Zusammenbruch der Blut-Hirn-Schranke verursacht und spezifische Verhaltensauffälligkeiten induziert, welche durch Erythropoietin verhindert werden konnten. Artefakte durch die hämatologische Wirkung von Erythropoietin, Handling und Operation der Tiere wurden durch das Studiendesign vermieden.

Histologisch zeigt sich 3 Monate nach Läsion ein Zellverlust der Hilus-Region des Gyrus dentatus im Hippokampus, der bei unilateraler Läsion bilateral gleichermaßen ausgeprägt ist; dieser Zellverlust findet bei Therapie mit Erythropoietin nicht statt. Morphologisch ist die Läsion klar zu identifizieren, aber es zeigen sich 3 Monate nach Läsion keine deutlichen Alterationen in der magnetresonanztomographischen Volumetrie von Gehirn, Ventrikel oder Hippokampus.

Aus den Ergebnissen läßt sich schlußfolgern, daß Erythropoietin in der Lage ist, frühzeitig in den Verlauf einer Schädigung des zentralen Nervensystems einzugreifen und diesen positiv im Sinne eines Erhaltes von Funktionen zu beeinflussen. Außerdem gelingt es, noch unbekannte, im weitesten Sinne degenerative Prozesse zu verzögern beziehungsweise zu verhindern; diese Prozesse sind zumindest auf mikroskopischer Ebene eindeutig nachweisbar.

Diese Wirkung des im klinischen Alltag langjährig eingesetzten und mit wenig Komplikationen behafteten Wirkstoffes machen Erythropoietin zu einer Substanz, der vielfältige Einsatzmöglichkeiten offen stehen könnten. 


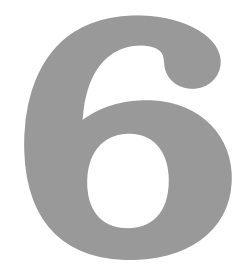

ANHANG 


\section{Literaturverzeichnis}

Agnello D, Bigini P, Vialla P, Menini T, Cerami A, Brines ML, Ghezzi P (2002):

Erythropoietin exerts an anti-inflammatory effect on CNS in a model of experimental autoimmune encephalomyelitis. Brain Res 1, Nr. 952, 128-134

Alafaci C, Salpietro F, Grasso G, Sfacteria A, Passalacqua M, Morabito A, Tripodo E, Calapai G, Buemi M, Tomasello F (2000): Effect of recombinant human erythropoietin on cerebral ischemia following experimental subarachnoid hemorrhage. Eur J Pharmacol 406, 219-225

Aydin A, Genc K, Akhisaroglu M, Yorukoglu K, Gokmen N, Gonullu E (2003): Erythropoietin exerts neuroprotective effect in neonatal rat model of hypoxic-ischemic brain injury. Brain Dev 25, Nr. 7, 494-498

Barnéoud P, Gyger M, Andrés F, van der Loos H (1991): Vibrissa-related behaviour in mice: transient effect of ablation of the barrel Cortex. Behav Brain Res $\underline{44}, 87-99$

Benveniste H, Blackband S (2002): MR microscopy and high resolution small animal MRI: applications in neuroscience research. Prog Neurobiol 주, 393-420

Bernaudin M, Marti HH, Roussel S, Divoux D, Nouvelot A, MacKenzie AT, Petit E (1999): A Potential Role for Erythropoietin in Focal Permanent Cerebral Ischemia in Mice. J Cereb Blood Flow Metab 19, 643-651

Bernaudin M, Bellail A, Marti HH, Yvon A, Vivien D, Duchatelle I, MacKenzie ET, Petit E (2000): Neurons and Astrocytes Express EPO mRNA: Oxygen-Sensing Mechanisms That Involve the Redox-State of the Brain. Glia 30, 271-278

Bešenski N (2002): Traumatic injuries: imaging of head injuries. Eur Radiol 12, 12371252 
Bianchi R, Buyukakilli B, Brines M, Savino C, Cavaletti G, Oggioni N, Lauria G, Borgna M, Lombardi R, Cimen B, Comelekoglu U, Kanik A, Tataroglu C, Cerami A, Ghezzi P (2004): Erythropoietin both protects from and reverses experimental diabetic neuropathy. Proc Natl Acad Sci USA 101, Nr. 3, 823-828

Bigler ED, Blatter DD, Anderson CV, Johnson SC, Gale SD, Hopkins RO, Burnett B (1997): Hippocampal Volume in Normal Aging and Traumatic Brain Injury. Am J Neuroradiol 18, 11-23

Bittorf T, Jaster R, Lüdtke B, Kamper B, Brock J (1997): Requirement for JAK2 in Erythropoietin-Induced Signalling Pathways. Cell Signal 9, Nr. 1, 85-89

Brines ML, Ghezzi P, Keenan S, Angnello D, de Lanerolle NC, Cerami C, Itri LM, Cerami A (2000): Erythropoietin crosses the blood-brain barrier to protect against experimental brain injury. Proc Natl Acad Sci USA 97, Nr. 19, 10526-10531

Buemi M, Grasso G, Corica F, Calapai G, Salpietro FM, Casuscelli T, Sfacteria A, Aloisi C, Concetta A, Sturiale A, Frisina N, Tomasello F (2000): In vivo evidence that erythropoietin has a neuroprotective effect during subarachnoid hemorrhage. Eur J Pharmacol 392, 31-34

Bullock MR, Lyeth BG, Muizelaar JP (1999): Current Status of Neuroprotection Trials for Traumatic Brain Injury: Lessons from Animal Models and Clinical Studies. Neurosurgery $\underline{45}$, Nr. 2, 207-220

Bulte JWM, van Zijl CM, Mori S (2002): Magnetic resonance microscopy and histology of the CNS. Trends Biotech 20, Nr. 8, S24-S28 suppl.

Calapai G, Marciano MC, Corica F, Allegra A, Parisi A, Frisina N, Caputi AP, Buemi M (2000): Erythropoietin protects against brain ischemic injury by inhibition of nitric oxide formation. Eur J Pharmacol 401, 349-356

Calvillo L, Latini R, Kajstura J, Leri A, Anversa P, Ghezzi P, Salio M, Cerami A, Brines M (2003): Recombinant human erythropoietin protects the myocardium from ischemia-reperfusion injury and promotes beneficial remodeling. Proc Natl Acad Sci USA $\underline{100}$, Nr. 8, 4802-4806 
Campana WM, Myers RR (2003): Exogenous erythropoietin protects against dorsal root ganglion apoptosis and pain following peripheral nerve injury. Eur J Neurosci $\underline{18}$, Nr. 6, 1497-1506

Cancilla PA, Frommes SP, Kahn LE, DeBault LE (1979): Regeneration of Microvessels: A Morphologic and Histochemical Study after Local Freeze-Injury. Lab Invest $\underline{40}$, Nr. 1, 74-82

Catania MA, Marciano MC, Parisi A, Sturiale A, Buemi M, Grasso G, Squadrito F, Caputi AP, Calapai G (2002): Erythropoietin prevents cognition impairment induced by transient brain ischemia in gerbils. Eur J Pharmacol 437, 137-150

Caviness VS (1975): Architechtonic Map of Neocortex of the Normal Mouse. J Comp Neurol 164, Nr. 2, 247-263

Celik M, Gokmen N, Erbayraktar S, Akhisaroglu M, Konakç S, Ulukus C, Genc S, Genc K, Sagiroglu E, Cerami A, Brines M (2002): Erythropoietin prevents motor neuron apoptosis and neurological disability in experimental spinal cord ischemic injury. Proc Natl Acad Sci USA 99, Nr. 4, 2258-2263

Chan PH, Yang GY, Chen SF, Carlson E, Epstein CJ (1991): Cold-induced Brain Edema and Infarction Are Reduced in Transgenic Mice Overexpressing CuZn-Superoxide Dismutase. Ann Neurol 29, 482-486

Crawley JN : What's wrong with my mouse? Behavioral phenotyping of transgenic and knockout mice. 1. Auflage; Wiley-Liss, New York 2000

Dagg CP : Teratogenesis in: Biology of the laboratory mouse. Green, E L (Hg.) 2. Auflage; McGraw-Hill, New York 1966, 309-328

Dame C, Bartmann P, Wolber EM, Fahnenstich H, Hofmann D, Fandrey J (2000): Erythropoietin gene expression in different areas of the developing human central nervous system Brain Res Dev Brain Res 125, 69-74

Digicaylioglu M, Lipton SA (2001): Erythropoietin-mediated neuroprotection involves cross-talk between Jak2 and NF-kB signalling cascades. Nature $\underline{412}$, Nr. 9, 641-647

Digicaylioglu M, Bichet S, Marti HH, Wenger RH, Rivas LA, Bauer C, Gassmann M (1995): Localization of specific erythropoietin binding sites in defined areas of the mouse brain. Proc Natl Acad Sci USA 92, 3717-3720 
Ehrenreich H, Hasselblatt M, Dembowski C, Cepek L, Lewczuk P, Stiefel M, Rustenbeck H, Breiter N, Jacob S, Knerlich F, Bohn M, Poser W, Rüther E, Kochen M, Gefeller O, Gleiter C, Wessel TC, de Ryck M, Itri L, Prange H, Cerami A, Brines M, Sirén AL (2002): Erythropoietin Therapy for Acute Stroke is Both Safe and Beneficial. Mol Med $\underline{8}$, Nr. 8, 495-505

Ehrenreich H, Degner D, Meller J, Brines M, Behe M, Hasselblatt M, Woldt H, Falkai P, Knerlich F, Jacob S, von Ahsen N, Maier W, Bruck W, Rüther E, Cerami A, Becker W, Sirén AL (2004): Erythropoietin: a candidate compound for neuroprotection in schizophrenia. Mol Psychiatry $\underline{9}$, Nr. 1, 42-54

Elf K, Nilsson P, Enblad P (2002): Outcome after traumatic brain injury improved by an organized secondary insult program and standardized neurointensive care. Crit Care Med $\underline{30}$, Nr. 9, 2129-2134

Espejo EF (1997): Structure of the mouse behaviour on the elevated plus-maze test of anxiety. Behav Brain Res $\underline{86}, 105-112$

Ferrag F, Pezet A, Chiarenza A, Buteau H, Nelson BH, Goffin V, Kelly PA (1998): Homodimerization of IL-2 receptor $\beta$ chain is necessary and sufficient to activate Jak2 and downstream signalling pathways. FEBS Lett 421, 32-36

Firsching R, Woischneck D (2001): Present Status of Neurosurgical Trauma in Germany. World J Surg 25, 1221-1223

Flentjar NJ, Crack PJ, Boyd R, Malin M, de Haan JB, Hertzog P, Kola I, Ianello R (2002): Mice Lacking Glutathione Peroxidase-1 Activity Show Increased Tunel Staining and an Accelerated Inflammatory Response in Brain Following a Cold-Induced Injury. Exp Neurol 177, 9-20

Garcia-Garcia F, Krueger JM (2003): Intracerebroventricular injection of erythropoietin enhances sleep in the rat. Brain Res Bull $\underline{61}$, Nr. 5, 541-546

Genc S, Kuralay F, Genc K, Akhisaroglu M, Fadiloglu S, Yorukoglu K, Fadiloĝlu M, Gure A (2001): Erythropoietin exerts neuroprotection in 1-methyl-4-phenyl1,2,3,6-tetrahydropyridine-treated C57/BL mice via increasing nitric oxide production. Neurosci Lett $\underline{298}, 139-141$ 
Genc S, Akhisaroglu M, Kuralay F, Genc K (2002): Erythropoietin restores glutathione peroxidase activity in 1-methyl-4-phenyl-1,2,5,6-tetrahydropyridine-induced neurotoxicity in C57BL mice and stimulates murine astroglial glutathione peroxidase production in vitro. Neurosci Lett $\underline{321}, 73-76$

Gennarelli TA (1994): Animate Models of Human Head Injury. J Neurotrauma 11, Nr. 4, 357-368

Ghajar J (2000): Traumatic Brain Injury. Lancet $\underline{356}, 923-929$

Giralt M, Penkowa M, Lago N, Molinero A, Hidalgo J (2002): Metallothionein-1+2 Protect the CNS after Focal brain Injury. Exp Neurol 173, 114-128

Gorio A, Gokmen N, Erbayraktar S, Yilmaz O, Madaschi L, Cichetti C, Di Gulio AM, Vardar E, Cerami A, Brines M (2002): Recombinant human erythropoietin counteracts secondary injury and markedly enhances neurological recovery from experimental spinal cord trauma. Proc Natl Acad Sci USA 99, Nr. 14, 9450-9455

Görlach C, Hortobágyi T, Hortobágyi S, Benyò Z, Relton J, Whalley ET, Wahl M (2001): Bradykinin $B_{2}$, but Not $B_{1}$, Receptor Antagonism Has a Neuroprotective Effect after Brain Injury. J Neurotrauma 18, Nr. 8, 833-838

Graham DI, McIntosh TK, Maxwell WL, Nicoll JAR (2000): Recent Advances in Neurotrauma. J Neuropathol Exp Neurol 모, Nr. 8, 641-651

Haroon ZA, Amin K, Jiang X, Arcasoy MO (2003): A novel role for erythropoietin during fibrin-induced wound-healing response. Am J Pathol 163, Nr. 3, 993-1000

Hengemihle JM, Abugo O, Rifkind J, Spangler E, Danon D, Ingram DK (1996): Chronic Treatment With Human Recombinant Erythropoietin Increases Hematocrit and Improves Water Maze Performance in Mice. Physiol Behav $\underline{59}$, Nr. 1, 153-156

Henry-Feugeas MC, Azouvi P, Fontaine A, Denys P, Bussel B, Maaz F, Samson Y, Schouman-Claeys E (2000): MRI analysis of brain atrophy after severe closed-head injury: relation to clinical status. Brain Injury $\underline{14}$, Nr. 7, 597-604

Hofman PAM, Stapert SZ, van Kroonenburg MJPG, Jolles J, de Kruijk J, Wilmink JT (2001): MR Imaging, Single-photon Emission CT, and Neurocognitive Performance after Mild Traumatic Brain Injury. Am J Neuroradiol 22, 441-449 
Hogg S (1996): A Review of the Validity and Variability of the Elevated Plus-Maze as an Animal Model of Anxiety. Pharmacol Biochem Behav 노, Nr. 1, 21-30

Hogg S, Moser PC, Sanger DJ (1998a): Mild traumatic lesion of the right parietal cortex of the rat: Selective behavioural deficits in the abscence of neurological impairment. Behav Brain Res $\underline{93}$, 143-155

Hogg S, Sanger DJ, Moser PC (1998b): Mild traumatic lesion of the right parietal cortex in the rat: Characterisation of a conditioned freezing deficit and its reversal by dizocilpine. Behav Brain Res 93, 157-165

Hortobágyi T, Hortobágyi S, Görlach C, Harkany T, Benyò Z, Görögh T, Nagel W, Wahl M (2000): A novel brain trauma model in the mouse: effects of dexamethasone treatment. Eur J Physiol 441, 409-415

Ihle JN (1995): Cytokine receptor signalling. Nature 377, Nr. 19, 591-594

Iwasaki Y, Ikeda K, Ichikawa Y, Igarashi O, Iwamoto K, Kinoshita M (2002): Protective effect of interleukin-3 and erythropoietin on motor neuron death after neonatal axotomy. Neurol Res 24, Nr. 7, 643-646

Jelkmann W (1996): Erythropoietin: Structure, Control of Production and Function. Physiol Rev $\underline{72}$, Nr. 2, 449-489

Junk AK, Mammis A, Savitz SI, Singh M, Roth S, Malhotra S, Rosenbaum PS, Cerami A, M B, Rosenbaum DM (2002): Erythropoietin administration protects retinal neurons from acute ischemia-reperfusion injury. Proc Natl Acad Sci USA 99, Nr. 16, 10659-10664

Juul SE, Anderson DK, Li Y, Christensen RD (1998): Erythropoietin and Erythropoietin Receptor in the Developing Human Central Nervous System. Pediatr Res $\underline{43}$, Nr. 1, 40-49

Juul SE, McPherson RJ, Farrell FX, Jolliffe L, Ness DJ, Gleason CA (2004): Erythropoietin Concentrations in Cerebrospinal Fluid of Nonhuman Primates and Fetal Sheep following High-Dose Recombinant Erythropoietin. Biol Neonate 모, 138-144

Kakinuma Y, Hama H, Sugiyama F, Yagami KI, Goto K, Murakami K, Fukamizu A (1998): Impaired blood-brain barrier function in angiotensinogen-deficient mice. Nat Med $\underline{4}$, Nr. 9, 1078-1080 
Kaptanoglu E, Solaroglu I, Okutan O, Surucu HS, Akbiyik F, Beskonakli E (2004): Erythropoietin exerts neuroprotection after acute spinal cord injury in rats: effect on lipid peroxidation and early ultrastructural findings. Neurosurg Rev 27, Nr. 2, 113-120

Kerr JF, Wyllie AH, Currie AR (1972): Apoptosis: a basic biological phenomenon with wide-ranging implications in tissue kinetics. Br J Cancer 26, Nr. 4, 239-57

Klatzo I (1967): Presidential Address Neuropathological Aspects of Brain Edema. J Neuropathol Exp Neurol 26, Nr. 1, 1-14

Klatzo I (1987): Pathophysiological aspects of brain edema. Acta Neuropathol 72, 236-239

Klatzo I, Piraux A, Laskowski EJ (1958): The Relationship between edema, bloodbrain-barrier and tissue elements in a local brain injury. J Neuropathol Exp Neurol 17, $548-564$

Knerlich F, Schilling L, Görlach C, Wahl M, Ehrenreich H, Sirén AL (1999): Temporal profile of expression and cellular localization of inducible nitric oxide synthase, interleukin-1 $\beta$ and interleukin converting enzyme after cryogenic lesion of the rat parietal cortex. Brain Res Mol Brain Res $\underline{68}, 73-87$

Kobori N, Clifton GL, Dash P (2002): Altered expression of novel genes in the cerebral cortex following experimental brain injury. Brain Res Mol Brain Res 104, Nr. 2, 148-158

Konishi A, Chui DH, Hirose H, Kunishita T, Tabira T (1993): Trophic effect of erythropoietin and other hematopoietic factors on central cholinergic neurons in vitro and in vivo. Brain Res $\underline{609}, 29-35$

Koponen S, Taiminen T, Portin R, Himanen L, Isoniemi H, Heinonen H, Hinkka S, Tenovuo O (2002): Axis I and II Psychiatric Disorders After Traumatic Brain Injury: A 30-Year Follow-up Study. Am J Psychiatry 159, Nr. 8, 1315-1321

Krejčí I, Hliňák Z, Schuh J (1993): Flunarizin and Sabeluzol improved behavioural Disorder caused by cold-induced cortical Lesions in Mice. Cesk Psychiatr $\underline{89}$, Nr. 2, 9193

Kumral A, Baskin H, Duman N, Yilmaz O, Tatli M, Ozer E, Gokmen N, Genc S, Ozkan H (2003a): Erythropoietin protects against necrotizing enterocolitis of newborn rats by the inhibiting nitric oxide formation. Biol Neonate $\underline{84}$, Nr. 4, 325-329 
Kumral A, Ozer E, Yilmaz O, Akhisaroglu M, Gokmen N, Duman N, Ulukus C, Genc S, Ozkan H (2003b): Neuroprotective effect of erythropoietin on hypoxicischemic brain injury in neonatal rats. Biol Neonate $\underline{83}$, Nr. 3, 224-228

Kumral A, Baskin H, Gokmen N, Yilmaz O, Genc K, Genc S, Tatli MM, Duman N, Ozer E, Ozkan H (2004): Selective inhibition of nitric oxide in hypoxic-ischemic brain model in newborn rats: is it an explanation for the protective role of erythropoietin? Biol Neonate $\underline{85}$, Nr. 1, 51-54

Laurer HL, McIntosh TK (1999): Experimental models of brain trauma. Curr Opin Neurol $\underline{12}, 715-721$

Leist M, Jäätelä M (2001): Four deaths and a funeral: from caspases to alternative mechanisms. Nat Rev Mol Cell Biol 2, Nr. 8, 589-598

Lewczuk P, Hasselblatt M, Kamrowski-Kruck H, Heyer A, Unzicker C, Sirén AL, Ehrenreich H (2000): Survival of hippocampal neurons in culture upon hypoxia: effect of erythropoietin. Neuroreport $\underline{11}$, Nr. 69, 3485-3488

Licata C, Cristofori L, Gambin R, Vivenza C, Turazzi S (2001): Post-traumatic hydrocephalus. J Neurosurg Sci $\underline{45}$, Nr. 3, 141-149

Longhi L, Saatmann KE, Raghupathi R, Laurer HL, Lenzlinger PM, Riess P, Neugebauer E, Trojanowski JQ, Lee VMY, Grady MS, Graham DI, McIntosh TK (2001): A Review and Rationale for the Use of Genetically Engineered Animals in the Study of Traumatic Brain Injury. J Cereb Blood Flow Metab 21, 1241-1258

Lye TC, Shores EA (2000): Traumatic Brain Injury as a Risk Factor for Alzheimer's Disease: A Review. Neuropsychol Rev 10, Nr. 2, 115-129

Maas AIR, Dearden M, Teasdae GM, Braakman R, Cohadon F, Iannotti F, Karimi A, Lapierre F, Murray G, Ohman J, Persson L, Servadei F, Stocchetti N, Unterberg A (1997): EBIC-Guidelines for the Management of Severe Head Injury in Adults. Acta Neurochir 139, 286-294

MacKenzie JD, Siddiqi F, Bagley LJ, Mannon LJ, Sinson GP, Grossmann RI (2002): Brain Atrophy in Mild to Moderate Traumatic Brain Injury: A Longitudinal Quantitative Analysis. Am J Neuroradiol 23, 1509-1515 
Marciano PG, Eberwine JH, Raghupathi R, Saatman KE, Meaney DF, McIntosh TK (2002): Expression profiling following traumatic brain injury: a review. Neurochem Res $\underline{27}$, Nr. 10, 1147.1455

Marti HH, Wenger RH, Rivas LA, Straumann U, Digicaylioglu M, Henn V, Yonekawa Y, Bauer C, Gassmann M (1996): Erythropoietin Gene Expression in Human, Monkey and Murine Brain. Eur J Neurosci $\underline{8}$, 666-676

Martinez-Estrada OM, Rodriguez-Millàn E, Gonzàles-de Vicente E, Reina M, Vilarò S, Fabre M (2003): Erythropoietin protects the in vitro blood-brain barrier against VEGF-induced permeability. Eur J Neurosci 18, 2538-2544

Masuda S, Nagao M, Takahata K, Konishi Y, Gallyas F, Tabira T, Sasaki $\mathbf{R}$ (1993): Functional erythropoietin receptor of the cells with neural characteristics. Comparison with receptor properties of erythroid cells. J Biol Chem 268, Nr. 15, 1120811219

Matsushita H, Johnston MV, Lange MS, Wilson MA (2003): Protective effect of erythropoietin in neonatal hypoxic ischemia in mice. Neuroreport 14, Nr. 13, 1757-1761

Maurer MH, Frietsch T, Waschke KF, Kuschinsky W, Gassmann M, Schneider A (2002): Cerebral transcriptome analysis of transgenic mice overexpressing erythropoietin. Neurosci Lett 327, Nr. 3, 181-184

McAllister AW (1998): Traumatic Brain Injury and Psychosis: What Is the Connection? Semin Clin Neuropsychiatry $\underline{3}$, Nr. 3, 211-223

McDaniel B, Sheng H, Warner DS, Hedlund LW, Benveniste H (2001): Tracking Brain Volume Changes in C57BL/6J and ApoE-Deficient Mice in a Model of Neurodegeneration: A 5-week Longitudinal Micro-MRI Study. Neuroimage 14, 1244-1255

McIntosh TK, Juhler M, Wieloch T (1998): Novel Pharmacologic Strategies in the Treatment of Experimental Traumatic Brain Injury: 1998. J Neurotrauma 15, Nr. 10, 731-769

Merrill JE, Beneveniste EN (1996): Cytokines in inflammatory brain lesions: helpful and harmful. Trends Neurosci $\underline{19}$, Nr. 8, 331-338

Mirnics K (2001): Microarrays in brain research: the good, the bad and the ugly. Nat Rev Neurosci $\underline{2}$, Nr. 6, 444-447 
Mittelmann M, Neumann D, Peled A, Kanter P, Haran-Ghera N (2001): Erythropoietin induces tumor regression and antitumor immune responses in murine myeloma models. Proc Natl Acad Sci USA 98, Nr. 9, 5181-5186

Mogensen J, Miskowiak K, Sorensen TA, Lind CT, Olsen NV, Springborg JB, Mala H (2004): Erythropoietin improves place learning in fimbria-fornix-transected rats and modifies the search pattern of normal rats. Pharmacol Biochem Behav $\underline{77}$, Nr. 2, $381-390$

Moon C, Krawczyk M, Ahn D, Ahmet I, Paik D, Lakatta EG, Talan MI (2003): Erythropoietin reduces myocardial infarction and left ventricular functional decline after coronary artery ligation in rats. Proc Natl Acad Sci USA 100, Nr. 20, 11612-11617

Morganti-Kossmann MC, Rancan M, Stahel PF, Kossmann T (2002): Inflammatory response in acute traumatic brain injury: a double-edged sword. Curr Opin Crit Care $\underline{8}$, Nr. 2, 101-105

Morishita E, Masuda S, Nagao M, Yasuda Y, Sasaki R (1997): Erythropoietin Receptor is expressed in rat hippocampal and cerebral cortical Neurons, and Erythropoietin prevents in vitro Glutamate-Induced neuronal Death. Neuroscience $\underline{76}$, Nr. 1, 105-116

Morita-Fujimura Y, Fujimura M, Kawase M, Chen SF, Chan PH (1999): Release of mitochondrial cytochrome $c$ and DNA fragmentation after cold-injury-induced brain trauma in mice: possible role in neuronal apoptosis. Neurosci Lett 267, 201-205

Murakami K, Kondo T, Sato S, Chan PJ (1997): Occurence of Apoptosis Following Cold Injury-Induced Brain Edema in Mice. Neuroscience 1ㅗ, Nr. 1, 231-237

Murakami K, Kondo T, Yang G, Chen SF, Morita-Fujimura Y, Chan PH (1999): Cold Injury in Mice: A Model to Study Mechanisms of Brain Edema and Neuronal Apoptosis. Prog Neurobiol 57, 289-299

Nag S (2002): The blood-brain barrier and cerebral angiogenesis: lessons from the coldinjury model. Trends Mol Med $\underline{8}, \mathrm{Nr} .1,38-44$

Narayan RK, Michel ME, Clinical Trials in Head Injury Study Group (2002): Clinical Trials in Head Injury. J Neurotrauma $\underline{19}$, Nr. 5, 503-557 
Natt O, Watanabe T, Boretius S, Radulovic J, Frahm J, Michaelis T (2002): High-resolution 3D MRI of mouse brain reveals small cerebral structures in vivo. J Neurosci Methods 120, 203-209

Noyan T, Onem O, Ramazan Sekeroglu M, Koseoglu B, Dulger H, Bayram I, Yalcinkaya AS, Bakan V (2003): Effects of erythropoietin and pentoxifylline on the oxidant and antioxidant systems in the experimental short bowel syndrome. Cell Biochem Funct 21, Nr. 1, 49-54

Olson JJ, Beck DW, Warner DS, Coester H (1987): The Role of New Vessels and Macrophages in the Development and Resolution of Edema Following a Cortical Freeze Lesion in the Mouse. J Neuropathol Exp Neurol 46, Nr. 6, 682-694

Park HK, Fernandez I, Dujovny M, Diaz FG (1999): Experimental animal models of traumatic brain injury: medical and biomechanical mechanism. Crit Rev Neurosurg $\underline{9}$, 44-52

Penkowa M, Moos T, Carrasco J, Hadberg H, Molinero A, Bluethmann H, Hidalgo J (1999): Strongly Compromised Inflammatory Response to brain Injury in Interleukin-6 deficient Mice. Glia 25, 343-357

Porter LL, White EL (1983): Afferent and Efferent Pathways of the Vibrissal Region of Primary Motor Cortex in the Mouse. J Comp Neurol 214, 279-289

Povlishock JT, Hayes RL, Michel ME, McIntosh TK (1994): Workshop on Animal Models of Traumatic Brain Injury. J Neurotrauma 11, Nr. 6, 723-732

Pratt J, Archambaud C, Böhme A, Roux M, Rataud J, Imperato A, Stutzmann JM (1999): The effect of riluzole and mannitol on cerebral oedema after cryogenic injury in the mouse. Neurosci Lett $\underline{272}, 143-146$

Raghupathi R, Graham DI, McIntosh TK (2000): Apoptosis after traumatic brain injury. J Neurotrauma 17, Nr. 10, 927-938

Reekum R van, Cohen T, Wong J (2000): Can Traumatic Brain Injury cause Psychiatric Disorders? J Psychiatry Clin Neurosci $\underline{12}$, Nr. 3, 316-327

Reilly PL (2001): Brain injury: the pathophysiology of the first hours. "Talk and Die revisited'. J Clin Neurosci $\underline{8}$, Nr. 5, 398-403 
Ribatti D, Presta M, Vacca A, Ria R, Giuliani R, Dell'Era P, Nico B, Roncalli L, Dammacco F (1993): Human Erythropoietin Induces a Pro-Angiogenic Phenotype in Cultured Endothelial Cells and Stimulates Neovascularization In Vivo. Blood 93, 26272636

Riechers CC : Experimentelles Neurotrauma bei der Maus: Analyse von Spätfolgen mit verhaltensbiologischen und bildgebenden Methoden. Med. Diss. Göttingen 2004

Roberts I, Schierhout G, Alderson P (1998): Abscence of evidence for the effectiveness of five interventions routinely used in the intensive care management of severe head injury: a systematic review. J Neurol Neurosurg Psychiatry 65, 729-733

Romsi P, Ronka E, Kiviluoma K, Vainionpaa V, Hirvonen J, Mennander A, Pokela M, Biancari F, Rimpilainen J, Juvonen T (2002): Potential neuroprotective benefits of erythropoietin during experimental hypothermic circulatory arrest. J Thorac Cardiovasc Surg $\underline{4}$, Nr. 124, 714-723

Rosen GD, Williams AG, Capra JA, Connolly MT, Cruz B, Lu L, Airey DC, Kulkarni K, Williams RW (2000): The Mouse Brain Library@www.mbl.org Int Mouse Genome Conference $\underline{14}, 166$

Rothwell NJ, Luheshi GN (2000): Interleukin 1 in the brain: biology, pathology and therapeutic agent. Trends Neurosci 23, 618-625

Ruscher C, Freyer D, Karsch M, Isaev N, Megow D, Sawitzki B, Priller J, Dirnagl U, Meisel A (2002): Erythropoietin Is a Paracrine Mediator of Ischemic Tolerance in the Brain: Evidence from an In Vitro Model. J Neurosci 22, Nr. 23, 1029110301

Sadamoto Y, Igase K, Sakanaka M, Sato K, Otsuka H, Sakaki S, Masuda S, Sasaki R (1998): Erythropoietin Prevents Place Navigation Disability and Cortical Infarction in Rats with Permanent Occlusion of the Middle Cerebral Artery. Biochem Biophys Res Commun 253, 26-32

Sakanaka M, Wen TC, Matsuda S, Morishita E, Nagao M, Sasaki R (1998): In vivo evidence that erythropoietin protects neurons from ischemic damage. Proc Natl Acad Sci USA $\underline{95}, 4635-4640$ 
Saray A, Ozakpinar R, Koc C, Serel S, Sen Z, Can Z (2003): Effect of chronic and short-term erythropoietin treatment on random flap survival in rats: an experimental study. Laryngoscope 113, Nr. 1, 85-89

Sattler R, Tymianski M (2001): Molecular mechanisms of glutamate receptor-mediated excitotoxic neuronal cell death. Mol Neurobiol 24, Nr. 1-3, 107-129

Schneider G, Fries P, Wagner-Jochem D, Thome D, Laurer H, Kramann B, Mautes A, Hagen T (2002): Pathophysiological changes after traumatic brain injury: comparison of two experimental animal models by means of MRI. MAGMA 14, 233-241

Sekiguchi Y, Kikuchi S, Myers RR, Campana WM (2003): ISSLS prize winner: Erythropoietin inhibits spinal neuronal apoptosis and pain following nerve root crush. Spine $\underline{28}$, Nr. 23, 2577-2584

Shoumitro D, Lyons I, Koutzoukis C, Ali I, McCarthy G (1999): Rate of Psychiatric Illness 1 Year After Traumatic Brain Injury. Am J Psychiatry 156, Nr. 3, 374-378

Silva M, Grillot D, Benito A, Richard C, Nuñez G, Fernàndez-Luna JL (1996): Erythropoietin Can Promote Erythroid Progenitor Survival by Repressing Apoptosis Through Bcl- $X_{L}$ and Bcl-2. Blood 88, Nr. 5, 1576-1582

Sirén AL, Fratelli M, Brines M, Goemans C, Casagrande S, Lewczuk P, Keenan S, Gleiter C, Pasquali C, Capobianco A, Mennini T, Heuman R, Cerami A, Ehrenreich H, Ghezzi P (2001a): Erythropoietin prevents neuronal apoptosis after cerebral ischemia and metabolic stress. Proc Natl Acad Sci USA 98, Nr. 7, 4044-4049

Sirén AL, Knerlich F, Poser W, Gleiter CH, Brück W, Ehrenreich H (2001b): Erythropoietin and erythropoietin receptor in human ischemic/hypoxic brain. Acta Neuropathol $\underline{101}, 271-276$

Sirén AL, Radyushkin K, Kämmer D, Riechers CC, Meyer B, Ilia M, Natt O, Boretius S, Sperling S, Michaelis T, Frahm J, Gruss P, Price J, Ehrenreich H (2004): Early treatment with erythropoietin abrogates long-term consequences of a discrete parietal cortical injury in mice. (Schriftliche Mitteilung von Sirén, A-L)

Solaroglu I, Solaroglu A, Kaptanoglu E, Dede S, Haberal A, Beskonakli E, Kilinc K (2003): Erythropoietin prevents ischemia-reperfusion from inducing oxidative damage in fetal rat brain. Childs Nerv Syst $\underline{19}$, Nr. 1, 19-22 
Springborg JB, Ma X, Rochat P, Knudsen GM, Amtorp O, Paulson OB, Juhler M, Olsen NV (2002): A single subcutaneous bolus of erythropoietin normalizes cerebral blood flow autoregulation after subarachnoid haemorrhage in rats. Br J Pharmacol $\underline{135}$, Nr. 5, 823-829

Squadrito F, Altavilla D, Squadrito G, Camp GM, Arlotta M, Quartarone C, Saitta A, Caputi AP (1999): Recombinant human erythropoietin inhibits iNOS activity and reverts vascular dysfunction in splanchnic artery occlusion shock. Br J Pharmacol $\underline{127}, 482-488$

Statler KD, Jenkins LW, Dixon CE, Clark RSB, Marion DW, Kochanek PM (2001): The Simple Model Versus the Super Model: Translating Experimental Traumatic Brain Injury Research to the Bedside. J Neurotrauma 18, Nr. 11, 1195-1206

Steward O, Schauwecker PE, Guth L, Zhang Z, Fujiki M, Inman D, Wrathall J, Kempermann G, Gage FH, Saatmann KE, Raghupathi R, McIntosh T (1999): Genetic Approaches to Neurotrauma Research: Opportunities and Potential Pitfalls of Murine Models. Exp Neurol 157, 19-42

Sun Y, Zhou C, Polk P, Nanda A, Zhang JH (2004): Mechanisms of erythropoietininduced brain protection in neonatal hypoxia-ischemia rat model. J Cereb Blood Flow Metab 24, Nr. 2, 259-270

The Brain Trauma Foundation (2000): The Brain Trauma Foundation. The American Association of Neurological Surgeons. The Joint Section on Neurotrauma and Critical Care. J Neurotrauma 17, Nr. 6-7, 457-627

Tilbrook PA, Klinken SP (1999): The erythropoietin receptor. Int J Biochem Cell Biol $\underline{31}, 1001-1005$

Verger K, Junqué C, Levin HS, Jurado MA, Pérez-Gómez M, Bartrés D, Barrios M, Álvarez A, Bartumeus F, Mercader JM (2001): Correlation of atrophy measures on MRI with neuropsychological sequelae in children and adolescents with traumatic brain injury. Brain Inj $\underline{15}$, Nr. 3, 211-221

Villa P, Bigini P, Mennini T, Agnello D, Laragione T, cagnotto A, Viviani B abd Marinovich M, Cerami A, Coleman TR, Brines M, Ghezzi P (2003): Erythropoietin selectively attenuates cytokine production and inflammation in cerebral ischemia by targeting neuronal apoptosis. J Exp Med 198, Nr. 6, 971-975 
Weishaupt JH, Rohde G, Polking E, Sirén AL, Ehrenreich H, Bähr M (2004): Erythropoietin Protects against Axotomy-Induced Apoptosis in Rat Retinal Ganglion Cells. Invest Ophthalmol Vis Sci $\underline{45}$, Nr. 5, 1514-1522

Wen TC, Sadamoto Y, Tanaka J, Zhu PX, Nakata K, Ma YJ, Hata R, Sakanaka M (2002): Erythropoietin Protects Neurons Against Chemical Hypoxia and Cerebral Ischemic Injury by Up-Regulating Bcl- $X_{L}$ Expression. J Neurosci Res $\underline{67}, 795-803$

Yakovlev AG, Faden AI (2001): Caspase-dependent apoptotic pathways in CNS injury. Mol Neurobiol 24, Nr. 1-3, 131-144

Yu X, Shacka JJ, Eells JB, Suarez-Quian C, Przygodzki RM, Beleslin-Cokic B, Lin CS, Nikodem VM, Hempstead B, Flanders KC, Costantini F, Noguchi CT (2002): Erythropoietin receptor signalling is required for normal brain development. Development $\underline{129}, 505-516$

Zainos A, Merchant H, Hernández A, Salinas E, Romo R (1997): Role of primary somatic sensory cortex in the categorization of tactile stimuli: effects of lesions. Exp Brain Res $\underline{115}, 357-360$

Zohar O, Schreiber S, Getslev V, Schwarzt JP, Mullins PG, Pick CG (2003): Closed-Head Minimal Traumatic Brain Injury produces Long-Term cognitive Deficits in Mice. Neuroscience 118, 949-955 


\section{Abbildungsverzeichnis}

2.1 Elevated Plus Maze . . . . . . . . . . . . . . . . . . . 21

2.2 Akzelerierendes Rotarod . . . . . . . . . . . . . . . . 22

2.3 Skizze des Morris-Water-Maze . . . . . . . . . . . . . . . 23

2.4 Volumetrisch evaluierte Areale . . . . . . . . . . . . . . . . . . . 28

2.5 Verlaufsschema der Experimente . . . . . . . . . . . . . . . . . 34

3.1 Darstellung der hämatologischen Verlaufsparameter . . . . . . . . . . . 37

3.2 Darstellung der hämatologischen Parameter in den Läsionsprotokollen . . . 38

3.3 Rotarod und Open-field für Protokoll 1 . . . . . . . . . . . . . . . . 41

3.4 Furchtkonditionierung für Protokoll 1 . . . . . . . . . . . . . . . . . 41

3.5 Morris-Water-Maze-Verlaufsdaten für Protokoll 1 . . . . . . . . . . . . . . 42

3.6 Probe-Trial für Protokoll 1 . . . . . . . . . . . . . . . . . . . . . . . 42

3.7 Holeboard für Protokoll 1 . . . . . . . . . . . . . . . . . 43

3.8 Elevated-Plus-Maze für Protokoll 1 . . . . . . . . . . . . . . . . . . . 43

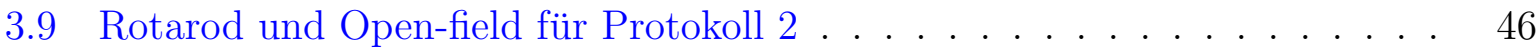

3.10 Furchtkonditionierung für Protokoll $2 \ldots$. . . . . . . . . . . . 46

3.11 Morris-Water-Maze-Verlaufsdaten für Protokoll 2 . . . . . . . . . . . . . 47

3.12 Probe-Trial für Protokoll $2 \ldots$. . . . . . . . . . . . . . . . . . 47

3.13 Holeboard für Protokoll 2 . . . . . . . . . . . . . . . . . . . . . 48

3.14 Elevated-Plus-Maze für Protokoll $2 \ldots$. . . . . . . . . . . . . . . . . . . 48 
3.15 Rotarod und Open-field für Protokoll 3 nach Abschluß der Injektionen . . 51

3.16 Furchtkonditionierung für Protokoll 3 nach Abschluß der Injektionen . . . 51

3.17 Morris-Water-Maze-Verlaufsdaten für Protokoll 3 nach Abschluß der Injek-

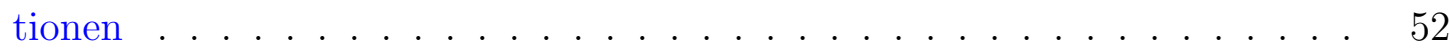

3.18 Probe-Trial für Protokoll 3 nach Abschluß der Injektionen . . . . . . . . . 52

3.19 Holeboard für Protokoll 3 nach Abschluß der Injektionen . . . . . . . . . . 53

3.20 Elevated-Plus-Maze für Protokoll 3 nach Abschluß der Injektionen . . . . . 53

3.21 Rotarod und Open-field für Protokoll 3 nach 3 Monaten . . . . . . . . . . 56

3.22 Furchtkonditionierung für Protokoll 3 nach 3 Monaten . . . . . . . . . . . 56

3.23 Morris-Water-Maze-Verlaufsdaten für Protokoll 3 nach 3 Monaten . . . . . 57

3.24 Probe-Trial für Protokoll 3 nach 3 Monaten . . . . . . . . . . . . . . 57

3.25 Holeboard für Protokoll 3 nach 3 Monaten . . . . . . . . . . . . . . . . 58

3.26 Elevated-Plus-Maze für Protokoll 3 nach 3 Monaten . . . . . . . . . . . . . 58

3.27 Darstellung der Kälteläsion in der MRT . . . . . . . . . . . . . . . 61

3.28 Darstellung von Kontrolltieren in der MRT . . . . . . . . . . . . . . . . . 62

3.29 Routinefärbung des Mausgehirns . . . . . . . . . . . . . . . . 63

3.30 Zellzahlen der Hilus-Region des Gyrus dentatus . . . . . . . . . . . . . . . 64

3.31 Evans-Blue-Färbungen des Mausgehirns . . . . . . . . . . . . 66 


\section{Tabellenverzeichnis}

1.1 Neuroprotektion durch Erythropoietin im Tiermodell . . . . . . . . . . . 13

1.2 Neuroprotektion durch Erythropoietin im Tiermodell (Fortsetzung) . . . . 14

2.1 Parameter der 3D FLASH Sequenz . . . . . . . . . . . . . . . 27

2.2 Zeitpunkte der Hirnentnahme nach Evans-Blue-Injektion . . . . . . . . . . 31

2.3 Zeitpunkte der Blutentnahme und Gruppengröße . . . . . . . . . . . . . 33

2.4 Läsionsprotokolle und Versuchsgruppen . . . . . . . . . . . . . . 33

3.1 Verhaltensdaten für Protokoll 1 . . . . . . . . . . . . . . . . 44

3.2 Morris-Water-Maze-Daten für Protokoll 1 . . . . . . . . . . . . . . . . 45

3.3 Verhaltensdaten für Protokoll 2 . . . . . . . . . . . . . . . . . . 49

3.4 Morris-Water-Maze-Daten für Protokoll 2 . . . . . . . . . . . . . . . 50

3.5 Verhaltensdaten für Protokoll 3 nach Abschluß der Injektionen . . . . . . . 54

3.6 Morris-Water-Maze-Daten für Protokoll 3 nach Abschluß der Injektionen . 55

3.7 Verhaltensdaten für Protokoll 3 nach 3 Monaten . . . . . . . . . . . . . 59

3.8 Morris-Water-Maze-Daten für Protokoll 3 nach 3 Monaten . . . . . . . . . 60

3.9 Volumetrische Ergebnisse im Gruppenvergleich . . . . . . . . . . . . . . . . 62

3.10 Größe der Evans-Blue-Anfärbung . . . . . . . . . . . . . . . 65 


\section{Abkürzungsverzeichnis}

Abb.

ANOVA

BALB/c-Mäuse

bidest.

bspw.

${ }^{\circ} \mathrm{C}$

CA

$\mathrm{cm}$

CRASH

CSF

C57BL/6J

d

$\mathrm{dB}(\mathrm{A})$

DNA

EDTA

EEG

$\mathrm{EPO}$

EPOR

et al.

ff.

g

$\mathrm{h}$

$\mathrm{HCl}$

$\mathrm{H}_{2} \mathrm{O}$

i.c.v.
Abbildung

Analysis of Variances

ein Mausstamm

zweifach destilliert

beispielsweise

Grad Celsius

Cornu ammonis

Zentimeter

Controlled trial of corticosteroids after significant

head injury

Cerebrospinalflüssigkeit

ein Mausstamm

Tag

Dezibel

Desoxyribonukleinsäure

Ethylendiamintetraessigsäure

Elektroenzephalogramm

Erythropoietin

Erythropoietinrezeptor

und andere

folgende

Gramm

Stunde

Salzsäure

Wasser

intrakranioventrikulär 


\begin{tabular}{|c|c|}
\hline IL & Interleukin \\
\hline in vivo & am Lebenden \\
\hline in vitro & im Reagenzglas \\
\hline i.p. & intraperitoneal \\
\hline i.v. & intravenös \\
\hline JAK & Janus-Kinase \\
\hline $\mathrm{KG}$ & Körpergewicht \\
\hline $\mathrm{kHz}$ & Kilohertz \\
\hline $\mathrm{m}$ & Meter \\
\hline $\mathrm{mA}$ & Milliampere \\
\hline $\mathrm{mg}$ & Milligramm \\
\hline $\min$ & Minuten \\
\hline $\mathrm{ml}$ & Milliliter \\
\hline $\mathrm{mm}$ & Millimeter \\
\hline$\mu \mathrm{m}$ & Mikrometer \\
\hline MPI & Max-Planck-Institut \\
\hline MPTP & 1-methyl-4-phenyl-1,2,3,6-Tetrahydropyridin \\
\hline mRNA & messenger-Ribonukleinsäure \\
\hline MRT & Magnetresonanztomographie \\
\hline $\mathrm{ms}$ & Millisekunden \\
\hline $\mathrm{n}$ & Anzahl der Versuche (Versuchstiere) \\
\hline $\mathrm{NaCl}$ & Natriumchlorid \\
\hline $\mathrm{NF} \kappa \mathrm{B}$ & nuclear factor $\kappa \mathrm{B}$ \\
\hline NMDA-Rezeptor & N-methyl-D-aspartat-Rezeptor \\
\hline NO & Stickstoffmonoxid \\
\hline $\mathrm{NO}_{2}$ & Stickstoffdioxid \\
\hline NZW-Rabbit & New Zealand White Rabbit \\
\hline $\mathrm{O}_{2}$ & Sauerstoff \\
\hline OF1-Mäuse & ein Mausstamm \\
\hline PBS & Phosphat-gepufferte Kochsalzlösung \\
\hline $\mathrm{PC}$ & Personal Computer \\
\hline PFA & Paraformaldehyd(lösung) \\
\hline $\mathrm{pH}$ & negativ dekadischer Logarithmus der \\
\hline
\end{tabular}


s.

S.

SAB

s.c.

SD

SE

SH-SP

SHT

STAT

$\mathrm{T}$

Tab.

$\mathrm{U}$

USA

z.B. siehe

Seite

Subarachnoidalblutung

subkutan

Sprague Dawley

Standardfehler der Mittelwerte

spontaneous hypertensive stroke-prone

Schädel-Hirn-Trauma

Signal Transducer and Activator of Transcription

Tesla

Tabelle

Unit

United States of America

zum Beispiel 


\section{Danksagung}

Frau Prof. Dr. Dr. Hannelore Ehrenreich danke ich für die Förderung, die sie mir zukommen ließ, für das Überlassen des Themas der vorliegenden Dissertation und nicht zuletzt für die nie abbrechende Motivation.

Frau Prof. Anna-Leena Sirén danke ich für die Betreuung dieser Arbeit und die Zeit, die sie hatte, um diese Arbeit und mich theoretisch und praktisch voranzubringen.

Der Abteilung Molekulare Zellbiologie von Herrn Prof. Dr. Peter Gruss am MPI für biophysikalische Chemie und dort im besonderen Frau Dr. Barbara Meyer und Herrn Dr. Konstantin Radyushkin gilt mein Dank für die Bereitstellung von Laboreinrichtung und Hilfe, wann immer es nötig war.

Die Abteilung Biomedizinische NMR Forschungs GmbH von Herrn Prof. Dr. Jens Frahm ermöglichte mir eine Zusammenarbeit, die sowohl produktiv als auch freundschaftlich war. Ich danke Herrn Dr. Thomas Michaelis, Dr. Takashi Watanabe und Dr. Oliver Natt.

Herrn Dr. Claas-Christian Riechers gilt mein besonderer Dank für die hervorragende Einarbeitung, die Hilfe und viele fruchtbare Diskussionen.

Der ganzen „Familie Ehrenreich“ danke ich für einen angenehmen Arbeitsplatz. 


\section{Lebenslauf}

Ich wurde am 21. März 1975 als Sohn von Hiltrud Kämmer, geborene Kirschhöfer, und Manfred Kämmer in Freudenberg geboren. Ab 1981 besuchte ich die Waldschule in Flensburg, ab 1985 dann das Alte Gymnasium in Flensburg und erwarb dort im Juni 1994 meine Allgemeine Hochschulreife. Von September 1994 bis Oktober 1995 leistete ich meinen Zivildienst in den Mürwiker Behindertenwerkstätten in Flensburg ab und begann im Anschluß daran mein Studium an der Georg-August-Universität Göttingen.

Von Oktober 1995 bis Oktober 1997 war ich für den Studiengang höheres Lehramt für Mathematik und Sportwissenschaften eingeschrieben, wechselte aber nach meiner Zwischenprüfung in Mathematik im Oktober 1997 das Studienfach zur Humanmedizin.

Im März 1999 absolvierte ich die ärztliche Vorprüfung, im März 2000 den ersten Abschnitt der Ärztlichen Prüfung und im August 2003 den zweiten Abschnitt der Ärztlichen Prüfung. Ab März 1999 arbeitete ich auf der chirurgischen Intensivstation des Evangelischen Krankenhauses Weende, und in der Zeit vom Oktober 2001 bis Januar 2003 war ich als wissenschaftliche Hilfskraft angestellt und bearbeitete die vorliegende Arbeit in der Arbeitsgruppe „Klinische Neurowissenschaften“ von Prof. Dr. Dr. H. Ehrenreich am Max-Planck-Institut für experimentelle Medizin. Zur Zeit bin ich im Praktischen Jahr am evangelischen Diakoniekrankenhaus Bremen tätig.

D. A. Kämmer

Bremen, den 23. August 2004 